Review Article

\title{
A New Theory to Forecast the Price of Nonrenewable Energy Resources with Mass and Energy-Capital Conservation Equations
}

\author{
Fabio Gori \\ Department of Industrial Engineering, University of Rome "Tor Vergata," Via del Politecnico 1, 00133 Rome, Italy \\ Correspondence should be addressed to Fabio Gori; fammannati@yahoo.com
}

Received 31 December 2013; Accepted 1 April 2014; Published 5 June 2014

Academic Editors: K. Abhary and Y. Demirel

Copyright (c) 2014 Fabio Gori. This is an open access article distributed under the Creative Commons Attribution License, which permits unrestricted use, distribution, and reproduction in any medium, provided the original work is properly cited.

\begin{abstract}
The mass and energy-capital conservation equations are employed to study the time evolution of mass and price of nonrenewable energy resources, extracted and sold to the market, in case of no-accumulation and no-depletion, that is, when the resources are extracted and sold to the market at the same mass flow rate. The Hotelling rule for nonrenewable resources, that is, an exponential increase of the price at the rate of the current interest multiplied the time, is shown to be a special case of the general energy-capital conservation equation when the mass flow rate of extracted resources is unity. The mass and energy-capital conservation equations are solved jointly to investigate the time evolution of the extracted resources.
\end{abstract}

\section{Introduction}

The price evolution of nonrenewable energy resources is a very important problem in an economy based on nonrenewable energy resources. The economics of exhaustible resources was investigated by Hotelling [1], and reviewed in [2], with the conclusion that the price of a resource increases exponentially with the product of time and interest rate of capital.

After the oil crisis of 1973 the problem of the energy resources became a very important issue and several energy models and forecasts have been developed and employed. During the decade of 1970s, among the others, McCall [3] presented a linear program for the world oil industry which was employed by an oil company. Tewksbury [4] described a practical general approach to forecast foreign oil prices to the year 2000. Pindyck [5] described a new version of an econometric policy model of the natural gas industry. Adelman [6] forecasted a decade of rising real oil prices for the US. DuMoulin and Newland [7] came to the conclusion that a rapid take-off in demand is likely to be followed by a rapid increase in the price of oil.

During the 1980s, among the others, Pearce [8] presented an overall look at the world energy demand forecasts with the conclusion that the judgment, rather than explicit modelling, is used to suggest a world crude oil scenario in which oil prices rise at $10 \%$ per year. French [9] discussed the markets of world oil, natural gas, coal, electricity, and the energy demand, with the conclusion that from mid-decade onward energy prices will most likely increase more rapidly than the overall price level. Roberts [10] concluded his analysis that through the mid-1980s, real crude prices should be flat to down and thereafter increase at a rate equal to or less than inflation. Campbell and Hubbard [11] showed that forecasts of prices-including oil, natural gas, equipment and drilling costs, and money-affect the evaluation of all projects. Clark [12] focused on generalized price formation in the U.S. gas industry. David and Carson [13] focused on the banks which use the long term oil supply and demand situation as the underlying support for making oil and gas price projections. Lorentsen and Roland [14] outlined a very open model, which can easily impose different assumptions about oil supply and demand in order to indicate a range of feasible projections for oil prices. Curlee [15] concluded that overall assessment of forecasts and recent oil market trends suggests that prices will remain constant in real terms for the remainder of the 1980 s, to increase by $2-3 \%$ during the 1990 s and beyond. Anon [16] studied the U.S. demand for petroleum products 
in 1987, based on the assumption that world oil prices will average 13 US \$/bbl through the third quarter of 1986 and rise gradually to 18 US $\$ /$ bbl by the end of 1987 . Dielwart and Coles [17] discussed the current market uncertainties and their impact on Canadian oil and natural gas prices. Yohe [18] presented an analytical technique based on an adaptive expectations model of incorporating current information into long-term forecast. Sekera [19] presented three price forecasting analyses with forecasts under each theory and the recommendation that all long term forecasts be based on fundamental/economic analysis, while short term forecasting needs to utilize other methods. Gately [20] reviewed recent and current opinions about prospects for prices in the world market for crude oil with two alternative views. Holden et al. [21] examined the accuracy and properties of forecasts by the OECD for 24 countries and 8 variables. Dougherty [22] presented some rules of thumb that may help to understand the evolution of oil prices, to identify factors to consider when deciding on the credibility of an oil price forecast, rather than to prophesize future oil price. Amano [23] developed an annual, small-scale econometric model of the world oil market to analyze oil market conditions and oil prices for the period 1986-1991.

During the 1990s, among the others, Garces [24] explored the effects of natural gas storage on short-term gas price forecasts, with preliminary results which indicate that by using natural gas storage as a causal variable, the final gas price forecasts can decrease by as much as $5 \%$ over the forecast period. Angelier [25] concluded his analytical framework with the forecast that, in the year 2000, oil prices will not be significantly different from those of 1990s. Bopp and Lady [26] concluded their analysis that when actual prices are employed, future prices did correctly anticipate the observed seasonal pattern. Abramson and Finizza [27] developed a system that forecasts crude oil prices via Monte Carlo analyses of the network. Charleson and Weber [28] forecasted energy consumption in Western Australia with Bayesian vector autoregressions to 2010. Fesharaki [29] believed that for the next three to five years oil prices will remain at lower levels than generally predicted, because price increases, even when they occur, will not be sustainable for very long. Huntington [30] reviewed forecasts of oil prices over the 1980s that were made in 1980, identifying the sources of errors due to such factors as exogenous GNP assumptions, resource supply conditions outside the cartel, and demand adjustments to price changes. Moosa and AlLoughani [31], on the basis of monthly observations on spot and future prices of the West Texas Intermediate (WTI) crude oil, suggested that future prices are neither unbiased nor efficient forecasters of spot prices. Abramson [32] discussed a knowledge-based system that models the crude oil market as a belief network and uses scenario generation and MonteCarlo analysis to forecast oil prices. Skov [33] reviewed some of the more significant forecasts of energy supply, demand, and oil prices made in the last 25 years and identifies the basic premises used and why they led to incorrect forecasts. Abramson and Finizza [34] described a case study in the use of inherently probabilistic belief network models to produce probabilistic forecasts of average annual oil prices.
Santini [35] investigated the statistical model of oil prices examining issues and trends related to both the U.S. and world oil supply. Williams [36], in order to forecast the future, examined historical trends and presents the new idea that there is an inverse relationship between crude oil prices volatility and the strength of the relationship between the owners of crude oil (host governments) and the oil companies that develop, refine, market, and sell the products. Chaudhuri and Daniel [37] demonstrated that the nonstationary behavior of US dollar real exchange rates, over the post-Bretton Woods era, is due to the nonstationary behavior of real oil prices. Pindyck [38] discussed how price forecasts also influence investment decisions and the choice of products to produce. Silvapulle and Moosa [39] examined the relationship between the spot and futures prices of WTI crude oil using a sample of daily data with the result that both spot and futures markets react simultaneously to new information.

During the 2000s, among the others, Alba and Bourdaire [40] consider the actual situation as a "cohabitation" between oil and the other energies with the oil price, extremely volatile, reflecting the trial and error adjustment of the market share left to the other energies. The Centre for Global Energy Studies [41] covers several topics including oilfields set to begin production in 2000, non-OPEC production, demand in western OECD countries and the Asia Pacific region, and oil price forecasts. According to the US energy information [42] global crude oil prices in 2000 will rise to 24 US \$/bbl, up by 2 US \$/bbl from its earlier estimate, while spot prices for West Texas Intermediate crude will average more than 22 US \$/bbl through 2001. Hare [43] reported that according to forecasts by the Energy Information Administration, increases in natural gas prices will continue all the way to the summer and winter of 2000, and that high oil prices will still be seen in 2001. According to the managing director of Shell's exploration and production [44] crude oil prices will average in the mid-teens of US \$/bbl over the next 10 years. The Energy Department of Energy Information Administration [45] forecasts the monthly average price of crude oil imported to the USA to stay above 28 US \$/bbl for the rest of 2000. Walde and Dos Santos [46] identified factors that have to be considered in speculating about the future evolution of oil prices. Birky et al. [47] examined the potentiality of unconventional natural gas resources with all other fossil fuels combined with the conclusion of a widespread production and use of these unconventional reserves. The trend of world crude oil price in 1999 has been reviewed and analyzed by Yang [48] and the prospects on world crude oil price in 2000 were predicted. MacAvoy and Moshkin [49] used a model framework consisting of a simultaneous equations system for production from reserves and for demands for production in the residential, commercial, and industrial sectors, with a significant negative trend in the long-term price of natural gas. Morana [50] showed how the GARCH properties of oil price changes can be employed to forecast the oil price distribution over short-term horizons, with a semiparametric methodology based on the bootstrap approach. Tang and Hammoudeh [51] investigated the behavior of the nonlinear model, based on the target zone theory, which has very 
good forecasting ability when the oil price approaches the upper or the lower limit of the band. Alvarez-Ramirez et al. [52] studied daily records of international crude oil prices using multifractal analysis methods, where rescaled range Hurst analysis provides evidence that the crude oil market is a persistent process with long-run memory effects, demonstrating that the crude oil market is consistent with the random-walk assumption only at time scales on the order of days to weeks. Ye et al. [53] presented a shortterm monthly forecasting model of West Texas Intermediate crude oil spot price using OECD petroleum inventory levels, which are a measure of the balance, or imbalance, between petroleum production and demand, and thus provide a good market barometer of crude oil price change. Sadorsky [54] used an ARMAX-ARCH model to estimate the conditional expected returns of petroleum futures prices under timevarying risk with results from a small forecasting experiment which indicates that the out-of-sample forecasts from an ARMAX-ARCH model generally outperform a random walk for all forecast horizons. Fong and See [55] examined the temporal behaviour of volatility of daily returns on crude oil futures using a generalised regime switching model that allows for abrupt changes in mean and variance, GARCH dynamics, basis-driven time-varying transition probabilities, and conditional leptokurtosis. Taal et al. [56] gave a summary of the most common methods used for cost estimation of heat exchange equipment in the process industry and the sources of energy price projections, showing the relevance of the choice of the right method and the most reliable source of energy price forecast used when choosing between alternative retrofit projects or when trying to determine the viability of a retrofit project. Cortazar and Schwartz [57] developed a parsimonious three-factor model of the term structure of oil future prices that can be easily estimated from available future price data. Cabedo and Moya [58] proposed to use value at risk (VaR) for oil price risk quantification, providing an estimation for the maximum oil price change associated with a likelihood level, which fits the continuous oil price movements well and provides an efficient risk quantification. Burg et al. [59] developed an econometric modeling of the world oil market suggesting that world oil prices are likely to fall in the latter part of 2004 and in 2005 as global demand pressures ease. Burg et al. [60] made a market forecast for various energy sources, including oil and gas and coal, with the conclusion that prices are forecasted to decline in 2005 to average 38 US \$/bbl WTI. Mirmirani and Li [61] applied VAR and ANN techniques to make ex-post forecast of U.S. oil price movements. Abosedra and Bagesthani [62] evaluated the predictive accuracy of 1-, 3-, 6-, 9-, and 12month-ahead crude oil future prices for the period from January 1991 until December 2001. Gori and Takanen [63] forecasted the energy demand in a specific country, where the analysis of the electricity demand was focused, for the first time, on the energy consumption and the possible substitution among the different energy resources by using a modified form of the econometric model EDM (Energy Demand Model). Feng et al. [64] predicted the oil price fluctuation by ARFIMA model, which takes the long memory feature into consideration, showing that ARFIMA model is better than ARMA model. Movassagh and Modjtahedi [65] tested the fair-game efficient-markets hypothesis for the natural gas future prices over the period 1990 through 2003. Ye et al. [66] presented a short-term forecasting model of monthly West Texas Intermediate crude oil spot prices using readily available OECD industrial petroleum inventory levels. Yousefi et al. [67] illustrated an application of wavelets as a possible vehicle for investigating the issue of market efficiency in future markets for oil. Sun and Lai [68] presented a forecast model of time series oil price about NYMEX with BP neural networks, analyzing the oil price fluctuation trend. Sadorsky [69] used several different univariate and multivariate statistical models to estimate forecasts of daily volatility in petroleum future price returns. Ye et al. [70] showed the effect that surplus crude oil production capacity has on short-term crude oil prices. Moshiri and Foroutan [71] modelled and forecasted daily crude oil future prices from 1983 to 2003, listed in NYMEX, applying ARIMA and GARCH models, tested for chaos using embedding dimension, BDS(L), Lyapunov exponent, and neural networks tests, and set up a nonlinear and flexible ANN model to forecast the series. The United States Energy Information Administration (EIA) [72] expects worldwide oil demand to increase from $80 \mathrm{million}$ bbl/day in 2003 to 98 million bbl/day in 2015 and to 118 million bbl/day in 2030. The latest forecast reference case calls for crude oil prices to climb from 31 US $\$ / \mathrm{bbl}$ in 2003 to $57 \mathrm{US} \$ / \mathrm{bbl}$ in 2030. Ghouri [73] analyzed qualitatively and quantitatively the relationship between US monthly ending oil stocks position with that of West Texas Intermediate (WTI) oil prices from February 1995 to July 2004, concluding that, if other things are held constant, WTI is inversely related to the petroleum products (PPP), combined petroleum products and crude oil (CPPP), crude oil alone (crude), total oil stocks including petroleum products, crude oil and strategic petroleum reserves SPR (total), total gasoline (TGO), and total distillate (TDO). Ye et al. [74] incorporated low- and high-inventory variables in a single equation model to forecast short-run WTI crude oil prices enhancing the model fit and forecast ability. The approach of using mass and energy-capital conservation equations to investigate the price evolution with time throughout the use of economic parameters was proposed in $[75,76]$ by the present author. The Hotelling rule was generalized in [75] with the conclusion that the price of the extracted resources increases exponentially with the product of the time and the difference between the inflation rate and the extraction rate of the resources, PIFE, "price increase factor of extracted resources." A further generalization was done in [76] with the introduction of the price of the selling resources, which depends on PIFE and the new parameter PIFS, "price increase factor of selling resources," that is, the difference between the prime rate of interest and the extraction rate of the resources. The political events and many complicated factors which happened in the last decades have made oil prices highly nonlinear and even chaotic, with irregularities and random oscillations, linked to the day-to-day events, giving reliability to forecast oil price and consumption in really short terms only, by using adaptive neural fuzzy inference systems (ANFIS), [77]. P. K. Narayan and S. Narayan [78] 
examined the volatility of the crude oil price using daily data for the period from 1991 to 2006, in various subsamples in order to judge the robustness of the results, implying that the behaviour of the oil prices tend to change over short periods of time. Knetsch [79] developed an oil price forecasting technique, based on the present value model of rational commodity pricing, suggesting the shifting of the forecasting problem to the marginal convenience yield, which can be derived from the cost-of-carry relationship. Deutsche Bank [80] reported that light sweet crude oil prices will average 80 US $\$ / b b l$ on the New York Mercantile Exchange in 2008 while natural gas prices will average 7.75 US \$/MMbtu and perhaps stay put there. It also reported that crude oil in this decade is likely to average nearly $55 \mathrm{US} \$ / \mathrm{bbl}$. It seems that crude oil markets are following the reciprocal of the declining value of the US dollar and ignoring deteriorating oil fundamentals. MacAskie and Jablonowski [81] developed a decision-analytic model to value commodity price forecasts in the presence of futures markets and applied the method to a data set on crude oil prices. Askari and Krichene [82] observed markets expecting oil prices to remain volatile and jumpy and, with higher probabilities, to rise, rather than fall, above the expected mean. Xu et al. [83] investigated with ILS approach the forecast of the relationship between commodity inventory levels and crude oil spot prices effectively, with the conclusion that their empirical study suggests that both the ILS method and the confidence interval method can produce comparable quality forecasts. Yu et al. [84] proposed empirical mode decomposition (EMD) based on neural network ensemble learning paradigm for world crude oil spot price forecasting, decomposing the original crude oil spot price series into a finite, and often small, number of intrinsic mode functions (IMFs). Fan et al. [85] applied pattern matching technique to multistep prediction of crude oil prices and proposed a new approach: generalized pattern matching based on genetic algorithm (GPMGA), which can be used to forecast future crude oil price based on historical observations. This approach can detect the most similar pattern in contemporary crude oil prices from the historical data. Kang et al. [86] investigated the efficacy of a volatility model for three crude oil markets-Brent, Dubai, and West Texas Intermediate (WTI) - with regard to its ability to forecast and identify volatility stylized facts, in particular volatility persistence or long memory with the conclusion that CGARCH and FIGARCH models are useful for modeling and forecasting persistence in the volatility of crude oil prices. Hamilton [87] examined the factors responsible for changes in crude oil prices, reviewing the statistical behavior of oil prices, in relation to the predictions of theory, and looking in detail at key features of petroleum demand and supply, discussing the role of commodity speculation, OPEC, and resource depletion. Cuaresma et al. [88], using a simple unobserved components model, showed that explicitly modelling asymmetric cycles on crude oil prices improves the forecast ability of univariate time series models of the oil price. Ye et al. [89] predicted crude oil prices from 1992 through early 2004 by using OECD's relative inventories and OPEC's excess production capacity improving forecasts for the post-Gulf War I time period over models without the ratchet mechanism. Cheong [90] investigated the timevarying volatility of two major crude oil markets, the West Texas Intermediate (WTI) and the Europe Brent, with a flexible autoregressive conditional heteroskedasticity (ARCH) model to take into account the stylized volatility facts such as clustering volatility, asymmetric news impact, and long memory volatility. Ghaffari and Zare [91] developed a method based on soft computing approaches to predict the daily variation of the crude oil price of the West Texas Intermediate (WTI), with comparison to the actual daily variation of the oil price, and the difference is implemented to activate the learning algorithms. The energy supply curve, that is, price versus consumption, of nonrenewable energy resources was constructed in [92] where new parameters were introduced to forecast the price evolution of nonrenewable resources. The present theory has been reviewed and applied to the period from 1966 until 2006 in [93].

During the 2010s, among the others, de Souza e Silva et al. [94] investigated the usefulness of a nonlinear time series model, known as hidden Markov model (HMM), to predict future crude oil price movements, developing a forecasting methodology that consists of employing wavelet analysis to remove high frequency price movements, assumed as noise, and using the probability distribution of the price return accumulated over the next days to infer future price trends. He et al. [95] presented two forecasting models, one based on a vector error correction mechanism and the other based on a transfer function framework with the range taken as a driver variable, for forecasting the daily highs and lows, showing that both of these models offer significant advantages over the naïve random walk and univariate ARIMA models in terms of out-of-sample forecast accuracy. Miller and Ni [96] examined how future real GDP growth relates to changes in the forecasted long-term average of discounted real oil prices and to changes in unanticipated fluctuations of real oil prices around the forecasts. Forecasts were conducted using a state-space oil market model, in which global real economic activity and real oil prices share a common stochastic trend. Yaziz et al. [97] obtained the daily West Texas Intermediate (WTI) crude oil prices data from Energy Information Administration (EIA) from the 2nd of January, 1986, to the 30th of September, 2009, by using the Box-Jenkins methodology and generalized autoregressive conditional heteroscedasticity $(\mathrm{GARCH})$ approach in analyzing the crude oil prices, which is able to capture the volatility by the nonconstant of conditional variance. Prat and Uctum [98] suggested a mixed expectation model, defined as a linear combination of these traditional processes, interpreted as the aggregation of individual mixing behavior and of heterogeneous groups of agents using these simple processes, consistent with the economically rational expectations theory. It was shown that the target oil price included in the regressive component of this model depends on the long-run marginal cost of crude oil production and on the short term macroeconomic fundamentals whose effects are subject to structural changes. Jammazi and Aloui [99] combined the dynamic properties of the multilayer back propagation neural network and the recent Harr A trous wavelet decomposition, implementing a hybrid model HTW-MPNN to achieve prominent prediction 
of crude oil price, by using three variants of activation function, namely, sigmoid, bipolar sigmoid, and hyperbolic tangent in order to test the model's flexibility. Mingming and Jinliang [100] constructed a multiple wavelet recurrent neural network (MWRNN) simulation model, in which trend and random components of crude oil and gold prices were considered to capture multiscale data characteristics, while a real neural network (RNN) was utilized to forecast crude oil prices at different scales, showing that the model has high prediction accuracy. Baumeister and Kilian [101] constructed a monthly real-time dataset consisting of vintages for the period from January, 1991, to December, 2010, that is suitable for generating forecasts of the real price of oil from a variety of models and documenting that revisions of the data typically represent news, and introducing backcasting and nowcasting techniques to fill gaps in the real-time data. It was shown that the real-time forecasts of the real oil price can be more accurate than the nochange forecast at horizons up to 1 year. Azadeh [102] presented a flexible algorithm based on artificial neural network (ANN) and fuzzy regression (FR) to cope with optimum long-term oil price forecasting in noisy, uncertain, and complex environments, incorporating the oil supply, crude oil distillation capacity, oil consumption of non-OECD, U.S. refinery capacity, and surplus capacity as economic indicators. Wang et al. [103] investigated the interacting impact between the crude oil prices and the stock market indices in China and analyzed the corresponding statistical behaviors introducing a jump stochastic time effective neural network model and applying it to forecast the fluctuations of the time series for the crude oil prices and the stock indices, and studying the corresponding statistical properties by comparison. Hu et al. [104] attempted to accurately forecast prices of the crude oil futures by adopting three popular neural networks methods including the multilayer perceptron, the Elman recurrent neural network (ERNN), and the recurrent fuzzy neural network (RFNN), with the conclusion that learning performance can be improved by increasing the training time and that the RFNN has the best predictive power and the MLP has the worst one among the three underlying neural networks. Ruelke et al. [105] derived internal consistency restrictions on short, medium, and long-term oil price forecasts, by analysing whether oil price forecasts extracted from the Survey of Professional Forecasters (SPF), conducted by the European Central Bank (ECB), satisfy these internal consistency restrictions, finding that neither short-term forecast is consistent with mediumterm forecasts nor that medium-term forecasts are consistent with long-term forecasts. A new category of cases, that is, the negative inflation rate, has been introduced, within the present theory, in [106], where some preliminary results have been presented. Pierdzioch et al. [107] found that the loss function of a sample of oil price forecasters is asymmetric in the forecast error, indicating that the loss oil price forecasters incurred when their forecasts exceeded the price of oil tended to be larger than the loss they incurred when their forecast fell short of the price of oil. Accounting for the asymmetry of the loss function does not necessarily make forecasts look rational. Shin et al. [108] proposed a study to exploit the method of representing the network between the time-series entities and to then employ SSL to forecast the upward and downward movement of oil prices by using onemonth-ahead monthly crude oil price predictions between January, 1992, and June, 2008. Alquist [109] addressed some of the key questions that arise in forecasting the price of crude oil. Xiong et al. [110] proposed a revised hybrid model built upon empirical mode decomposition (EMD) based on the feed-forward neural network (FNN) modeling framework incorporating the slope-based method (SBM), which is capable of capturing the complex dynamic of crude oil prices. The results obtained in this study indicate that the proposed EMD-SBM-FNN model, using the MIMO strategy, is the best in terms of prediction accuracy with accredited computational load. Chang and Lai [111] attempted to develop an integrated model to forecast the cycle of energy prices with respect to the level of economic activity, showing that the oil price cycle and economic activities have bidirectional causality in the short run, and that the upwards (downwards) cycle of oil prices is accompanied by expansion (contraction) of economic activities, and vice versa, with a comovement trend in the long run. Conceptually, the model developed in this work is useful with regard to forecasting the level of economic activities using the oil price cycle, as most economic activities depend on energy. Salehnia et al. [112] used the gamma test for the first time as a mathematically nonparametric nonlinear smooth modeling tool to choose the best input combination before calibrating and testing models and developing several nonlinear models with the aid of the gamma test, including regression models, local linear regression (LLR), dynamic local linear regression (DLLR) and artificial neural networks (ANN) models. Shin et al. [113] exploited the method of representing the network between the time-series entities to employ semisupervised learning (SSL) to forecast the upward and downward movement of oil prices, by using one-month-ahead monthly crude oil price predictions between January, 1992, and June, 2008. Yang et al. [114] forecasted the international crude oil price by using the grey system theory and creating a MATLAB program to achieve it. The present theory has been confirmed in case of negative inflation rate [115], projecting the forecast to the following five months of 2013 [116], with a very recent verification [117].

\section{Mass Conservation Equation of Extracted Resources}

Assume the mass $M$ of nonrenewable energy resources is in the reservoir, $C$, reported in Figure 1 . The mass flow rate of extraction from the reservoir is, $G$, with dimensions (mass/annum).

The mass conservation equation of the extracted resources is

$$
\frac{d M}{d t}=-G,
$$

which, after integration, becomes

$$
M=M_{0}-\int_{0}^{t} G d t,
$$




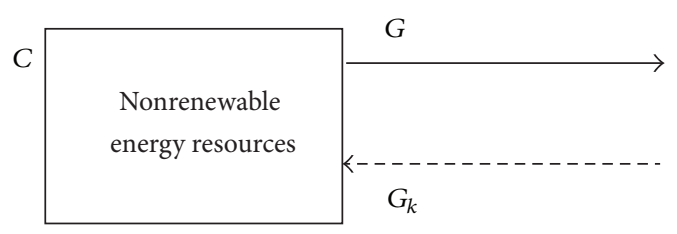

Figure 1: Nonrenewable energy resources in the reservoir $C$.

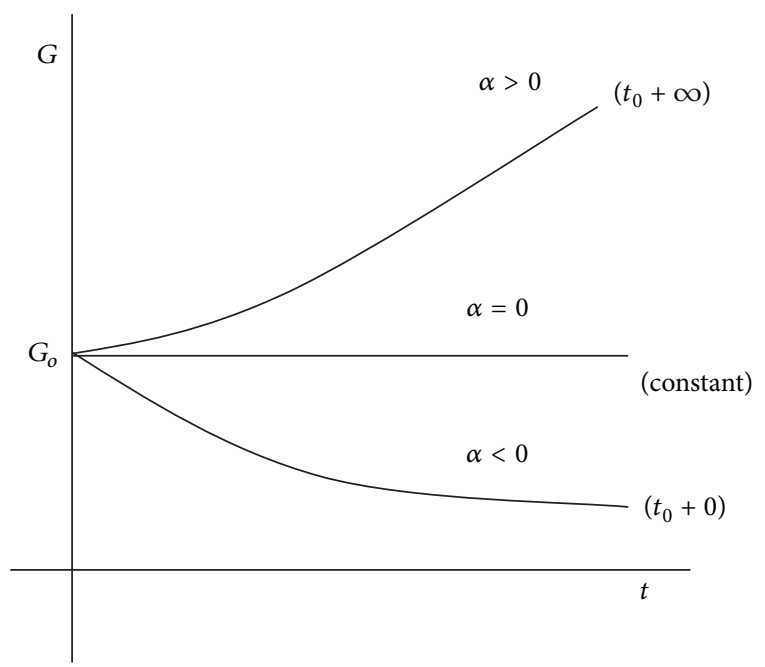

FIGURE 2: Time evolution of the mass flow rate of extraction, $G$.

where $M_{0}$ is the mass of resources in the reservoir at the initial time $t=0$.

Assuming the extraction rate, $\alpha$, at the time $t$, given by

$$
\frac{1}{G} \frac{d G}{d t}=\alpha,
$$

the mass flow rate of extraction with constant $\alpha$ in the time interval $0-t$ is

$$
G=G_{0} \exp (\alpha t) .
$$

The evolution of the mass flow rate of extraction, given by (4) and presented in Figure 2, depends on the value of $\alpha$. $G$ is constant with time if $\alpha=0, G$ increases if $\alpha>0$, and $G$ decreases if $\alpha<0$.

The mass of nonrenewable resources in the reservoir $C$ becomes, dividing by $G_{0}$,

$$
\frac{M}{G_{0}}=\frac{M_{0}}{G_{0}}+\frac{[1-\exp (\alpha t)]}{\alpha},
$$

and its time evolution is presented in Figure 3.

In case of a constant extraction rate, $G=G_{0}$, that is, $\alpha=0$, (1) gives

$$
M=M_{0}-G_{0} \cdot t
$$

that is, the mass of resources in the reservoir $C$ decreases linearly with time. Equation (6) gives the time $t_{f}=M_{0} / G_{0}$ when $M=0$, that is, the time of exhaustion of the nonrenewable resources.

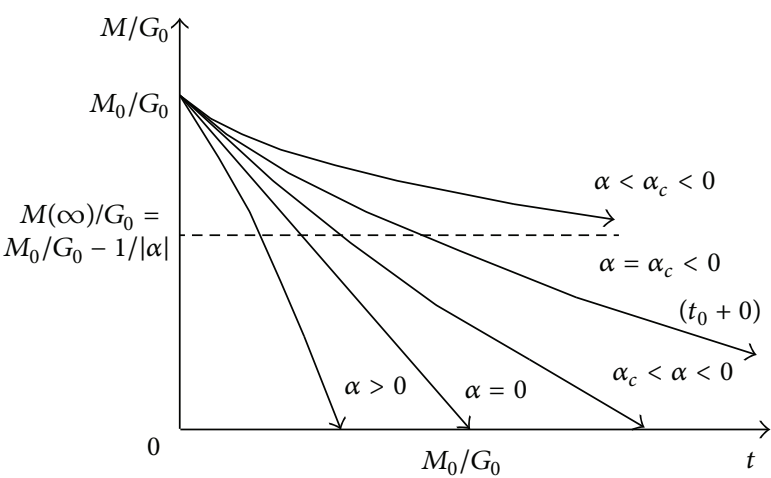

FIgURE 3: Time evolution of $M / G_{0}$ (years) at the extraction rate $\alpha$.

If, for example, the ratio $M_{0} / G_{0}$ is equal to 50 years, the time to exhaust the resources is $t_{f}=50$ years. If $\alpha>0$, the mass of resources in the reservoir $C$ is exhausted faster than for $\alpha=0$, that is, before 50 years. The time $t_{f}$, which gives $M=0$, is given by (5) as

$$
t_{f}=\frac{1}{\alpha} \ln \left[1+\alpha \frac{M_{0}}{G_{0}}\right] .
$$

Assuming $M_{0} / G_{0}=50$ years, the number of years for the exhaustion of the resources depends on the value of $\alpha$. From (7) it can be found that

(i) $t_{f}=40.55$ years for $\alpha=0.01$ (1/annum);

(ii) $t_{f}=17.92$ years for $\alpha=0.1$ (1/annum).

If $\alpha<0$, (5) can be written as

$$
\frac{M}{G_{0}}=\frac{M_{0}}{G_{0}}-\frac{[1-\exp (|\alpha| t)]}{|\alpha|},
$$

which, for an infinite time $t \rightarrow \infty$, gives

$$
\frac{M(\infty)}{G_{0}}=\frac{M_{0}}{G_{0}}-\frac{1}{|\alpha|} .
$$

The extraction policy to exhaust the nonrenewable resources in an infinite time $t \rightarrow \infty$ is to have

$$
\frac{M(\infty)}{G_{0}}=\frac{M_{0}}{G_{0}}-\frac{1}{|\alpha|}=0,
$$

which gives the critical extraction rate, $\alpha_{c}$,

$$
\left|\alpha_{c}\right|=\frac{G_{0}}{M_{0}}
$$

For $M_{0} / G_{0}=50$ years the critical extraction rate is $\alpha_{c}=-0.02$ (1/annum). by

If $\alpha_{c}<\alpha<0$, the time to exhaust the resources is given

$$
t_{f}=-\frac{1}{|\alpha|} \ln \left[1-|\alpha| \frac{M_{0}}{G_{0}}\right]
$$


which depends on $\alpha$. For $M_{0} / G_{0}=50$ years the time $t_{f}$ is

(i) $t_{f}=69.31$ years for $\alpha=-0.01$ (1/annum);

(ii) $t_{f}=51.29$ years for $\alpha=-0.001$ (1/annum).

The owner of the nonrenewable resources does not find convenient to have

$$
\frac{M(\infty)}{G_{0}}=\frac{M_{0}}{G_{0}}-\frac{1}{|\alpha|}>0,
$$

at an infinite time, $t \rightarrow \infty$, because the resources could remain nonextracted.

If $\alpha<\alpha_{c}<0$, the nonrenewable resources will never be extracted and a certain amount of resources will remain in the reservoir as nonextracted. For example, if $\alpha=$ -0.04 (1/annum) the amount of resources which will remain nonextracted is $M(\infty) / G_{0}=25$ years.

\section{Hotelling Rule}

Assume the nonrenewable resource can be extracted without cost. Denote $p_{o}$ the initial price per unit of resource at the initial time $t=0$ and suppose the interest rate, $r$, is constant in the time interval from $t=0$ to $t$. The owner of the resources unit has two options: to keep the unit of resources in the reservoir for the time interval $t$ with the real expectation that the price at $t$ will be higher, saying $p(t)$, or to sell the unit of resources and put the money, obtained from the sale, in a bank for the same time interval $t$ to get an interest return equal to $p(t) t r$. Under competitive conditions the owner is indifferent between these two options; then, the price of the unit at $t, p(t)$, must be equal to the price $p_{0}$ at the time $t_{0}$, increased of the interest return $p(t) t r$. In other words

$$
p(t)=p_{0}+p(t) t r
$$

or, taking the limit as $t \rightarrow 0$, it can be obtained

$$
\frac{d p}{d t}=p \cdot r .
$$

After integration, (15) becomes

$$
p(t)=p_{0} \exp (r t)
$$

also called Hotelling rule, [2], in honour of Hotelling [1], where, $r$, the interest rate of capital, is assumed constant in the time period $0-t$.

Equation (16) states that the price of nonrenewable resources can only increase exponentially with time if the interest rate $r$ is positive while only decreasing in case of negative inflation rate. The price evolution is independent of any other variable present in the energy game of nonrenewable resources.

\section{Energy-Capital Conservation Equation of Extracted Resources}

The energy-capital conservation equation can be written in unsteady state, similarly to the energy conservation equation of thermal engineering, for the nonextracted resources of the reservoir $C$, Figure 1, with interest rate $r_{N}$ (1/annum), as

$$
\frac{d K}{d t}=G_{k}
$$

The left term expresses the time variation of the capital $K$, due to the resources of the reservoir $C$, while $G_{k}$ is the capital flow rate entering into the reservoir $C$, which derives from the mass flow rate of extraction, $G$.

The capital $K$ is written as

$$
K=G \cdot p
$$

where $p$ is the current price of a unity of extracted resources and $G$ is the mass flow rate of extraction.

The right term of (17), that is, the capital flow rate entering into the reservoir, is written as

$$
G_{k}=K \cdot r_{N}=G \cdot p \cdot r_{N}
$$

where $r_{N}$ is the interest rate of the nonextracted resources.

Equation (17) then becomes

$$
\frac{d(G \cdot p)}{d t}=G \cdot p \cdot r_{N}
$$

which, for a mass flow rate of extraction being equal to 1 , that is, $G=1$, it gives (15), that is, the Hotelling rule before integration. In conclusion, the Hotelling rule can be obtained from the energy-capital conservation equation with a mass flow rate of extraction being equal to $G=1$.

Differentiation of the capital conservation equation, (20), and division by the capital $K$ gives

$$
\frac{1}{p} \frac{d p}{d t}+\frac{1}{G} \frac{d G}{d t}=r_{N} .
$$

Equation (21) can be used, with (3), to study the price evolution of the extracted resources with interest rate $r_{N}$. Equation (21) becomes, indicating $p$ as $p_{E}$ for the extracted resources and using (3),

$$
\frac{1}{p_{E}} \frac{d p_{E}}{d t}=r_{N}-\alpha,
$$

which, after integration, gives

$$
p_{E}=p_{E 0} \cdot \exp (\beta \cdot t)
$$

where,

$$
\beta=r_{N}-\alpha,
$$

that is, the difference between the interest rate of nonextracted resources, $r_{N}$, and the extraction rate, $\alpha$, is a new parameter called "price increase factor of extracted resources," PIFE. The price evolution with time of the extracted resources, given by (23), is shown in Figure 4.

The price of extracted resources evolves with time according to the value of PIFE, $\beta$. If the extraction rate $\alpha$ is equal to the interest rate of nonextracted resources, $r_{N}$, the price 


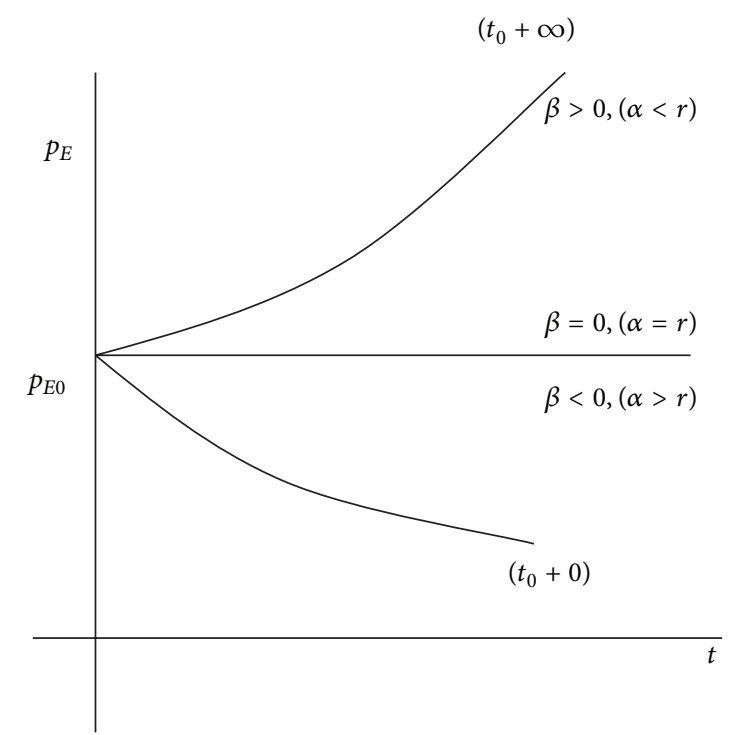

FiguRE 4: Time evolution of the price of extracted resources.

increase factor, PIFE is equal to zero, $\beta=0$, and the price $p_{E}$ remains constant with time. If the extraction rate $\alpha$ is higher than $r_{N}$, the price increase factor, PIFE is negative, $\beta<0$, and the price $p_{E}$ decreases with time. If the extraction rate $\alpha$ is lower than $r_{N}$, the price increase factor, PIFE is positive, $\beta>0$, and the price $p_{E}$ increases with time. In case of a conservative policy of extraction; that is, $\alpha<0$, the price increase factor, is greater than zero, $\beta>0$, and the price $p_{E}$ increases with time.

\section{Mass and Energy-Capital Conservation Equations of Selling Resources}

Assume that nonextracted and extracted energy resources are in the two reservoirs, $C_{N}$ and $C_{E}$, of Figure 5.

The nonextracted resources are in the reservoir $C_{N}$ with mass $M_{N}$ and interest rate $r_{N}$. The mass flow rate of extracted resources from the reservoir $C_{N}$ is $G_{E}$ while the capital flow rate, relative to the mass flow rate $G_{E}$, is $G_{K E}$. The resources of the reservoir $C_{N}$ are extracted at the price of the extracted resources, $p_{E}$, and allocated in the reservoir $C_{E}$, where $M_{E}$ is the mass of extracted resources. The resources of the reservoir $C_{E}$ are sold at the price $p_{S}$. The mass flow rate of the selling resources from the reservoir $C_{E}$ is $G_{S}$ while the capital flow rate, relative to the mass flow rate $G_{S}$, is $G_{K S}$.

The mass conservation equation of the extracted resources in the reservoir $C_{E}$ is

$$
\frac{d M_{E}}{d t}=G_{E}-G_{S}
$$

while the relative energy-capital conservation equation is

$$
\frac{d}{d t}\left(K_{E}\right)=G_{K S}-G_{K E}
$$

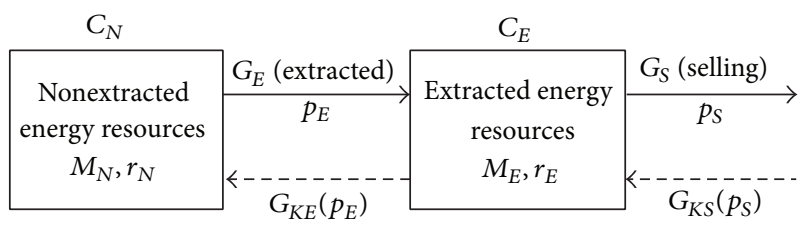

FIGURE 5: Nonextracted and extracted energy resources.

which becomes

$$
\frac{d}{d t}\left(G_{S} \cdot p_{S}\right)=G_{S} \cdot p_{S} \cdot r_{E}-G_{E} \cdot p_{E} \cdot r_{N}
$$

and finally

$$
\frac{1}{p_{S}} \cdot \frac{d p_{S}}{d t}+\frac{1}{G_{S}} \cdot \frac{d G_{S}}{d t}=r_{E}-\frac{G_{E} \cdot p_{E}}{G_{S} \cdot p_{S}} \cdot r_{N} .
$$

In case of no-accumulation and no-depletion of the extracted resources, $G_{E}=G_{S}$, the right term of (25) is zero; that is, the mass $M_{E}$ of extracted resources in the reservoir $C_{E}$ is constant with time. The mass flow rates of extracted and selling resources have the same extraction rate $\alpha$ from the reservoirs $C_{N}$ and $C_{E}$; that is,

$$
\frac{1}{G_{E}} \frac{d G_{E}}{d t}=\frac{1}{G_{S}} \frac{d G_{S}}{d t}=\alpha,
$$

which gives, after integration,

$$
G_{E}=G_{S}=G_{E 0} \cdot \exp \cdot(\alpha \cdot t)=G_{S 0} \cdot \exp \cdot(\alpha \cdot t),
$$

and the time evolution is similar to that of Figure 2.

Equation (28) becomes

$$
\frac{1}{p_{S}} \frac{d p_{S}}{d t}+\alpha=r_{E}-\frac{p_{E}}{p_{S}} r_{N}
$$

or

$$
\frac{d p_{S}}{d t}=p_{S}\left(r_{E}-\alpha\right)-p_{E} \cdot r_{N}
$$

The substitution of (23) into (32) and the solution of the relative differential equation give the time evolution of the price of sold resources

$$
p_{S}=p_{S 0}^{*} \exp (\beta \cdot t)+\left[p_{S 0}-p_{S 0}^{*}\right] \exp \left(\beta^{\prime} \cdot t\right)
$$

where

$$
\beta^{\prime}=r_{E}-\alpha
$$

is called the "Price Increase Factor of Selling resources," PIFS, and

$$
p_{S 0}^{*}=\frac{r_{N} \cdot p_{E 0}}{r_{E}-r_{N}}=\frac{r_{N} \cdot p_{E 0}}{\beta^{\prime}-\beta},
$$

the "critical initial price of selling resources," CIPS. 
The price of selling resources, (33), has an extreme (maximum or minimum) for the time $t_{m}$ given by

$$
t_{m}=\frac{1}{\left(\beta-\beta^{\prime}\right)} \ln \left[\frac{\beta^{\prime} \cdot\left(p_{S 0}^{*}-p_{S 0}\right)}{\beta \cdot p_{S 0}^{*}}\right] .
$$

The extreme is a maximum if

$$
\beta^{\prime}\left(\beta^{\prime}-\beta\right)\left(p_{S 0}-p_{S 0}^{*}\right)<0,
$$

otherwise it is a minimum.

The time $t_{m}$ of the extreme is zero if $p_{S 0}$ is equal to

$$
p_{S 0}^{* *}=\frac{p_{S 0}^{*}\left(\beta^{\prime}-\beta\right)}{\beta^{\prime}}=\frac{r_{N} p_{E 0}}{\beta^{\prime}},
$$

which is called "critical initial price extreme of selling resources," CIPES.

The time $t_{m}$ of the maximum is greater than zero if

$$
p_{S 0}>p_{S 0}^{* *} \text { for } \beta^{\prime}>\beta \text { (i.e., } r_{E}>r_{N} \text { ), }
$$

or

$$
\left.p_{S 0}<p_{S 0}^{* *} \text { for } \beta^{\prime}<\beta \text { (i.e., } r_{E}<r_{N}\right) \text {. }
$$

For $p_{S 0}=p_{S 0}^{*}$ the time of the maximum is

$$
t_{m}=+\infty
$$

for $\beta^{\prime}>\beta$, or

$$
t_{m}=-\infty
$$

for $\beta^{\prime}<\beta$.

For $r_{N}=r_{E}$, that is, $\beta^{\prime}=\beta, p_{S}$ is given by

$$
p_{S}=\left(p_{S 0}-p_{S 0}^{* *} \beta t\right) \exp (\beta t)
$$

where CIPS, that is, $p_{S 0}^{*}$, is not defined.

The price of selling resources has an extreme for the time $t_{m}$ given by

$$
t_{m}=\frac{\left(p_{S 0}-p_{S 0}^{* *}\right)}{p_{S 0}^{* *} \beta^{\prime}} .
$$

The extreme is a maximum if $p_{S 0}^{* *}>0$ and a minimum if $p_{S 0}^{* *}<0$. The time $t_{m}$ of the maximum is zero if the initial price $p_{S 0}$ is

$$
p_{S 0}=p_{S 0}^{* *}=\frac{r_{N} \cdot p_{E 0}}{\beta^{\prime}}
$$

The possible cases can be classified into six categories:

(i) Category $0-r_{N}=0$;

(ii) Category 1: $r_{N}>\alpha$, that is, $\beta=\operatorname{PIFE}>0$;

(iii) Category 2: $\alpha>r_{N}$, that is, $\beta=\operatorname{PIFE}<0$;

(iv) Category 3: $\alpha=r_{N}$, that is, $\beta=\mathrm{PIFE}=0$;

(v) Category 4: $r_{N}=r_{E}$, that is, $\beta^{\prime}=\beta$ or PIFE $=$ PIFS;

(vi) Category 5: $r_{N}<0$.

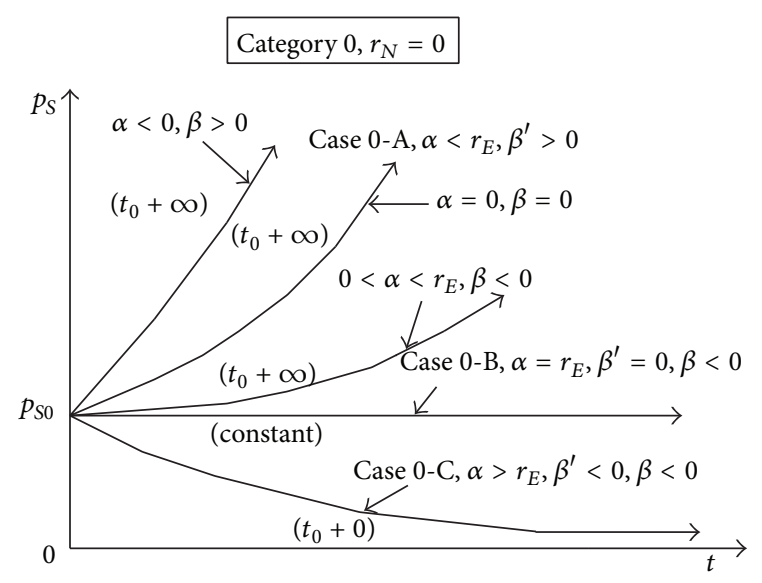

Figure 6: Price evolution of selling resources for Category 0.

On their side, each category presents the following possible cases.

Category $0\left(r_{N}=0\right)$. If the interest rate of nonextracted resources is $r_{N}=0$, (i.e., $p_{S 0}^{*}=p_{S 0}^{* *}=0$ ), the price evolution of selling resources is

$$
p_{S}=p_{S 0} \exp \left(\beta^{\prime} t\right)
$$

where $\beta^{\prime}$ is the PIF of sold resources.

Figure 6 presents the price evolution of selling resources according to the relation between extraction rate, $\alpha$, and interest rate of extracted resources $r_{E}$.

Case 0 - $A\left(\alpha<r_{E}\right.$, (i.e., $\left.\left.\beta^{\prime}>0\right)\right)$. The price $p_{S}$ increases with time at different rates, according to the values of $\alpha$. The rate of increase is higher for $\alpha<0, \beta>0$, intermediate for $\alpha=0$, $\beta=0$, and lower for $\alpha<r_{E}, \beta<0$.

Case $0-B\left(\alpha=r_{E}\right.$, (i.e., $\left.\left.\beta^{\prime}=0, \beta<0\right)\right)$. The price $p_{S}$ is constant with time at $p_{S 0}$.

Case $0-C\left(\alpha>r_{E}\right.$, (i.e., $\left.\left.\beta^{\prime}<0, \beta<0\right)\right)$. The price $p_{S}$ is decreasing with time towards +0 .

In conclusion, for $r_{N}=0$ the criterium to evaluate the price evolution of selling resources, $p_{S}$, is $\beta^{\prime}$. If $\beta^{\prime}>0$ the price $p_{S}$ increases, if $\beta^{\prime}=0$ the price $p_{S}$ remains constant, and if $\beta^{\prime}<0$ the price $p_{S}$ decreases towards +0 .

Category $1\left(r_{N}>\alpha\right.$, that is, $\beta=$ PIFE $\left.>0\right)$. The price evolutions of $p_{S}$ are reported in Figure 7 according to the relation between $r_{N}$ and $r_{E}$.

Case 1- $A\left(r_{E}>r_{N}>\alpha\right.$, that is, $\left.\beta^{\prime}>\beta>0\right)$. The price of selling resource increases with time if the initial price $p_{S 0}$ is $p_{S 0} \geq p_{S 0}^{*}>p_{S 0}^{* *}>0$, that is, equal to or greater than CIPS $>$ CIPES $>0$.

Case $1-B\left(r_{E}>r_{N}>\alpha\right.$ and $p_{S 0}^{*}>p_{S 0}>p_{S 0}^{* *}>0$ or $r_{N}>r_{E}>$ $\alpha$ and $\left.p_{S 0}>p_{S 0}^{* *}>0>p_{S 0}^{*}\right)$. The price of selling resource increases temporarily with time up to $t_{m}$, given by (19), 


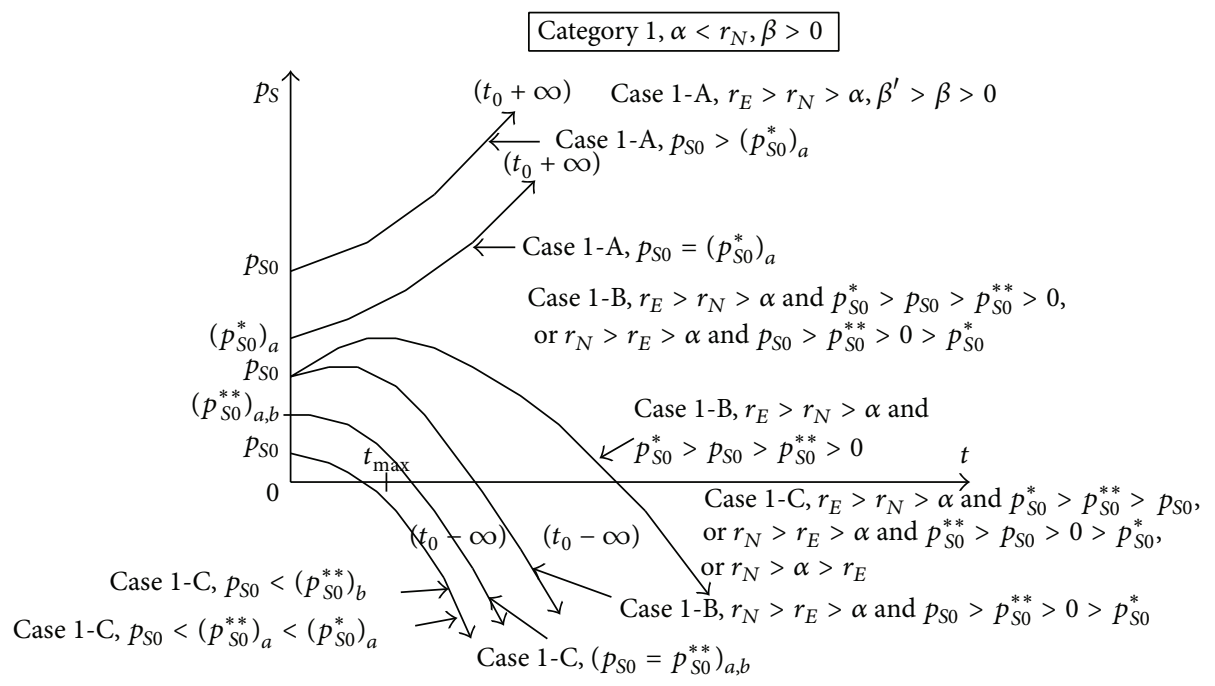

FIgURE 7: Price evolution of selling resources for Category 1.

and then decreases for $r_{E}>r_{N}>\alpha$ if the initial price $p_{S 0}$ has a value comprised between CIPS and CIPES, that is, $p_{S 0}^{*}>p_{S 0}>p_{S 0}^{* *}>0$, or, for $r_{N}>r_{E}>\alpha$, if the initial price $p_{S 0}$ is greater than CIPES, that is, $p_{S 0}>p_{S 0}^{* *}>0>p_{S 0}^{*}$.

Case 1-C $\left(r_{E}>r_{N}>\alpha\right.$ and $p_{S 0}^{*}>p_{S 0}^{* *}>p_{S 0}$, or $r_{N}>r_{E}>$ $\alpha$ and $p_{S 0}^{* *}>p_{S 0}>0>p_{S 0}^{*}$, or $r_{N}>\alpha>r_{E}$ ). The price of selling resource decreases with time for $r_{E}>r_{N}>\alpha$ if the initial price $p_{S 0}$ is smaller than CIPS and CIPES, that is, $p_{S 0}^{*}>$ $p_{S 0}^{* *}>p_{S 0}$, or, for $r_{N}>r_{E}>\alpha$, if the initial price $p_{S 0}$ is smaller than CIPES, that is, $p_{S 0}^{* *}>p_{S 0}>0>p_{S 0}^{*}$, or, for $r_{N}>\alpha>r_{E}$ for every initial price $p_{S 0}$ because $p_{S 0}>0>p_{S 0}^{*}>p_{S 0}^{* *}$.

Category $2\left(\alpha>r_{N}\right.$, that is, $\beta=$ PIFE $\left.<0\right)$. The time evolution is presented in Figure 8 according to $\beta$ and $\beta^{\prime}$ or the relation between $r_{N}$ and $r_{E}$.

Case 2- $A\left(r_{E}>\alpha>r_{N}\right.$, that is, $\left.\beta^{\prime}>\beta\right)$. The price of selling resource increases with time if the initial price $p_{S 0}$ is $p_{S 0} \geq$ $p_{S 0}^{* *}>p_{S 0}^{*}$, that is, equal to or greater than CIPES $>$ CIPS, $p_{S 0}^{* *}>p_{S 0}^{*}$.

Case 2- $B\left(r_{E}>\alpha>r_{N}\right.$, that is, $\left.\beta^{\prime}>\beta\right)$. The price of selling resource decreases temporarily with time up to $t_{m}$, given by (19), and then increases if the initial price, $p_{S 0}$, has a value comprised between CIPS and CIPES, that is, $p_{S 0}^{*}>p_{S 0}>$ $p_{S 0}^{* *}>0$.

Case 2-C $\left(\alpha>r_{N}\right.$, that is, $\left.\beta<0\right)$. In all other cases the price of selling resource decreases with time including $r_{E}=\alpha>r_{N}$, or $\alpha>r_{N}>r_{E}$, or $\alpha>r_{N}>r_{E}$.

Category $3\left(\alpha=r_{N}\right.$, that is, $\beta=$ PIFE $=0$ ). The price evolution of selling resources, $p_{S}$, is dependent on the relation between $r_{N}$ and $r_{E}$, as reported in Figure 9.

Case 3- $A\left(r_{E}>r_{N}=\alpha\right.$, that is, $\left.\beta^{\prime}>\beta=0\right)$. The price of selling resource increases with time if the initial price $p_{S 0}$ is $p_{S 0}>p_{S 0}^{* *}=p_{S 0}^{*}$, that is, greater than CIPS $=$ CIPES, $p_{S 0}^{* *}=p_{S 0}^{*}$.

Case 3- $B\left(r_{E}>r_{N}=\alpha\right.$, that is, $\left.\beta^{\prime}>\beta=0\right)$. The price of selling resource remains constant with time if the initial price $p_{S 0}$ is $p_{S 0}=p_{S 0}^{* *}=p_{S 0}^{*}$, that is, equal to CIPS $=$ CIPES, $p_{S 0}^{* *}=$ $p_{S 0}^{*}$.

Case 3-C $\left(r_{E}>r_{N}=\alpha\right.$, that is, $\beta^{\prime}>\beta=0$, or $r_{N}=\alpha>$ $r_{E}$, that is, $\beta^{\prime}<\beta=0$ ). The price of selling resource, for $r_{E}>$ $r_{N}=\alpha$, decreases with time if the initial price $p_{S 0}$ is $p_{S 0}<$ $p_{S 0}^{* *}=p_{S 0}^{*}$, that is, smaller than CIPS and CIPES, $p_{S 0}^{* *}=p_{S 0}^{*}$. In the other cases the price of the selling resource decreases with time for every value of $p_{S 0}$.

Category $4\left(r_{N}=r_{E}\right.$, that is, $\left.\beta^{\prime}=\beta\right)$. The time evolutions are presented in Figure 10.

Case $4-A\left(r_{N}=r_{E}>\alpha\right.$, that is, $\left.\beta^{\prime}=\beta>0\right)$. The price cannot increase with time.

Case 4- $B\left(r_{N}=r_{E}>\alpha\right.$, that is, $\left.\beta^{\prime}=\beta>0\right)$. The price of selling resource increases temporarily with time up to $t_{m}$, given by (2), and then decreases if the initial price $p_{S 0}$ is $p_{S 0}>p_{S 0}^{* *}>0$, that is, greater than CIPES $>0$.

Case 4- $C\left(r_{N}=r_{E}>\alpha\right.$, that is, $\beta^{\prime}=\beta>0$, or $r_{N}=r_{E}<$ $\alpha$, that is, $\beta^{\prime}=\beta<0$, or $r_{N}=r_{E}=\alpha$, that is, $\left.\beta^{\prime}=\beta=0\right)$. The price of selling resource decreases with time if the initial price $p_{S 0}$ is $p_{S 0}^{* *} \geq p_{S 0}>0$, that is, equal to or smaller than CIPES $>0$. In all the other cases the price of selling resource decreases with time for every value of $p_{S 0}$.

Category $5\left(r_{N}<0\right)$. A new category of cases has been introduced for negative inflation rate, $r_{N}<0$, which was registered from March to October, 2009, after the economic crisis of 2008. This new category is interesting because the Hotelling rule forecasts a decrease of the oil price if 


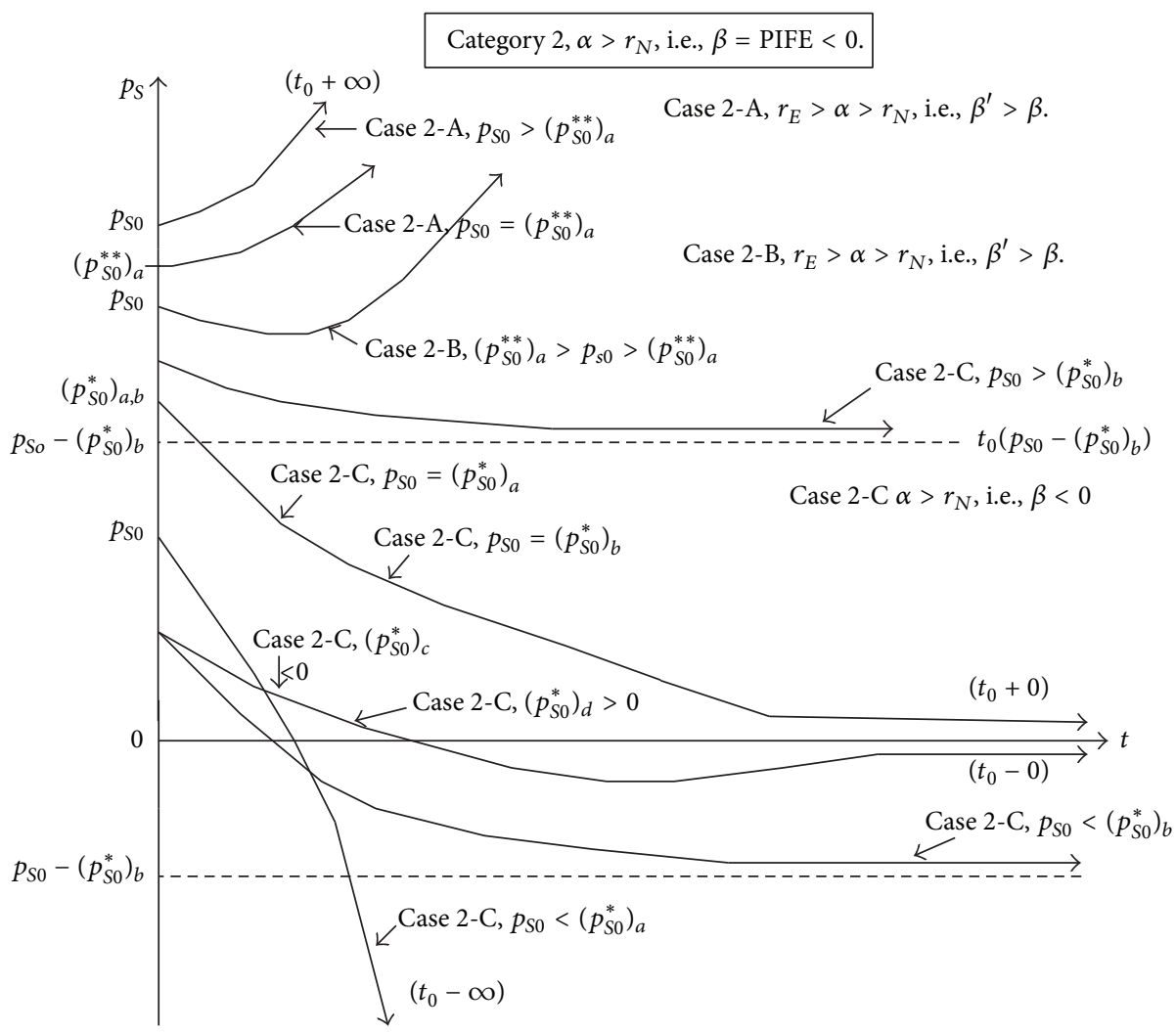

Figure 8: Price evolution of selling resources for Category 2.

the interest rate is assumed to be equal to the inflation rate, that is, negative, while the conclusions of the present approach are different.

The time evolutions are presented in Figure 11.

Case 5- $A\left(r_{E}>\alpha>0>r_{N}\right.$, that is, $\left.\beta^{\prime}>0>\beta\right)$. The price of selling resource increases with time for every value of the initial price $p_{S 0}$ because $p_{S 0}>0>p_{S 0}^{*}>p_{S 0}^{* *}$, since CIPS and CIPES are negative, or $0>p_{S 0}^{*}>p_{S 0}^{* *}$.

Case 5- $B\left(\alpha>r_{E}>0>r_{N}\right.$, that is, $\left.0>\beta^{\prime}>\beta\right)$. The price of selling resource increases temporarily with time up to $t_{m}$ and then decreases if the initial price, $p_{S 0}$, is $p_{S 0}^{* *}>p_{S 0}>0>p_{S 0}^{*}$, that is, smaller than CIPES $>0>$ CIPS.

Case 5-C $\left(\alpha>r_{E}>0>r_{N}\right.$, that is, $\left.0>\beta^{\prime}>\beta\right)$. The price of selling resource decreases with time if the initial price, $p_{S 0}$, is $p_{S 0}>p_{S 0}^{* *}>0>p_{S 0}^{*}$, that is, greater than CIPES $>0>$ CIPS.

\section{Price Difference between Selling and Extracted Resources}

The difference between selling and extracted resources $\Delta p=$ $\left(p_{S}-p_{E}\right)$ is defined as

$$
\begin{aligned}
\Delta p & =\left(p_{S}-p_{E}\right) \\
& =\left(p_{S 0}-p_{S 0}^{*}\right) \exp \left(\beta^{\prime} t\right)-\left(p_{E 0}-p_{S 0}^{*}\right) \exp (\beta t) \\
& =\left(\Delta p_{0}-\Delta^{*} p_{0}\right) \exp \left(\beta^{\prime} t\right)+\Delta^{*} p_{0} \exp (\beta t),
\end{aligned}
$$

where

$$
\Delta^{*} p_{0}=p_{S 0}^{*}-p_{E 0}=p_{E 0} \frac{\left(2 r_{N}-r_{E}\right)}{\left(r_{E}-r_{N}\right)}
$$

is the critical initial price difference, $\operatorname{CIPD}, \Delta^{*} p_{0}$.

The price difference $\Delta p$ has an extreme (maximum or minimum) for

$$
\begin{aligned}
t_{m} & =\frac{1}{\left(\beta^{\prime}-\beta\right)} \ln \left[\frac{\beta \cdot\left(p_{S 0}^{*}-p_{E 0}\right)}{\beta^{\prime} \cdot\left(p_{S 0}^{*}-p_{S 0}\right)}\right] \\
& =\frac{1}{\left(\beta^{\prime}-\beta\right)} \ln \left[\frac{\beta \cdot \Delta^{*} p_{0}}{\beta^{\prime} \cdot\left(\Delta^{*} p_{0}-\Delta p_{0}\right)}\right] \\
& =\frac{1}{\left(\beta-\beta^{\prime}\right)} \ln \left[\frac{\beta^{\prime} \cdot\left(\Delta^{*} p_{0}-\Delta p_{0}\right)}{\beta^{\prime} \cdot \Delta^{*} p_{0}}\right] .
\end{aligned}
$$

The extreme is a maximum if

$$
\beta^{\prime}\left(\beta^{\prime}-\beta\right)\left(\Delta p_{0}-\Delta^{*} p_{0}\right)<0,
$$

otherwise it is a minimum.

The time $t_{m}$ of the extreme is zero if $\Delta p_{0}$ is equal to

$$
\Delta^{* *} p_{0}=\Delta^{*} p_{0}\left[\frac{\left(\beta^{\prime}-\beta\right)}{\beta^{\prime}}\right]=p_{E 0} \frac{\left(2 r_{N}-r_{E}\right)}{\beta^{\prime}},
$$


Category $3, \alpha=r_{N}$, i.e., $\beta=\mathrm{PIFE}=0$.

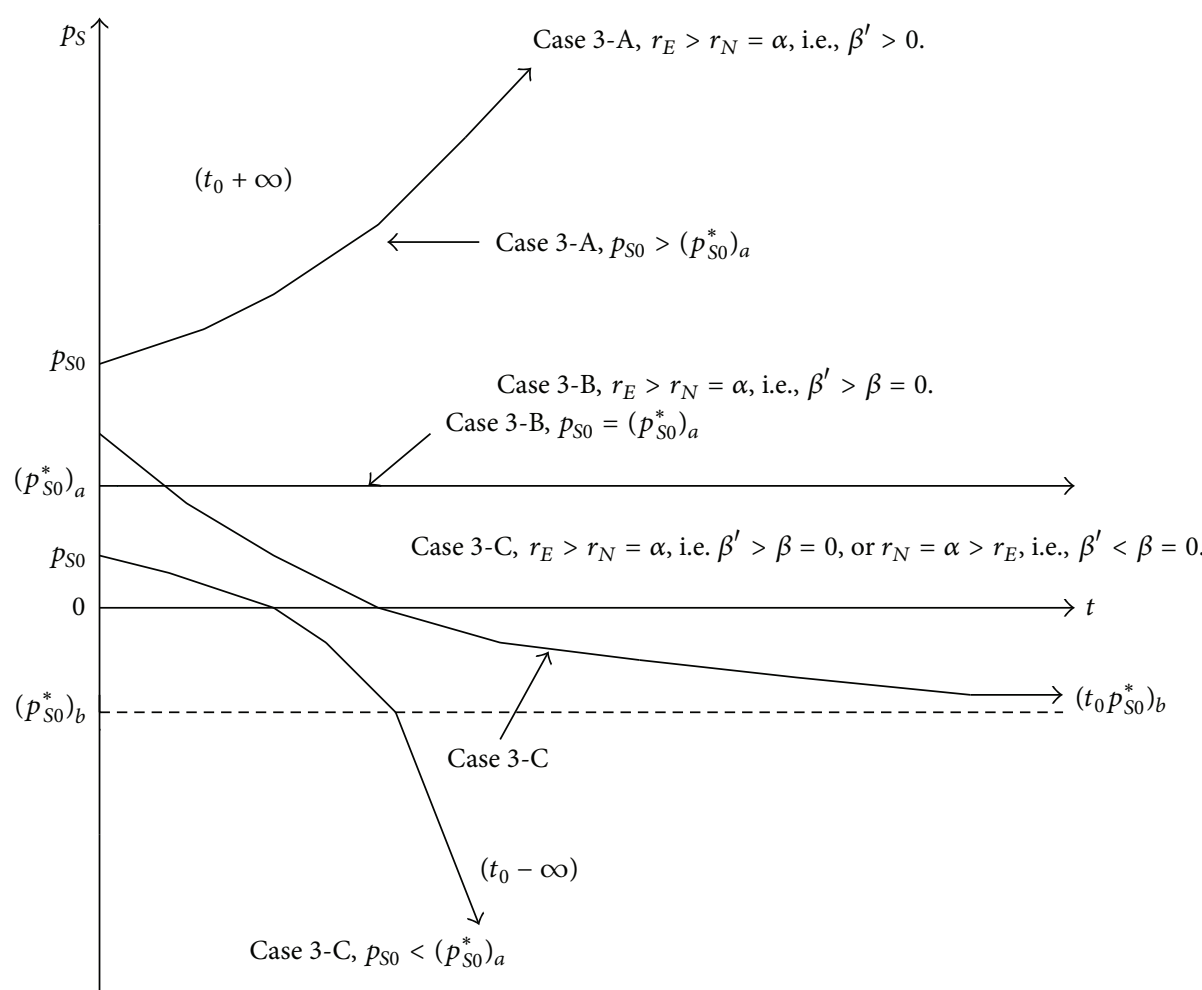

FIGURE 9: Price evolution of selling resources for Category 3.

Category $4, r_{N}=r_{E}$, i.e., $\beta^{\prime}=\beta$.

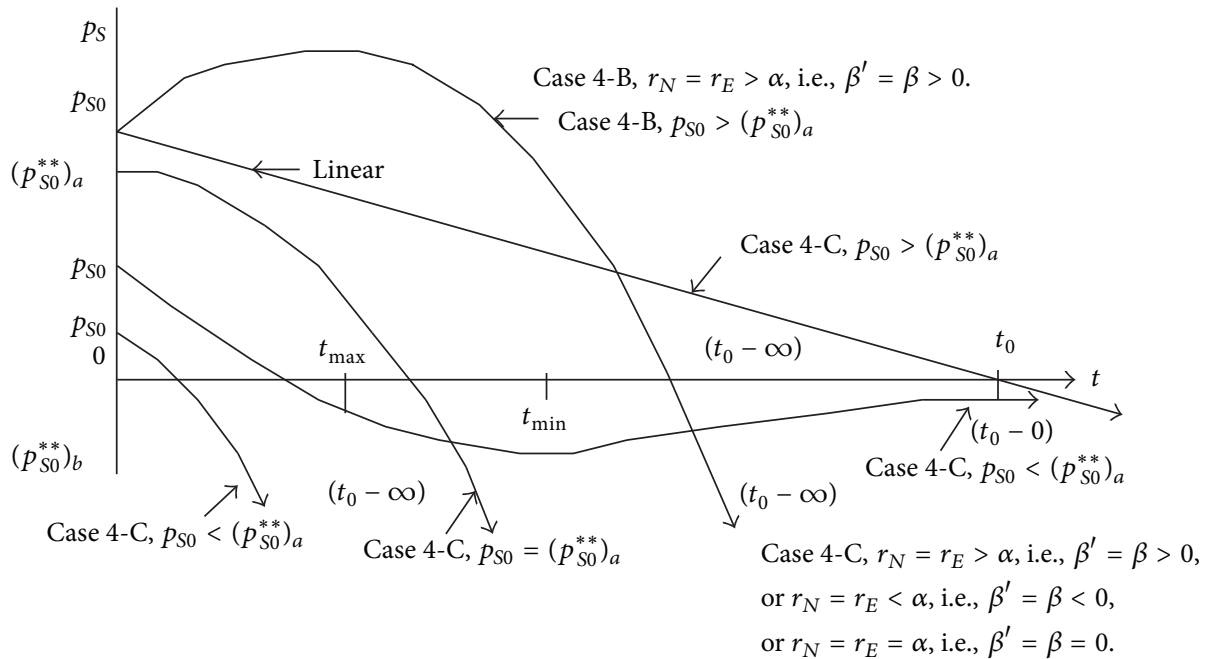

FIgURE 10: Price evolution of selling resources for Category 4.

where $\Delta^{* *} p_{0}$ is the critical initial extreme of the initial price difference, CIEIPD.

The time $t_{m}$ of the extreme is greater than zero if

$$
\begin{array}{ll}
\Delta p_{0}>\Delta^{* *} p_{0} & \text { for } \beta^{\prime}>\beta, \\
\Delta p_{0}<\Delta^{* *} p_{0} & \text { for } \beta^{\prime}<\beta .
\end{array}
$$

For $\Delta p_{S 0}=\Delta p_{S 0}^{*}$ the time of the extreme is

$$
t_{m}=+\infty
$$

for $\beta^{\prime}>\beta$, and

$$
t_{m}=-\infty \text {, }
$$

for $\beta^{\prime}<\beta$. 


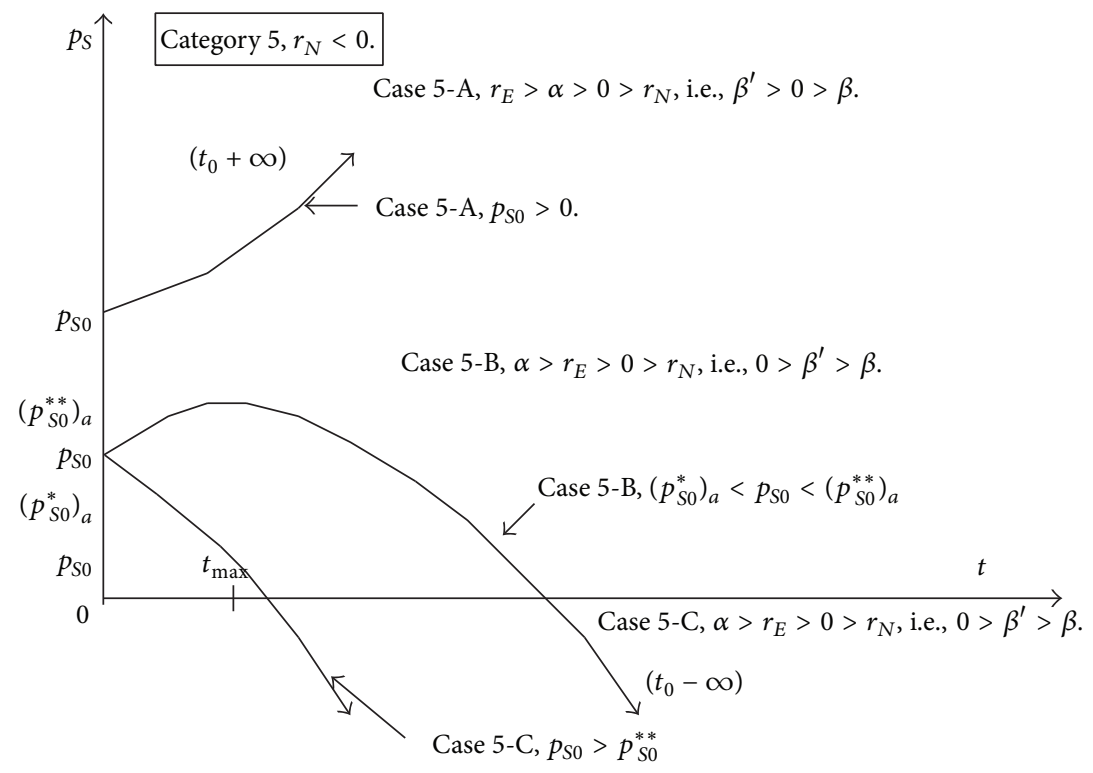

FIGURE 11: Price evolution of selling resources for Category 5.

The time $t_{0}$ is

$$
t_{0}=\frac{1}{\left(\beta^{\prime}-\beta\right)} \ln \left[\frac{\Delta^{*} p_{0}}{\left(\Delta^{*} p_{0}-\Delta p_{0}\right)}\right],
$$

when $\Delta P=0$.

The possible cases can be classified in five categories:

$$
\begin{aligned}
& \text { Category 0D: } r_{N}=0 \text {; } \\
& \text { Category 1D: } r_{N}>\alpha \text {, that is, } \beta=\mathrm{PIFE}>0 \text {; } \\
& \text { Category 2D: } \alpha>r_{N} \text {, that is, } \beta=\mathrm{PIFE}<0 \text {; } \\
& \text { Category 3D: } \alpha=r_{N} \text {, that is, } \beta=\mathrm{PIFE}=0 \text {; } \\
& \text { Category 4D: } r_{N}=r_{E} \text {, that is, } \beta^{\prime}=\beta \text { or PIFE }=\text { PIFS. }
\end{aligned}
$$

On their side, each category presents the following possible cases.

Category $O D\left(r_{N}=0\right)$. The difference between selling and extracted resources, $\Delta p$, is function of the initial difference $\Delta p_{0}=\left(p_{S 0}-p_{E 0}\right)$ and the extraction rate, $\alpha$, as compared to $r_{E}$. It can be remarked that for $r_{N}=0$ the critical initial price and differences of sold resources are $p_{S 0}^{*}=p_{S 0}^{* *}=0$, $\Delta^{*} p_{0}=-p_{E 0}$, and $\Delta^{* *} p_{0}=-r_{E} p_{E 0} / \beta^{\prime}$.

The price difference is then given by

$$
\begin{aligned}
\Delta p & =\left(p_{S}-p_{E}\right)=p_{S 0} \exp \left(\beta^{\prime} t\right)-p_{E 0} \exp (\beta t) \\
& =\left(\Delta p_{0}-\Delta^{*} p_{0}\right) \exp \left(\beta^{\prime} t\right)+\Delta^{*} p_{0} \exp (\beta t) .
\end{aligned}
$$

The time $t_{m}$ of the extreme is given by

$$
t_{m}=\frac{1}{\left(\beta^{\prime}-\beta\right)} \ln \left[\frac{\beta \cdot p_{E 0}}{\beta^{\prime} \cdot p_{S 0}}\right],
$$

which is obtained for $p_{S 0}^{*}=0$ and the extreme is a maximum for

$$
\beta^{\prime}\left(\beta^{\prime}-\beta\right) p_{S 0}<0
$$

The price difference is $\Delta p=0$ at the time $t_{0}$

$$
t_{0}=\frac{1}{\left(\beta^{\prime}-\beta\right)} \ln \left[\frac{p_{E 0}}{p_{S 0}}\right] .
$$

Four initial conditions are investigated:

(i) if the initial price difference $\Delta p_{0}$ is $\Delta p_{0} \geq 0$ or $\left(p_{S 0} \geq\right.$ $\left.p_{E 0}\right)$;

(ii) if the initial price difference $\Delta p_{0}$ is $0>\Delta p_{0} \geq \Delta^{* *} p_{0}$;

(iii) if the initial price difference $\Delta p_{0}$ is $\Delta^{* *} p_{0}>\Delta p_{0}>$ $\Delta^{*} p_{0}$

(iv) if the initial price difference $\Delta p_{0}$ is $\Delta^{*} p_{0}=\Delta p_{0}$ or $p_{S 0}=p_{S 0}^{*}$.

The time evolutions are presented in Figure 12.

Case $0 D-A\left(\alpha \leq 0<r_{E}\right.$, (i.e., $\left.\left.\beta^{\prime}>0, \beta^{\prime}>\beta,\left(\Delta^{* *} p_{0}\right)_{a}<0\right)\right)$

Case $0 D-A 1$. If the initial $\Delta p_{0} \geq 0, \Delta p$ increases exponentially towards $+\infty$ with a higher rate for $\alpha<0,(\beta>0)$, an intermediate one for $\alpha=0,(\beta=0)$, and a smaller one for $r_{E}>\alpha>0,(\beta<0)$.

Case $0 D-A 2$. If the initial $\Delta p_{0}$ is $0>\Delta p_{0}>\Delta^{* *} p_{0}$ the evolution is similar to the previous case but now $\Delta p$ increases from a negative value $\Delta p_{0}$ and all the curves pass through 


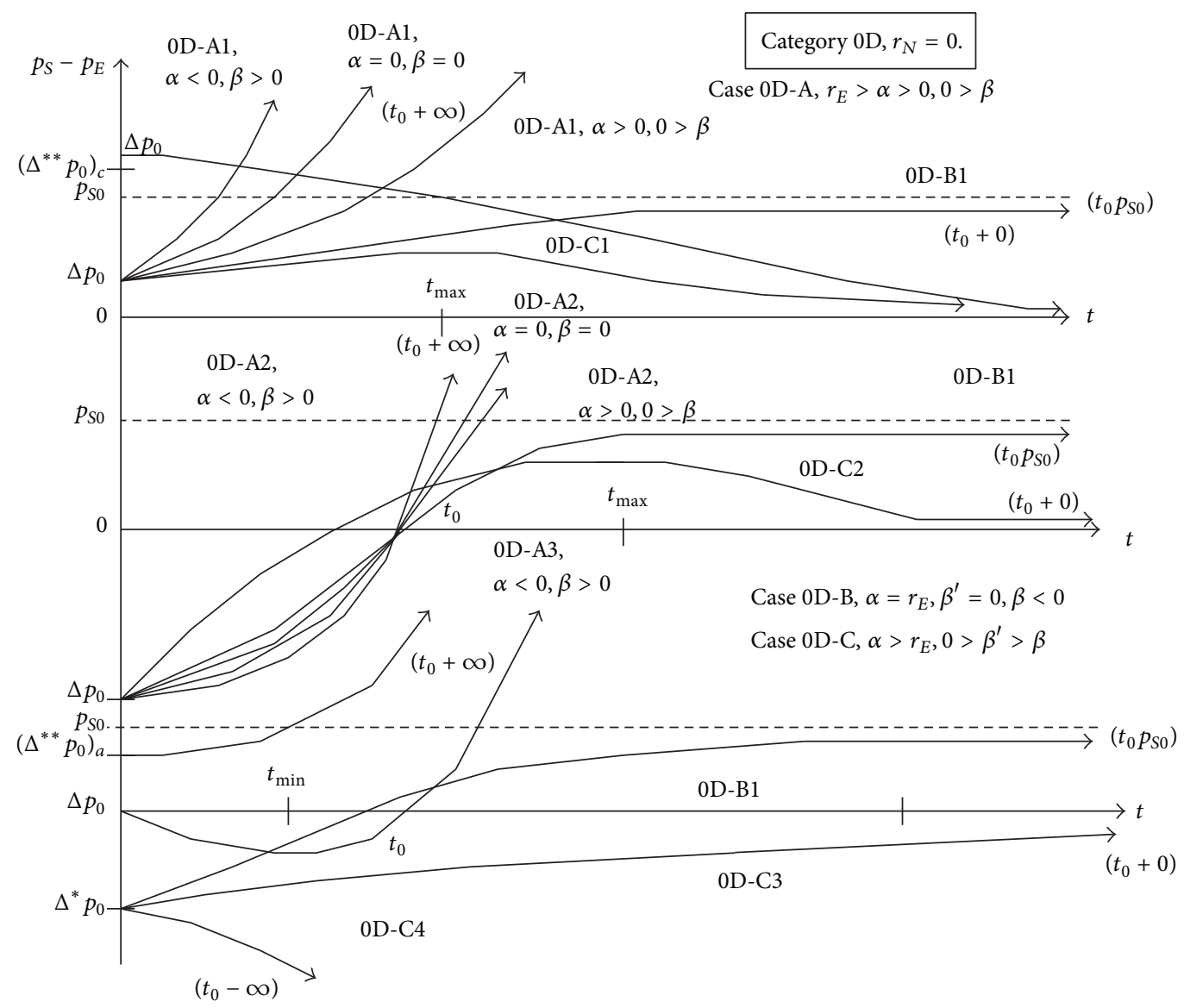

FIgURE 12: Price difference evolution for Category 0D.

the same point $\Delta p=0$ at $t_{0}$. If the initial $\Delta p_{0}=\Delta^{* *} p_{0}, \Delta p$ increases exponentially with the minimum at $t_{\min }=0$.

Case 0D-A3. If the initial $\Delta p_{0}$ is $\Delta^{* *} p_{0}>\Delta p_{0}>\Delta^{*} p_{0}$ and $\beta>0, \Delta p$ decreases initially to a minimum and then increases exponentially as in the previous cases.

Case OD-B $\left(\alpha=r_{E}\right.$, (i.e., $\beta^{\prime}=0>\beta$, $p_{S 0}^{* *}$ is not defined and $\left.\left.\Delta^{* *} p_{0}=-\infty<\Delta^{*} p_{0}<0\right)\right)$

Case $0 D$ - B1. If the initial $\Delta p_{0} \geq \Delta^{*} p_{0}, \Delta p$ tends towards $p_{S 0}=$ $\Delta p_{0}-\Delta^{*} p_{0}$ as asymptote.

Case 0D-C $\left(\alpha>r_{E}\right.$, (i.e., $\beta<\beta^{\prime}<0,\left(\Delta^{* *} p_{0}\right)_{c}>0>$ $\left.\left.\left(\Delta^{*} p_{0}\right)_{c}\right)\right)$

Case 0D-C1. If the initial value $\Delta p_{0} \geq \Delta^{* *} p_{0}$, the difference $\Delta p$ decreases towards +0 , with the maximum at $t=0$ for $\Delta p_{0}=\Delta^{* *} p_{0}$.

Case 0D-C2. If the initial value $\Delta^{*} p_{0}<\Delta p_{0}<\Delta^{* *} p_{0}$, the difference $\Delta p$ increases up to the time $t_{\max }$ when $\Delta p$ reaches a maximum value, $\Delta p_{\max }$, and then decreases towards +0 .

Case 0D-C3. If the initial $\Delta p_{0}=\Delta^{*} p_{0}, \Delta p$ increases towards 0 .
Case 0D-C4. If the initial value $\Delta p_{0}=\Delta^{*} p_{0}<\Delta^{* *} p_{0}, \Delta p$ decreases towards $-\infty$ for $\beta>0$, tends to 0 for $\beta<0$, and remains constant for $\beta=0$.

In conclusion, for $r_{N}=0$, the criteria to evaluate the evolution of $\Delta p$ are the extraction rate $\alpha$ and the initial value $\Delta p_{0}$. If $\alpha<r_{E}, \Delta p$ increases towards $+\infty$ if the initial $\Delta p_{0}$ is $\Delta p_{0}>\Delta^{*} p_{0}$. If $\alpha=r_{E}, \Delta p$ tends towards the asymptotic value $p_{S 0}=\Delta p_{0}-\Delta^{*} p_{0}$, for $\Delta p_{0} \geq \Delta^{*} p_{0}$. If $\alpha>r_{E}, \Delta p$ tends towards +0 if $\Delta p_{0} \geq \Delta^{*} p_{0}$.

Category $1 D\left(r_{N}>\alpha\right.$, that is, $\beta=$ PIFE $\left.>0\right)$. The price evolution of the difference between selling and extracted resources, $\Delta p$, is investigated according to the initial value $\Delta p_{0}=\left(p_{S 0}-p_{E 0}\right)$ and the extraction rate $\alpha$, as compared to $r_{E}$.

Case $1 D-A\left(\alpha \leq 0<r_{N}<r_{E}\right.$, (i.e., $\beta^{\prime}>\beta>0$, $\left.\left.p_{S 0}^{*} \geq 0\right)\right)$. Three relations between $r_{E}$ and $r_{N}$ can be investigated:

(i) $r_{E}>2 r_{N}$, that is, $\left(\Delta^{*} p_{0}\right)_{a}<\left(\Delta^{* *} p_{0}\right)_{a}<0$;

(ii) $r_{E}=2 r_{N}$, that is, $\left(\Delta^{*} p_{0}\right)_{a}=\left(\Delta^{* *} p_{0}\right)_{a}=0$;

(iii) $r_{E}<2 r_{N}$, that is, $\left(\Delta^{*} p_{0}\right)_{a}>\left(\Delta^{* *} p_{0}\right)_{a}>0$. 


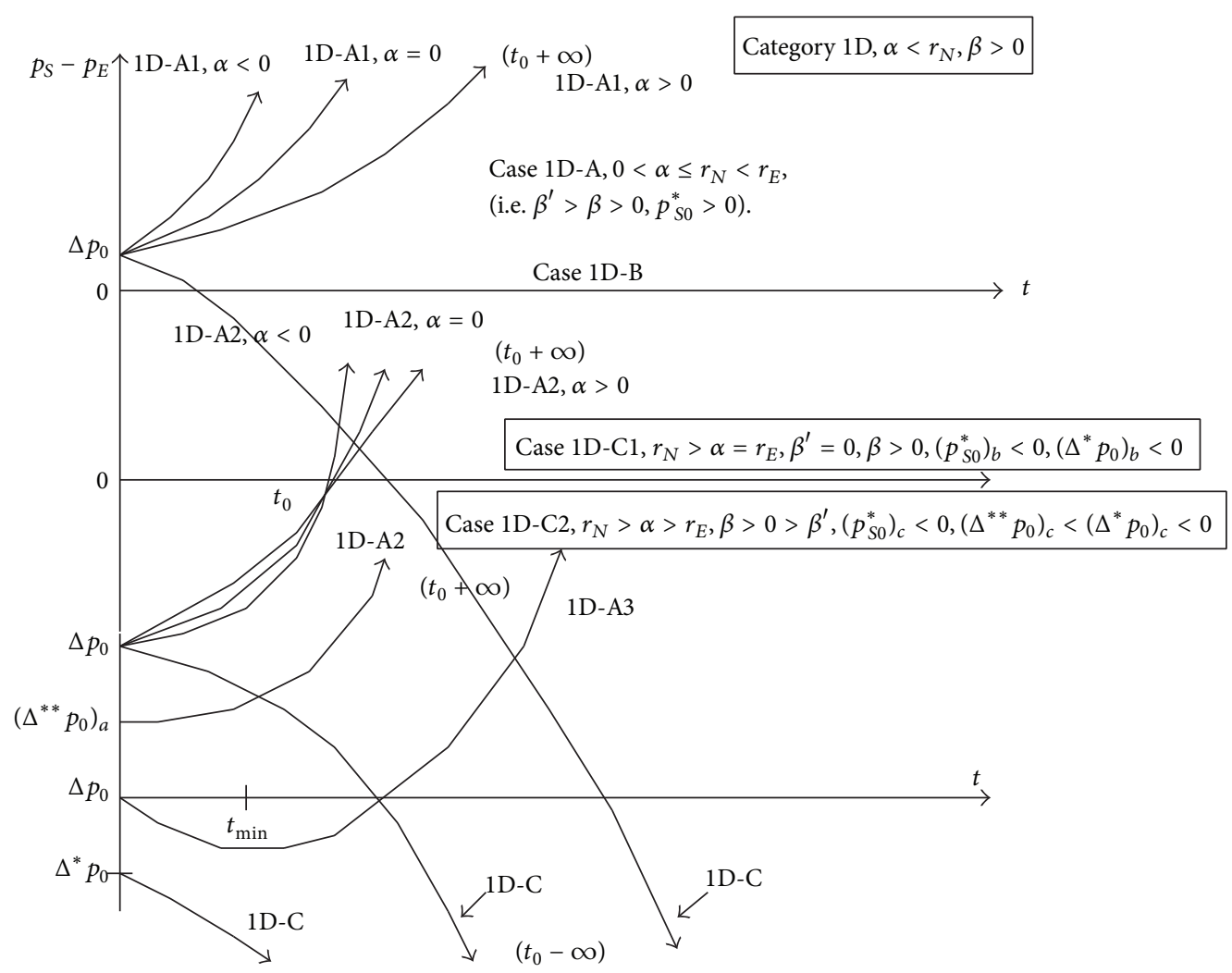

Figure 13: Price difference evolution for Category 1D.

If $r_{E}>2 r_{N}$, that is, $\Delta^{*} p_{0}<\Delta^{* *} p_{0}<0$, the following four initial conditions are investigated:

(i) the initial price difference $\Delta p_{0}$ is $\Delta p_{0} \geq 0$ (or $p_{S 0} \geq$ $\left.p_{E 0}\right)$;

(ii) the initial price difference $\Delta p_{0}$ is $\Delta^{* *} p_{0} \leq \Delta p_{0}<0$;

(iii) the initial price difference $\Delta p_{0}$ is $\Delta^{* *} p_{0}>\Delta p_{0}>$ $\Delta^{*} p_{0}$

(iv) the initial price difference $\Delta p_{0}$ is $\Delta p_{0} \leq \Delta^{*} p_{0}$, or $p_{S 0} \leq$ $p_{S 0}^{*}$;

and the price evolutions are presented in Figure 13.

Case $1 D$ - $A 1$. If $\Delta p_{0} \geq 0$ the difference $\Delta p$ increases exponentially towards $+\infty$ with a higher rate for $\alpha<0$, an intermediate one for $\alpha=0$, and a smaller one for $0<\alpha$.

Case $1 D-A 2$. If $0>\Delta p_{0}>\Delta^{* *} p_{0}$ the difference $\Delta p$ increases exponentially towards $+\infty$ as in the previous case and the curves pass through the same point $\Delta p=0$ at $t_{0}$. If $\Delta p_{0}=$ $\Delta^{* *} p_{0}$ the difference $\Delta p$ increases exponentially with the minimum at $t=0$.

Case $1 D-A 3$. If $\Delta^{* *} p_{0}>\Delta p_{0}>\Delta^{*} p_{0}, \Delta p$ decreases initially down to a minimum and then increases exponentially as in the previous cases.

If $r_{E}=2 r_{N}$, that is, $\Delta^{*} p_{0}=\Delta^{* *} p_{0}=0$, the following cases are discussed.

Case $1 D$ - $A 1$. If $\Delta p_{0}>\Delta^{*} p_{0}=0$ the difference $\Delta p$ increases exponentially towards $+\infty$ with a higher rate for $\alpha<0$, an intermediate one for $\alpha=0$, and a smaller one for $0<\alpha$.
If $r_{E}<2 r_{N}$, that is, $\Delta^{*} p_{0}>\Delta^{* *} p_{0}>0$, the following cases are discussed.

Case $1 D$ - $A 1$. If $\Delta p_{0} \geq \Delta^{*} p_{0}>0$ the difference $\Delta p$ increases exponentially towards $+\infty$ with a higher rate for $\alpha<0$, an intermediate one for $\alpha=0$, and a smaller one for $0<\alpha$.

Case $1 D-B\left(\Delta p_{0}=\Delta^{*} p_{0}=0\right) . \Delta p$ remains constant at $\Delta^{*} p_{0}=0$ with time.

Case 1D-C1 $\left(\alpha=r_{E}<r_{N}\right.$, (i.e., $\beta^{\prime}=0, \beta>0,\left(p_{S 0}^{*}\right)_{b}<0<$ $\left(p_{S 0}^{* *}\right)_{b}=\infty$, and $\left.\left.\left(\Delta^{*} p_{0}\right)_{b}<0<\left(\Delta^{* *} p_{0}\right)_{b}=\infty\right)\right)$. If $\Delta p_{0}$ is $-p_{E 0}<\Delta p_{0}<\Delta^{*} p_{0}, \Delta p$ decreases towards $-\infty$. If $\Delta p_{0}$ is $\Delta^{*} p_{0}>\Delta p_{0}>\Delta^{* *} p_{0}, \Delta p$ increases up to a maximum and then decreases towards $-\infty$. If $\Delta p_{0} \leq \Delta^{* *} p_{0}, \Delta p$ decreases towards $-\infty$.

Case 1D-C2 $\left(r_{E}<\alpha<r_{N}\right.$, (i.e., $\beta^{\prime}<0<\beta$, $\left(p_{S 0}^{*}\right)_{c}<0$, $\left.\left.\left(\Delta^{* *} p_{0}\right)_{c}<\left(\Delta^{*} p_{0}\right)_{c}<0\right)\right)$. The difference $\Delta p$ decreases towards $-\infty$ for every initial $\Delta p_{0}$.

In conclusion, for $\alpha<r_{N}$, (i.e., $\beta>0$ ) the criteria to evaluate the price difference evolution are the extraction rate $\alpha$, the initial condition, and the relation between $r_{E}$ and $r_{N}$. For $\beta^{\prime}>0$ and $r_{E}>2 r_{N}, \Delta p$ increases towards $+\infty$ if $\Delta p_{0}>\Delta^{*} p_{0}$. For $\beta^{\prime}>0$ and $r_{E}=2 r_{N}, \Delta p$ increases towards $+\infty$ if $\Delta p_{0}>\Delta^{*} p_{0}$. For $\beta^{\prime}>0$ and $r_{E}<2 r_{N}, \Delta p$ increases towards $+\infty$ if $\Delta p_{0} \geq \Delta^{*} p_{0}$, while $\Delta p$ increases up to a maximum and then decreases if $\Delta^{*} p_{0}>\Delta p_{0}>\Delta^{* *} p_{0}$. For $\beta^{\prime} \leq 0, \Delta p$ decreases towards $-\infty$. 
Category $2 D\left(\alpha>r_{N}\right.$, that is, $\left.\beta=P I F E<0\right)$. The price evolution of the difference $\Delta p$ is investigated for $\beta<0$ according to the initial value $\Delta p_{0}$ and the relation between $r_{N}$ and $r_{E}$.

The price evolutions are presented in Figure 14.

Case $2 D-A\left(r_{E}>\alpha>r_{N}\right.$, (i.e., $\left.\left.\beta^{\prime}>0>\beta\right)\right)$. If $2 r_{N}<r_{E}$, that is, $\Delta^{* *} p_{0}<\Delta^{*} p_{0}<0$, the following situations are discussed.

Case $2 D$ - $A 1$. If $\Delta p_{0}>\Delta^{*} p_{0}$ the difference $\Delta p$ increases towards $+\infty$.

If $2 r_{N}>r_{E}$, that is, $\Delta^{* *} p_{0}>\Delta^{*} p_{0}>0$, the following situations are discussed.

Case 2D-A1. If $\Delta p_{0} \geq \Delta^{* *} p_{0}$ the difference $\Delta p$ increases towards $+\infty$. If $\Delta p_{0}$ is $\Delta^{* *} p_{0}>\Delta p_{0}>\Delta^{*} p_{0}>0$ the difference $\Delta p$ increases towards $+\infty$ after a minimum at $t_{\min }$.

If $2 r_{N}=r_{E}$, that is, $\Delta^{* *} p_{0}=\Delta^{*} p_{0}=0$, the following situations are discussed.

Case $2 D$ - $A 1$. If $\Delta p_{0}>\Delta^{*} p_{0}=0$ the difference $\Delta p$ increases towards $+\infty$.

Case $2 D-B\left(\alpha=r_{E}>r_{N}\right.$, (i.e., $\beta^{\prime}=0>\beta, \Delta^{* *} p_{0}=\infty$, $\Delta^{*} p_{0}>0$ for $2 r_{N}>r_{E}, \Delta^{*} p_{0}=0$ for $2 r_{N}=r_{E}$, and $\Delta^{*} p_{0}<$ 0 for $\left.2 r_{N}<r_{E}\right)$ )

Case 2D-B1. If $\Delta p_{0}=\Delta^{*} p_{0}=0$, the difference $\Delta p$ remains constant at $\Delta p_{0}=\Delta^{*} p_{0}=0$. If $\Delta p_{0}=\Delta^{*} p_{0}>0$ the difference $\Delta p$ tends to +0 .

Case 2D-B2. If $\Delta p_{0}>\Delta^{*} p_{0}$, the difference $\Delta p$ decreases towards $\left(\Delta p_{0}-\Delta^{*} p_{0}\right)$. For $r_{E}=2 r_{N}, \Delta p$ remains constant at $\left(\Delta p_{0}-\Delta^{*} p_{0}\right)$.

Case 2D-C $\left(\alpha>r_{E}>r_{N}\right.$, (i.e., $0>\beta^{\prime}>\beta, \Delta^{*} p_{0}>$ $0>\Delta^{* *} p_{0}$ for $2 r_{N}>r_{E}, \Delta^{*} p_{0}<0<\Delta^{* *} p_{0}$ for $2 r_{N}<$ $r_{E}$, and $\Delta^{* *} p_{0}=\Delta^{*} p_{0}=0$ for $\left.2 r_{N}=r_{E}\right)$ )

Case $2 D$-C1. If $\Delta p_{0}$ is $\Delta^{* *} p_{0}<\Delta p_{0}<\Delta^{*} p_{0}<0$ the difference $\Delta p$ decreases towards $-\infty$ after a maximum at $t_{\max }$.

Case 2D-C2. If $\Delta p_{0}<\Delta^{*} p_{0}=0$, the difference $\Delta p$ decreases towards $-\infty$. If $\Delta p_{0} \leq \Delta^{* *} p_{0}$ the difference $\Delta p$ decreases towards $-\infty$. If $\Delta p_{0}<\Delta^{*} p_{0}$ the difference $\Delta p$ decreases towards $-\infty$.

For $r_{E}>2 r_{N}, \Delta p$ tends towards 0 , if $\Delta p_{0} \geq \Delta^{* *} p_{0}>0$, $\Delta p$ increases up to a maximum and then tends towards +0 , if $\Delta^{* *} p_{0}>\Delta p_{0}>\Delta^{*} p_{0}>0$, and $\Delta p$ tends towards +0 , if $\Delta p_{0} \leq \Delta^{*} p_{0}<0$. For $r_{E}=2 r_{N}, \Delta p$ decreases to +0 if $\Delta p_{0}>\Delta^{* *} p_{0}$, remains constant at $\Delta p_{0}$ if $\Delta p_{0}=\Delta^{* *} p_{0}$, and increases towards -0 if $\Delta p_{0}<\Delta^{* *} p_{0}$. For $r_{E}<2 r_{N}, \Delta p$ decreases towards 0 for every $\Delta p_{0}$.

Case 2D-D $\left(\alpha>r_{N}>r_{E}\right.$, (i.e., $\beta^{\prime}<\beta, \Delta^{*} p_{0}<\Delta p_{0}^{* *}<$ $0)$ ). For every $\Delta p_{0}$ the difference $\Delta p$ decreases down to a minimum and then increases towards -0 .

In conclusion, for $\alpha>r_{N}$, (i.e., $\beta<0$ ) the criteria to evaluate the evolution of $\Delta p$ are the extraction rate $\alpha$ and the initial condition. For $\alpha<r_{E}, \Delta p$ increases towards $+\infty$ if
$\Delta p_{0}>\Delta^{*} p_{0} \leq 0$, or $\Delta p_{0}>\Delta^{* *} p_{0}>\Delta^{*} p_{0}>0$ or $\Delta^{* *} p_{0}>$ $\Delta p_{0}>\Delta^{*} p_{0}, \Delta p$ decreases towards +0 if $\Delta p_{0}=\Delta^{*} p_{0}>$ or $<0$. For $\alpha=r_{E}, \Delta p$ tends towards $\left(\Delta p_{0}-\Delta^{*} p_{0}\right)$. If $\alpha>r_{E}$, $\Delta p$ tends towards +0 for every initial $\Delta p_{0}$ except for $r_{E}>2 r_{N}$ and $\Delta^{* *} p_{0}>\Delta p_{0}>\Delta^{*} p_{0}$ when $\Delta p$ tends towards 0 after a maximum.

Category $3 D\left(\alpha=r_{N}\right.$, that is, $\left.\beta=P I F E=0\right)$. The price evolution of the difference $\Delta p$ is investigated for $\beta=0$, (i.e., $\left.\Delta^{*} p_{0}=\Delta^{* *} p_{0}\right)$ according to the initial value $\Delta p_{0}$ and the relation between $\alpha=r_{N}$ and $r_{E}$.

The price evolutions are reported in Figure 15.

Case $3 D-1\left(r_{E}>r_{N}=\alpha\right.$, that is, $\left.\beta^{\prime}>\beta=0\right)$

Case $3 D-1 A$. If $\Delta p_{0}>\Delta^{*} p_{0}$ the difference $\Delta p$ increases exponentially with time towards $+\infty$.

Case $3 D-1 B$. If $\Delta p_{0}=\Delta^{*} p_{0}$ the difference $\Delta p$ remains constant at the initial value $\Delta p_{0}$.

Case 3D-1C. If $\Delta p_{0}<\Delta^{*} p_{0}$ the difference $\Delta p$ decreases towards $-\infty$.

Case 3D-2 $\left(\alpha=r_{N}>r_{E}\right.$, (i.e., $\left.\left.\beta^{\prime}<\beta=0\right)\right)$. The difference $\Delta p$ decreases towards $\Delta^{*} p_{0}$ for every initial $\Delta p_{0}$.

In conclusion, for $\beta=0$, the criteria to evaluate the evolution of $\Delta p$ are the relation between $r_{N}$ and $r_{E}$ and the initial condition $\Delta p_{0}$. For $r_{N}<r_{E}, \Delta p$ increases towards $+\infty$ if $\Delta p_{0}>\Delta^{*} p_{0}, \Delta p$ remains constant if $\Delta p_{0}=\Delta^{*} p_{0}$, and $\Delta p$ decreases towards $-\infty$ if $\Delta p_{0}<\Delta^{*} p_{0}$. For $r_{N}>r_{E}, \Delta p$ tends towards the asymptotic value $\Delta^{*} p_{0}$.

Category $4 D\left(r_{N}=r_{E}\right.$, that is, $\left.\beta^{\prime}=\beta\right)$. The price difference $\Delta p$ is given by

$$
\begin{aligned}
\Delta p & =\left(p_{S}-p_{E}\right) \\
& =\left[\left(p_{S 0}-r_{E} p_{E 0} t\right)-p_{E 0}\right] \exp \left(\beta^{\prime} t\right) \\
& =\left(\Delta p_{0}-r_{E} p_{E 0} t\right) \exp \left(\beta^{\prime} t\right) \\
& =\left(\Delta p_{0}-p_{S 0}^{* *} \beta^{\prime} t\right) \exp \left(\beta^{\prime} t\right) .
\end{aligned}
$$

The critical initial price difference $\Delta^{*} p_{0}$ and the critical initial extreme price difference $\Delta^{* *} p_{0}$ are not defined and the only critical price defined is the critical initial price extreme of the sold resources $p_{S 0}^{* *}$, already defined in the second part of (38) or (45).

The price difference $\Delta p$ has an extreme for the time $t_{m}$ given by

$$
t_{m}=\frac{\left(\Delta p_{0}-p_{S 0}^{* *}\right)}{\beta^{\prime} \cdot p_{S 0}^{* *}}
$$

The extreme is a maximum if $\beta^{\prime}>0$ and a minimum if $\beta^{\prime}<0$. The time of maximum $t_{\max }$ is zero if

$$
\Delta p_{0}=p_{S 0}^{* *}=\frac{r_{E} p_{E 0}}{\beta^{\prime}}
$$




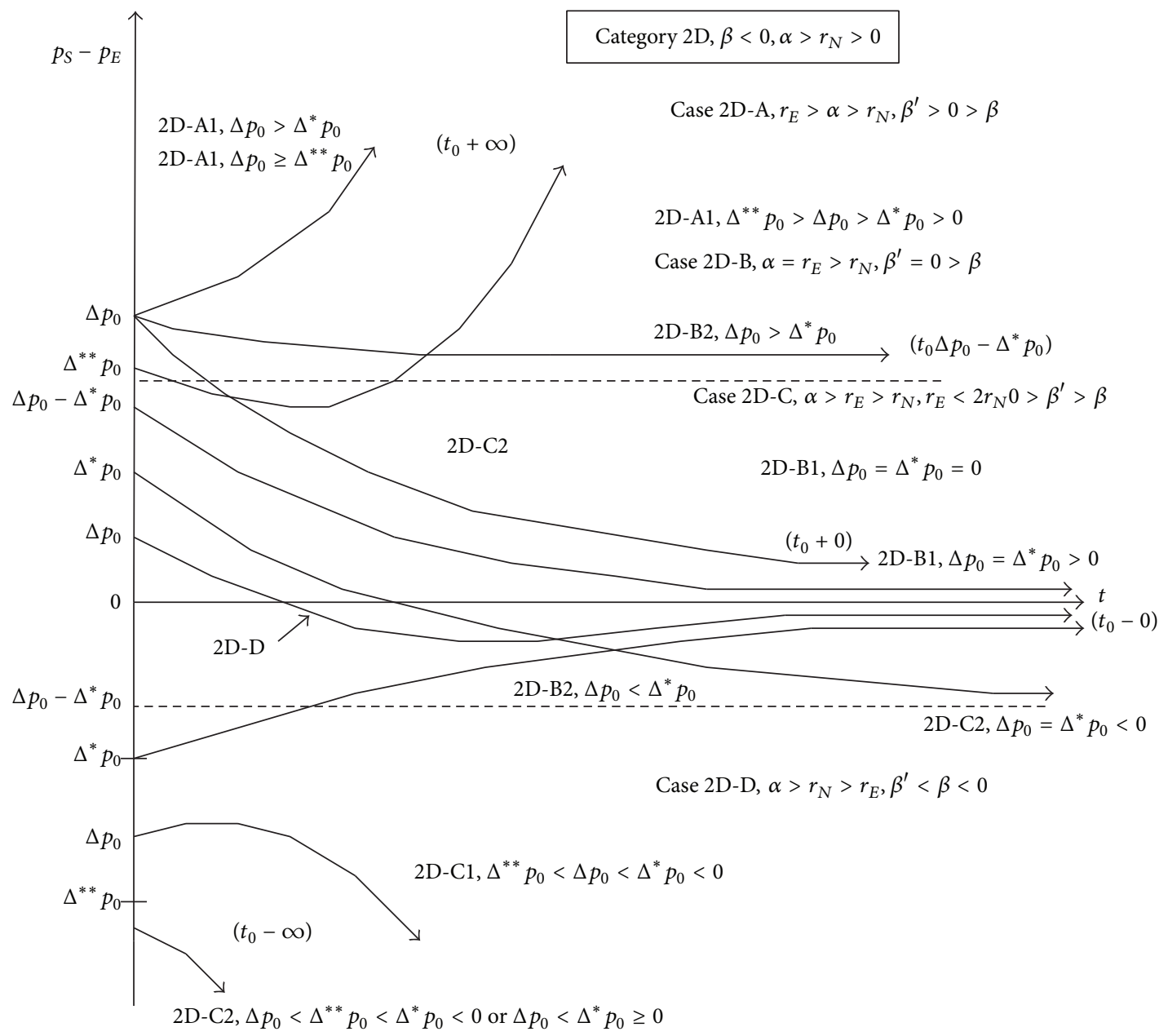

FIgURE 14: Price difference evolution for Category 2D.

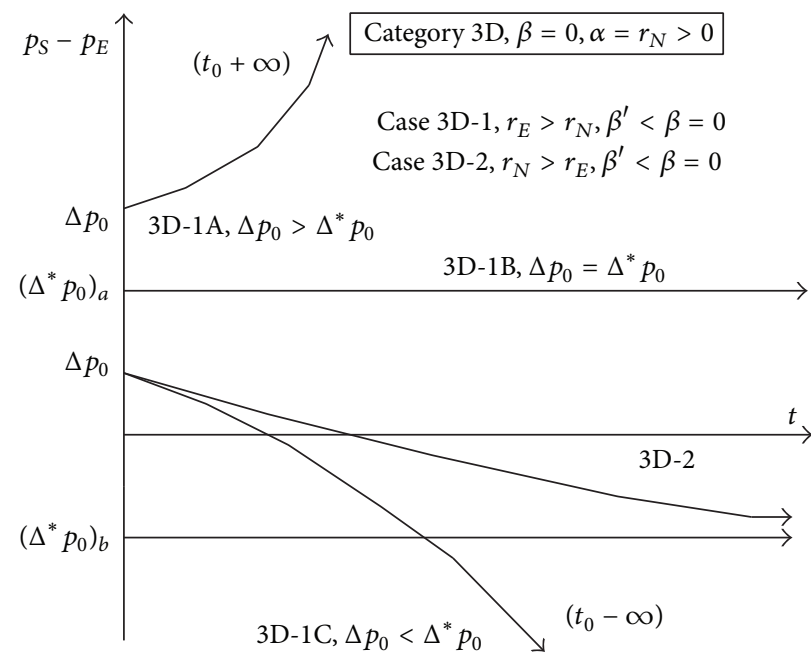

FIgURE 15: Price difference evolution for Category 3D. 
and $t_{\max }$ is greater than zero if

$$
\begin{array}{ll}
\Delta p_{0}>p_{S 0}^{* *}, & p_{S 0}^{* *} \beta^{\prime}>0, \\
\Delta p_{0}<p_{S 0}^{* *}, & p_{S 0}^{* *} \beta^{\prime}<0 .
\end{array}
$$

The difference $\Delta p$ is zero for the time $t_{0}$ equal to

$$
t_{0}=\frac{\left(p_{S 0}-p_{E 0}\right)}{\left(r_{E} p_{E 0}\right)}=\frac{\Delta p_{0}}{\left(r_{E} p_{E 0}\right)}=\frac{\Delta p_{0}}{\left(p_{S 0}^{* *} \beta^{\prime}\right)} .
$$

The price evolution of the difference $\Delta p$ is investigated according to the initial value $\Delta p_{0}=\left(p_{S 0}-p_{E 0}\right)$ and the extraction rate $\alpha$.

The price evolutions are reported in Figure 16.

Case $4 D-1\left(r_{N}=r_{E}>\alpha\right.$, (i.e., $\left.\left.\beta^{\prime}=\beta>0\right)\right)$

Case 4D-1A. The price cannot increase with time.

Case $4 D-1 B$. If $\Delta p_{0}>p_{S 0}^{* *}$ the difference $\Delta p$ initially increases up to the maximum time $t_{\max }$ and then decreases towards $-\infty$.

Case 4D-1C. If $\Delta p_{0}=p_{S 0}^{* *}$ the difference $\Delta p$ decreases towards $-\infty$ with the maximum at $t=0$. If $\Delta p_{0}<p_{S 0}^{* *}$, the difference $\Delta p$ decreases towards $-\infty$.

Case $4 D-2\left(\alpha>r_{N}\right.$, (i.e., $\left.\left.\beta^{\prime}=\beta<0, p_{S 0}^{* *}<0\right)\right)$

Case $4 D-2 A$. The price cannot increase with time.

Case $4 D-2 B$. If $\Delta p_{0}>p_{S 0}^{* *}$, the difference $\Delta p$ decreases with time, reaches a minimum at $t_{\min }$, and then increases towards -0 . If $\Delta p_{0} \leq p_{S 0}^{* *}$ the difference $\Delta p$ increases towards 0 .

Case $4 D-3\left(\alpha=r_{E}=r_{N}\right.$, (i.e., $\left.\left.\beta^{\prime}=\beta=0, p_{S 0}^{* *}=\infty\right)\right)$. The difference $\Delta p$ decreases linearly towards $-\infty$ for every initial $\Delta p_{0}$.

Discussion. The discussion on the price evolutions of sold resources, $p_{S}$, and price difference, $\Delta p=\left(p_{S}-p_{E}\right)$, in case of no-accumulation and no-depletion of the extracted resources, is carried out summarizing the results in the following Tables 1-8.

Table 1 presents the price trends of $p_{S}, p_{E}$, and $\Delta p$, for nonrenewable resources without interest rate, $r_{N}=0$, that is, $\beta^{\prime}>\beta, p_{S 0}^{*}=p_{S 0}^{* *}=0, \Delta^{*} p_{0}=-p_{E 0}$, and $\Delta^{* *} p_{0}=-r_{E} p_{E 0} / \beta^{\prime}$ with the following conclusions:

(i) the price $p_{E}$ of extracted resources increases towards $+\infty$ if $\alpha<0$, (i.e., $\beta>0$ ), $p_{E}$ remains constant at $p_{E 0}$ if $\alpha=0$, (i.e., $\beta=0$ ), and $p_{E}$ decreases towards +0 if $\beta<0$;

(ii) the price $p_{S}$ of sold resources increases towards $+\infty$ if $\alpha \leq 0<r_{E}$, (i.e., $\beta^{\prime}>0$ ), $p_{S}$ remains constant at $p_{S 0}$ if $\alpha=r_{E}$, (i.e., $\beta^{\prime}=0$ ), and $p_{S}$ decreases towards +0 if $\alpha>r_{E}$, (i.e., $\beta^{\prime}<0$ );

(iii) if the extraction rate $\alpha<0$, (i.e., $\beta^{\prime}>\beta>0$ ), the trends of the price difference $\Delta p$ depend on the initial value, $\Delta p_{0}$. If $\Delta p_{0} \geq \Delta^{* *} p_{0}=\Delta^{*} p_{\max }, \Delta p$ increases towards $+\infty$, if $\Delta^{*} p_{\text {min }}=\Delta^{*} p_{0}<\Delta p_{0}<\Delta^{* *} p_{0}=$ $\Delta^{*} p_{\max }, \Delta p$ increases towards $+\infty$ after a minimum, and if $\Delta p_{0}=\Delta^{*} p_{0}=\Delta^{*} p_{\min }, \Delta p$ decreases towards $-\infty$;

(iv) if the extraction rate is $\alpha=0$, (i.e., $\beta^{\prime}>\beta=0$ ), the price difference $\Delta p$ increases towards $+\infty$ if $\Delta p_{0}>$ $\Delta^{* *} p_{0}=\Delta^{*} p_{0}=\Delta^{*} p_{\min }=\Delta^{*} p_{\max }=-p_{E 0}$ while tending towards $\Delta p_{0}$ if $\Delta p_{0}=\Delta^{*} p_{\text {min }}$. It can be noticed that $\Delta p_{0}$ cannot be smaller than $\Delta^{*} p_{0}$ because $p_{S 0}$ cannot be smaller than 0 ;

(v) if the extraction rate $\alpha<r_{E}$, (i.e., $\beta^{\prime}>0>\beta$ ), the price difference $\Delta p$ increases towards $+\infty$ if $\Delta p_{0}>$ $\Delta^{*} p_{0}=\Delta^{*} p_{\max }=-p_{E 0}$ while tends towards 0 if $\Delta^{*} p_{0}=\Delta^{*} p_{\min }$

(vi) if the extraction rate $\alpha=r_{E}$, (i.e., $\beta^{\prime}=0>\beta$ ), the price difference $\Delta p$ tends towards $p_{S 0}=\Delta p_{0}-\Delta^{*} p_{0}$;

(vii) if the extraction rate $\alpha>r_{E}$, (i.e., $0>\beta^{\prime}>\beta$ ), the price difference $\Delta p$ tends towards +0 for any $\Delta p_{0}$ but with a maximum at $t_{\max }$ if $\Delta^{*} p_{\max }>\Delta p_{0}>\Delta^{*} p_{\min }$.

Table 2 presents the price trends of $p_{S}, p_{E}$, and $\Delta p$, for $\alpha<r_{N}$, that is, $\beta>0$, with the following conclusions:

(i) the price $p_{E}$ increases towards $+\infty$, because $\beta>0$;

(ii) the price $p_{S}$ increases towards $+\infty$ if $r_{E}>r_{N}$, (i.e., $\left.\beta^{\prime}>\beta>0\right)$, and $p_{S 0} \geq p_{S 0}^{*}=p_{S \max }^{*}$

(iii) the price $p_{S}$ initially increases, reaches a maximum at $t_{\text {max }}$, and then decreases towards $-\infty$ in the following cases: $r_{N}<r_{E}$ and $p_{S \max }^{*}=p_{S 0}^{*}>p_{S 0}>p_{S 0}^{* *}=p_{S \min }^{*}$, $r_{N}=r_{E}$ and $p_{S 0} \geq p_{S 0}^{* *}$, and $r_{N}>r_{E}$ and $p_{S 0} \geq p_{S 0}^{* *}=$ $p_{S \text { max }}^{*}$

(iv) the price, $p_{S}$, decreases towards $-\infty$, in all the other cases;

(v) the price difference $\Delta p$ has different trends for $r_{E}>$ $r_{N}$ according to the relation between $2 r_{N}$ and $r_{E}$. If $r_{E}>2 r_{N}$, the price difference $\Delta p$ increases towards $+\infty$ if $\Delta p_{0} \geq \Delta^{*} p_{\max }=\Delta^{* *} p_{0}, \Delta p$ increases towards $+\infty$ after a minimum if $\Delta^{* *} p_{0}>\Delta p_{0}>\Delta^{*} p_{0}$, and $\Delta p$ decreases towards $-\infty$ if $\Delta p_{0} \leq \Delta^{*} p_{\min }$. If $r_{E}=2 r_{N}$, the price difference $\Delta p$ increases towards $+\infty$ if $\Delta p_{0}>\Delta^{*} p_{\max }=\Delta^{*} p_{0}=0, \Delta p$ remains constant at $\Delta^{*} p_{0}=0$ if $\Delta p_{0}=\Delta^{*} p_{0}=0$, and $\Delta p$ decreases to $-\infty$ if $\Delta p_{0}<\Delta^{*} p_{0}=0$. If $r_{E}<2 r_{N}$, the price difference $\Delta p$ increases towards $+\infty$ if $\Delta p_{0} \geq$ $\Delta^{*} p_{\max }=\Delta^{*} p_{0}, \Delta p$ decreases towards $-\infty$, after a maximum, if $\Delta^{*} p_{0}>\Delta p_{0}>\Delta^{* *} p_{0}$, and $\Delta p$ decreases to $-\infty$ if $\Delta p_{0} \leq \Delta^{* *} p_{0}=\Delta^{*} p_{\min }$;

(vi) the price difference $\Delta p$ for $r_{N}=r_{E}$ initially increases up to a maximum at $t_{\max }$ and then decreases towards $-\infty$ if $\Delta p_{0}>p_{S 0}^{* *}$;

(vii) the price difference $\Delta p$ decreases towards $-\infty$ in all other cases. 
TABLE 1: Price trends to $t \rightarrow \infty$ of selling resources, $p_{S}$, extracted resources, $p_{E}$, and difference $\Delta p=\left(p_{S}-p_{E}\right)$ for $r_{N}=0$, (i.e., $p_{S 0}^{*}=p_{S 0}^{* *}=$ $0, \beta^{\prime}>\beta, \Delta^{*} p_{0}=-p_{E 0}$, and $\left.\Delta^{* *} p_{0}=-r_{E} p_{E 0} / \beta^{\prime}\right)$.

\begin{tabular}{|c|c|c|c|c|}
\hline Extraction rate, $\alpha, \beta^{\prime}=r_{E}-\alpha \beta=r_{N}-\alpha$ & $\begin{array}{l}\text { Initial condition } p_{E 0}, p_{S 0}, \text { or } \\
\Delta p_{0}\end{array}$ & $\begin{array}{l}\text { Selling } \\
\text { resources, } p_{S} \\
(\infty)\end{array}$ & $\begin{array}{l}\text { Extracted } \\
\text { resources, } p_{E} \\
(\infty)\end{array}$ & $\begin{array}{l}\text { Price difference } \\
\Delta p(\infty)\end{array}$ \\
\hline \multirow{4}{*}{$\begin{array}{l}\alpha<0, \beta^{\prime}>\beta>0 \\
\left(\Delta^{*} p_{0}=\Delta^{*} p_{\min }<\Delta^{*} p_{\max }=\Delta^{* *} p_{0}<0\right)\end{array}$} & $p_{0}>p_{S 0}^{*}$ & $+\infty$ & $+\infty$ & \\
\hline & $\Delta p_{0} \geq \Delta^{*} p_{\max }$ & & & $+\infty$ \\
\hline & $\Delta^{*} p_{0}<\Delta p_{0}<\Delta^{* *} p_{0}$ & & & $+\infty$ (Min) \\
\hline & $\Delta p_{0}=\Delta^{*} p_{\min }$ & & & $-\infty$ \\
\hline \multirow{3}{*}{$\begin{array}{l}\alpha=0<r_{E}, \beta^{\prime}>\beta=0\left(\Delta^{*} p_{0}=\Delta^{*} p_{\min }=\Delta^{*} p_{\max }=\right. \\
\left.\Delta^{* *} p_{0}<0\right)\end{array}$} & $p_{0}>p_{S 0}^{*}$ & $+\infty$ & $p_{E 0}$ & \\
\hline & $\Delta p_{0}>\Delta^{*} p_{\max }=\Delta^{*} p_{0}$ & & & $+\infty$ \\
\hline & $\Delta p_{0}=\Delta^{*} p_{\min }=\Delta^{*} p_{0}$ & & & $\Delta p_{0}$ \\
\hline \multirow{3}{*}{$\begin{array}{l}0<\alpha<r_{E}, \beta^{\prime}>0>\beta\left(\Delta^{* *} p_{0}=\Delta^{*} p_{\min }<\Delta^{*} p_{\max }=\right. \\
\left.\Delta^{*} p_{0}<0\right)\end{array}$} & $p_{0}>p_{S 0}^{*}$ & $+\infty$ & 0 & \\
\hline & $\Delta p_{0}>\Delta^{*} p_{\max }=\Delta^{*} p_{0}$ & & & $+\infty$ \\
\hline & $\Delta p_{0}=\Delta^{*} p_{\min }=\Delta^{*} p_{0}$ & & & 0 \\
\hline \multirow{2}{*}{$\begin{array}{l}0<\alpha=r_{E}, \beta^{\prime}=0>\beta\left(p_{S 0}^{* *} \text { undefined, }\right. \\
\left.\Delta^{* *} p_{0}=-\infty<\Delta^{*} p_{0}=\Delta^{*} p_{\max }<0\right)\end{array}$} & $p_{0}>p_{S 0}^{*}$ & $p_{S 0}$ & 0 & \\
\hline & $\Delta p_{0} \geq \Delta^{*} p_{\max }=\Delta^{*} p_{0}$ & & & $p_{S 0}=\Delta p_{0}-\Delta^{*} p_{0}$ \\
\hline \multirow{4}{*}{$\begin{array}{l}\alpha>r_{E}, \beta<\beta^{\prime}<0\left(\Delta^{*} p_{\max }=\Delta^{* *} p_{0}>0>\Delta^{*} p_{0}=\right. \\
\left.\Delta^{*} p_{\min }\right)\end{array}$} & $p_{0}>p_{S 0}^{*}$ & 0 & 0 & \\
\hline & $\Delta p_{0} \geq \Delta^{*} p_{\max }$ & & & 0 \\
\hline & $\Delta^{*} p_{0}<\Delta p_{0}<\Delta^{* *} p_{0}$ & & & 0 (Max) \\
\hline & $\Delta p_{0}=\Delta^{*} p_{\min }$ & & & 0 \\
\hline
\end{tabular}

TABLE 2: Price trends to $t \rightarrow \infty$ of selling resources, $p_{S}$, extracted resources, $p_{E}$, and difference $\Delta p=\left(p_{S}-p_{E}\right)$ in a conservative policy of extraction, $\alpha<r_{N}, \beta>0$.

\begin{tabular}{|c|c|c|c|c|}
\hline $\begin{array}{l}\text { Extraction rate: } \alpha \leq 0<r_{N}, \beta>0, \beta^{\prime}=r_{E}-\alpha, \\
\beta=r_{N}-\alpha\end{array}$ & Initial condition $p_{S 0}$ or $\Delta p_{0}$ & $\begin{array}{l}\text { Selling } \\
\text { resources, } p_{S} \\
(\infty)\end{array}$ & $\begin{array}{l}\text { Extracted } \\
\text { resources, } p_{E} \\
(\infty)\end{array}$ & $\begin{array}{c}\text { Price } \\
\text { difference } \Delta p \\
(\infty) \\
\end{array}$ \\
\hline \multirow{3}{*}{$r_{N}<r_{E}, \beta^{\prime}>\beta,\left(p_{S 0}^{*}=p_{S \text { max }}^{*}>p_{S \text { min }}^{*}=p_{S 0}^{* *}>0\right)$} & $p_{S 0} \geq p_{S \max }^{*}$ & $+\infty$ & $+\infty$ & \\
\hline & $p_{S 0}^{*}>p_{S 0}>p_{S 0}^{* *}$ & $-\infty(\operatorname{Max})$ & $+\infty$ & \\
\hline & $0<p_{S 0} \leq p_{S \text { min }}^{*}$ & $-\infty$ & $+\infty$ & \\
\hline \multirow{3}{*}{$\begin{array}{l}2 r_{N}<r_{E}, \beta^{\prime}>\beta \\
\left(\Delta^{*} p_{0}=\Delta^{*} p_{\min }<\Delta^{*} p_{\max }=\Delta^{* *} p_{0}<0\right)\end{array}$} & $\Delta p_{0} \geq \Delta^{*} p_{\max }$ & & $+\infty$ & $+\infty$ \\
\hline & $\Delta^{* *} p_{0}>\Delta p_{0}>\Delta^{*} p_{0}$ & & $+\infty$ & $+\infty$ (Min) \\
\hline & $\Delta p_{0} \leq \Delta^{*} p_{\min }$ & & $+\infty$ & $-\infty$ \\
\hline \multirow{3}{*}{$\begin{array}{l}2 r_{N}=r_{E}, \beta^{\prime}>\beta \\
\left(\Delta^{*} p_{0}=\Delta^{*} p_{\min }=\Delta^{*} p_{\max }=\Delta^{* *} p_{0}=0\right)\end{array}$} & $\Delta p_{0}>\Delta^{*} p_{\max }$ & & $+\infty$ & $+\infty$ \\
\hline & $\Delta p_{0}=\Delta^{*} p_{\min }$ & & $+\infty$ & $\Delta^{*} p_{0}$ \\
\hline & $\Delta p_{0}<\Delta^{*} p_{\min }$ & & $+\infty$ & $-\infty$ \\
\hline \multirow{3}{*}{$\begin{array}{l}r_{N}<r_{E}, 2 r_{N}>r_{E}, \beta^{\prime}>\beta \\
\left(\Delta^{*} p_{0}=\Delta^{*} p_{\max }>\Delta^{*} p_{\min }=\Delta^{* *} p_{0}>0\right)\end{array}$} & $\Delta p_{0} \geq \Delta^{*} p_{\max }$ & & $+\infty$ & $-\infty$ \\
\hline & $\Delta^{*} p_{0}>\Delta p_{0}>\Delta^{*} p_{0}$ & & $+\infty$ & $-\infty(\operatorname{Max})$ \\
\hline & $\Delta p_{0} \leq \Delta^{*} p_{\min }$ & & $+\infty$ & $-\infty$ \\
\hline \multirow{4}{*}{$r_{N}=r_{E}>\alpha, \beta^{\prime}=\beta,\left(p_{S 0}^{* *}>0\right)$} & $p_{S 0}>p_{S 0}^{* *}$ & $-\infty$ (Max) & $+\infty$ & \\
\hline & $0<p_{S 0} \leq p_{S 0}^{* *}$ & $-\infty$ & $+\infty$ & \\
\hline & $\Delta p_{0}>p_{S 0}^{* *}$ & & $+\infty$ & $-\infty(\operatorname{Max})$ \\
\hline & $\Delta p_{0} \leq p_{S 0}^{* *}$ & & $+\infty$ & $-\infty$ \\
\hline \multirow{3}{*}{$\begin{array}{l}r_{N}>r_{E}>\alpha, \beta^{\prime}<\beta,\left(p_{S \max }^{*}=p_{S 0}^{* *}>0>p_{S 0}^{*}=p_{S \min }^{*}\right) \\
\left(0>\Delta^{*} p_{\max }=\Delta^{*} p_{0}>\Delta^{* *} p_{0}=\Delta^{*} p_{\min }\right)\end{array}$} & $p_{S 0} \geq p_{S 0}^{* *}$ & $-\infty(\operatorname{Max})$ & $+\infty$ & \\
\hline & $0<p_{S 0}<p_{S 0}^{* *}$ & $-\infty$ & $+\infty$ & \\
\hline & Every $\Delta p_{0}$ & & $+\infty$ & $-\infty$ \\
\hline $\begin{array}{l}r_{E}=\alpha<r_{N}, \beta^{\prime}=0, \\
\left(p_{S 0}^{*}=p_{S \min }^{*}<0<p_{S 0}^{* *}=p_{S \max }^{*}=\infty\right) \\
\left(\Delta^{*} p_{0}=\Delta^{*} p_{\min }<0<\Delta^{* *} p_{0}=\Delta^{*} p_{\max }=\infty\right)\end{array}$ & $\begin{array}{l}p_{S 0}>0 \\
\text { Every } \Delta p_{0}\end{array}$ & $-\infty$ & $+\infty$ & $-\infty$ \\
\hline
\end{tabular}




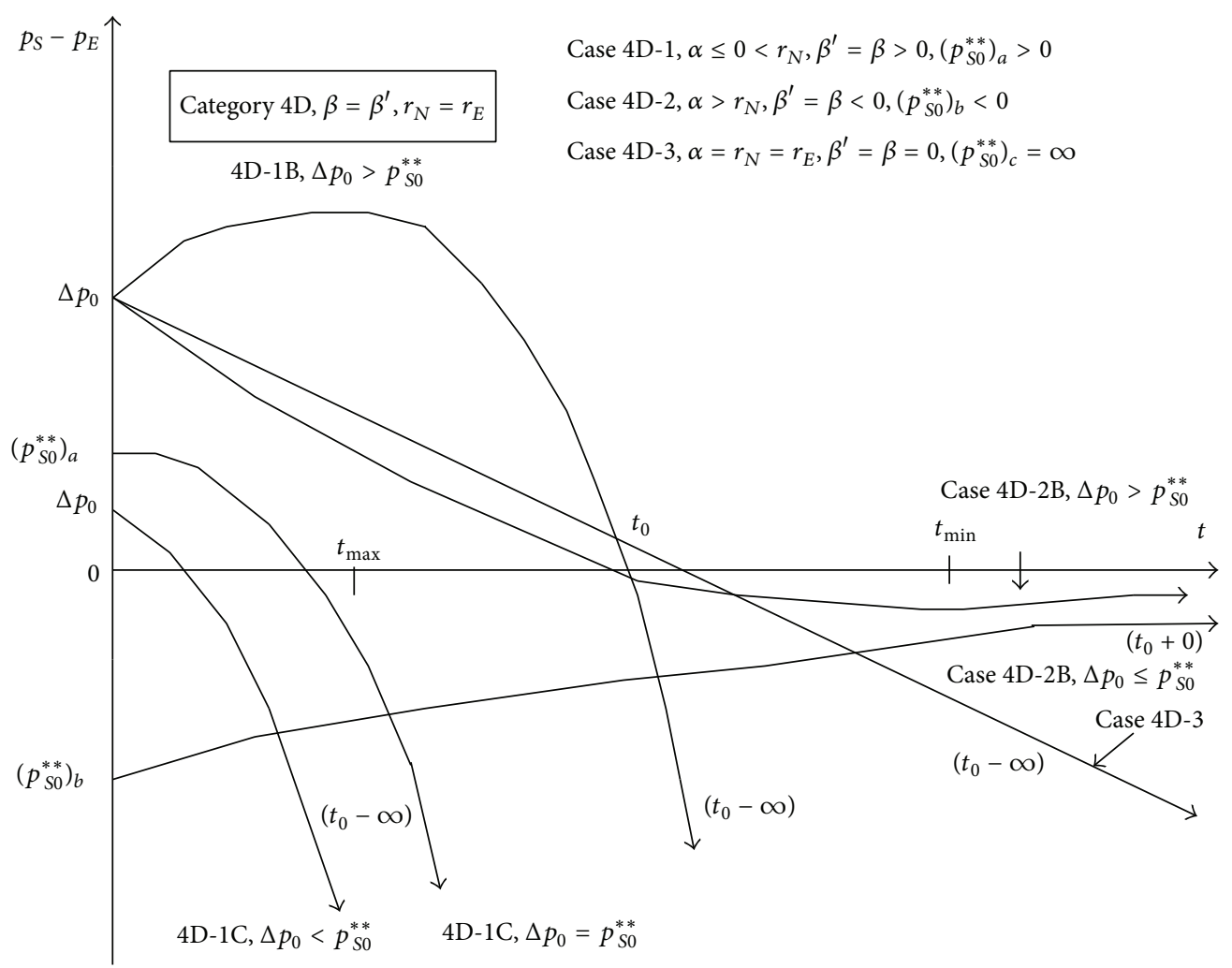

FIGURE 16: Price difference evolution for Category 4D.

TABLE 3: Price trends to $t \rightarrow \infty$ of selling resources, $p_{S}$, extracted resources, $p_{E}$, and difference $\Delta p=\left(p_{S}-p_{E}\right)$ for a rate of extraction $0<\alpha=r_{N},\left(\beta=0, p_{S 0}^{*}=p_{S 0}^{* *}\right.$, and $\left.\Delta^{*} p_{0}=\Delta^{* *} p_{0}\right)$.

\begin{tabular}{|c|c|c|c|c|}
\hline $\begin{array}{l}\text { Extraction rate: } \\
\alpha=r_{N}, \beta=0 \\
\beta^{\prime}=r_{E}-\alpha, \beta=r_{N}-\alpha \\
\end{array}$ & Initial condition $p_{S 0}$ or $\Delta p_{0}$ & $\begin{array}{l}\text { Selling } \\
\text { resources, } p_{S} \\
(\infty)\end{array}$ & $\begin{array}{l}\text { Extracted } \\
\text { resources, } p_{E} \\
(\infty)\end{array}$ & $\begin{array}{c}\text { Price } \\
\text { difference } \Delta t \\
(\infty) \\
\end{array}$ \\
\hline \multirow{6}{*}{$\begin{array}{l}r_{N}<r_{E}, \beta^{\prime}>\beta,\left(p_{S \min }^{*}=p_{S 0}^{*}=p_{S \max }^{*}=p_{S 0}^{* *}>0\right) \\
\left(\Delta^{*} p_{\min }=\Delta^{*} p_{0}=\Delta^{* *} p_{0}=\Delta^{*} p_{\max }>\text { or }=\text { or }<0\right)\end{array}$} & $p_{S 0}>p_{S \max }^{*}$ & $+\infty$ & $p_{E 0}$ & \\
\hline & $p_{S 0}=p_{S \text { min }}^{*}$ & $p_{S 0}^{*}$ & $p_{E 0}$ & \\
\hline & $0<p_{S 0}<p_{S \text { min }}^{*}$ & $-\infty$ & $p_{E 0}$ & \\
\hline & $\Delta p_{0}>\Delta^{*} p_{\max }$ & & $p_{E 0}$ & $+\infty$ \\
\hline & $\Delta p_{0}=\Delta^{*} p_{\min }$ & & $p_{E 0}$ & $\Delta^{*} p_{0}$ \\
\hline & $\Delta p_{0}<\Delta^{*} p_{\min }$ & & $p_{E 0}$ & $-\infty$ \\
\hline \multirow{2}{*}{$\alpha=r_{N}=r_{E}, \beta^{\prime}=\beta,\left(p_{S 0}^{* *}=\infty\right)$} & Every $p_{S 0}>0$ & $-\infty(\operatorname{Lin})$ & $p_{E 0}$ & \\
\hline & Every $\Delta p_{0}$ & & $p_{E 0}$ & $-\infty(\operatorname{Lin})$ \\
\hline \multirow{2}{*}{$\begin{array}{l}r_{N}>r_{E}, \beta^{\prime}<\beta,\left(p_{S \min }^{*}=p_{S 0}^{*}=p_{S 0}^{* *}=p_{S \max }^{*}<0\right) \\
\left(\Delta^{*} p_{\min }=\Delta^{*} p_{0}=\Delta^{* *} p_{0}=\Delta^{*} p_{\max }<0\right)\end{array}$} & $p_{S 0}>0$ & $p_{S 0}^{*}$ & $p_{E 0}$ & \\
\hline & Every $\Delta p_{0}$ & & $p_{E 0}$ & $\Delta^{*} p_{0}$ \\
\hline
\end{tabular}

Table 3 presents the price trends of $p_{S}, p_{E}$, and $\Delta p$, for $\alpha=r_{N}$, that is, $\beta=0$, with the following conclusions:

(i) the price $p_{E}$ is constant at $p_{E 0}$, because $\beta=0$;

(ii) the price $p_{S}$ increases towards $+\infty$, for $r_{N}<r_{E}$, and $p_{S 0}>p_{S 0}^{*}=p_{S \max }^{*}=p_{S 0}^{* *}=p_{S \min }^{*}$

(iii) the price $p_{S}$ is constant at $p_{S 0}^{*}$ for $r_{N}<r_{E}$ and $p_{S 0}=$ $p_{S 0}^{*}=p_{S \min }^{*}$ or for $r_{N}>r_{E}$ and every $p_{S 0}>0$; (iv) the price $p_{S}$ decreases towards $-\infty$ for $r_{N}<r_{E}$ and $0<p_{S 0}<p_{S 0}^{*}=p_{S \max }^{*}$ or decreases linearly towards $-\infty$ for $r_{N}=r_{E}$ and every $p_{S 0}>0$;

(v) the price difference $\Delta p$ increases towards $+\infty$ for $r_{N}<$ $r_{E}$, and $\Delta p_{0}>\Delta^{*} p_{0}=\Delta^{*} p_{\max } ;$

(vi) the price difference $\Delta p$ is constant at $\Delta^{*} p_{0}$, for $r_{N}<$ $r_{E}$, and $\Delta p_{0}=\Delta^{*} p_{0}$ or for $r_{N}>r_{E}$ and every $\Delta p_{0}$; 
TABLE 4: Price trends to $t \rightarrow \infty$ of selling resources, $p_{S}$, extracted resources, $p_{E}$, and difference $\Delta p=\left(p_{S}-p_{E}\right)$ for a rate of extraction $\alpha>r_{N}>0, \beta<0$.

\begin{tabular}{|c|c|c|c|c|}
\hline $\begin{array}{l}\text { Extraction rate: } \\
\alpha>r_{N}>0, \beta<0 \\
\beta^{\prime}=r_{E}-\alpha, \beta=r_{N}-\alpha\end{array}$ & $\begin{array}{l}\text { Initial condition } \\
p_{S 0} \text { or } \Delta p_{0}\end{array}$ & $\begin{array}{l}\text { Selling resources, } \\
\qquad p_{S}(\infty)\end{array}$ & $\begin{array}{l}\text { Extracted } \\
\text { resources, } p_{E} \\
(\infty) \\
+0 \\
\end{array}$ & $\begin{array}{l}\text { Price } \\
\text { difference } \\
\Delta p(\infty)\end{array}$ \\
\hline$r_{E}>\alpha>r_{N}, \beta^{\prime}>0>\beta,\left(p_{S 0}^{* *}=p_{S \max }^{*}>p_{S \min }^{*}=p_{S 0}^{*}>0\right)$ & $\begin{array}{l}p_{S 0} \geq p_{S \max }^{*} \\
p_{S 0}^{* *}>p_{S 0}>p_{S 0}^{*} \\
p_{S 0}=p_{S \text { min }}^{*} \\
0<p_{S 0}<p_{S \text { min }}^{*}\end{array}$ & $\begin{array}{c}+\infty \\
+\infty \text { (Min) } \\
0 \\
-\infty \\
\end{array}$ & & \\
\hline $\begin{array}{l}r_{E}>\alpha>r_{N}, r_{E}>2 r_{N}, \beta^{\prime}>0>\beta \\
\left(0>\Delta^{*} p_{0}=\Delta^{*} p_{\max }>\Delta^{*} p_{\min }=\Delta^{* *} p_{0}\right)\end{array}$ & $\begin{array}{l}\Delta p_{0}>\Delta^{*} p_{\max } \\
\Delta p_{0}=\Delta^{*} p_{\max } \\
\Delta^{* *} p_{0}<\Delta p_{0}<\Delta^{*} p_{0} \\
\Delta p_{0} \leq \Delta^{*} p_{\min }\end{array}$ & & & $\begin{array}{c}+\infty \\
0 \\
-\infty(\operatorname{Max}) \\
-\infty \\
\end{array}$ \\
\hline $\begin{array}{l}r_{E}>\alpha>r_{N}, r_{E}=2 r_{N}, \beta^{\prime}>0>\beta \\
\left(\Delta^{*} p_{0}=\Delta^{*} p_{\min }=\Delta^{*} p_{\max }=\Delta^{* *} p_{0}=0\right)\end{array}$ & $\begin{array}{l}\Delta p_{0}>\Delta^{*} p_{\max } \\
\Delta p_{0}=\Delta^{*} p_{\min } \\
\Delta p_{0}<\Delta^{*} p_{\min }\end{array}$ & & & $\begin{array}{l}+\infty \\
\Delta^{*} p_{0} \\
-\infty\end{array}$ \\
\hline $\begin{array}{l}r_{E}>\alpha>r_{N}, 2 r_{N}>r_{E}, \beta^{\prime}>0>\beta \\
\left(0<\Delta^{*} p_{0}=\Delta^{*} p_{\min }<\Delta^{*} p_{\max }=\Delta^{* *} p_{0}\right)\end{array}$ & $\begin{array}{l}\Delta p_{0} \geq \Delta^{*} p_{\max } \\
\Delta^{* *} p_{0}>\Delta p_{0}>\Delta^{*} p_{0} \\
\Delta p_{0}=\Delta^{*} p_{\min } \\
\Delta p_{0}<\Delta^{*} p_{\min }\end{array}$ & & & $\begin{array}{c}+\infty \\
+\infty(\text { Min }) \\
0 \\
-\infty \\
\end{array}$ \\
\hline $\begin{array}{l}\alpha=r_{E}>r_{N}>0, \beta^{\prime}=0>\beta \\
\left(p_{S \max }^{*}=p_{S 0}^{* *}=\infty>p_{S 0}^{*}=p_{S \min }^{*}>0\right) \\
\left(\Delta^{*} p_{\min }=\Delta^{*} p_{0}>\text { or }=\text { or }<0, \Delta^{*} p_{\max }=\Delta^{* *} p_{0}=\infty\right)\end{array}$ & $\begin{array}{l}p_{S 0}^{* *}>p_{S 0}>p_{S 0}^{*} \\
p_{S 0}=p_{S 0}^{*} \\
0<p_{S 0}<p_{S 0}^{*} \\
\Delta^{* *} p_{0}>\Delta p_{0}>\Delta^{*} p_{0} \\
\Delta p_{0}=\Delta^{*} p_{0} \\
\Delta p_{0}<\Delta^{*} p_{0}\end{array}$ & $\begin{array}{c}\left(p_{S 0}-p_{S 0}^{*}\right) \\
\left(p_{S 0}-p_{S 0}^{*}\right)=0 \\
\left(p_{S 0}-p_{S 0}^{*}\right)\end{array}$ & & $\begin{array}{c}\Delta p_{0}-\Delta^{*} p_{0} \\
\Delta p_{0}-\Delta^{*} p_{0}=0 \\
\Delta p_{0}-\Delta^{*} p_{0} \\
\end{array}$ \\
\hline$\alpha>r_{N}=r_{E}, \beta^{\prime}=\beta<0,\left(p_{S 0}^{* *}<0\right)$ & $\begin{array}{l}\text { Every } p_{S 0} \\
\text { Every } \Delta p_{0}\end{array}$ & 0 (Min) & & 0 \\
\hline$\alpha>r_{E}>r_{N}, \beta<\beta^{\prime}<0\left(p_{S 0}^{*}=p_{S \max }^{*}>0>p_{S 0}^{* *}=p_{S \min }^{*}\right)$ & $p_{S 0}>p_{S \max }^{*}$ & 0 (Min) & & \\
\hline $\begin{array}{l}\alpha>r_{E}>2 r_{N}, \beta<\beta^{\prime}<0 \\
\left(\Delta^{*} p_{0}=\Delta^{*} p_{\min }<0<\Delta^{*} p_{\max }=\Delta^{* *} p_{0}\right)\end{array}$ & $\begin{array}{l}\Delta p_{0} \geq \Delta^{*} p_{\max } \\
\Delta^{* *} p_{0}>\Delta p_{0}>\Delta^{*} p_{0} \\
\Delta p_{0} \leq \Delta^{*} p_{\min }\end{array}$ & & & $\begin{array}{c}0 \\
0(\operatorname{Max}) \\
0\end{array}$ \\
\hline $\begin{array}{l}\alpha>r_{E}>r_{N}, r_{E}=2 r_{N}, \beta^{\prime}=\beta, \\
\left(\Delta^{* *} p_{0}=\Delta^{*} p_{\min }=\Delta^{*} p_{0}=\Delta^{*} p_{\max }=0\right)\end{array}$ & $\begin{array}{l}\Delta p_{0}>\Delta^{*} p_{\min } \\
\Delta p_{0}=\Delta^{*} p_{\min } \\
\Delta p_{0}<\Delta^{*} p_{\min }\end{array}$ & & & $\begin{array}{c}0 \\
\Delta p_{0} \\
0\end{array}$ \\
\hline $\begin{array}{l}\alpha>r_{E}>r_{N}, 2 r_{N}>r_{E}, 0>\beta^{\prime}>\beta, \\
\left(\Delta^{*} p_{0}=\Delta^{*} p_{\max }>0>\Delta^{*} p_{\min }=\Delta^{* *} p_{0}\right)\end{array}$ & Every $\Delta p_{0}$ & & & 0 \\
\hline $\begin{array}{l}\alpha>r_{N}>r_{E}>0, \beta^{\prime}<\beta<0, \\
\left(p_{S 0}^{*}=p_{S \min }^{*}<p_{S 0}^{* *}=p_{S \max }^{*}<0\right) \\
\left(\Delta^{*} p_{0}=\Delta^{*} p_{\min }<\Delta^{* *} p_{0}=\Delta^{*} p_{\max }<0\right)\end{array}$ & $\begin{array}{l}p_{S 0}>0 \\
\text { Every } \Delta p_{0}\end{array}$ & 0 (Min) & & 0 (Min) \\
\hline
\end{tabular}

(vii) the price difference $\Delta p$ decreases towards $-\infty$, for $r_{N}<r_{E}$, and $\Delta p_{0}<\Delta^{*} p_{0}$ or linearly to $-\infty$ for $\alpha=r_{N}=r_{E}$ and every $\Delta p_{0}$.

Table 4 presents the price trends of $p_{S}, p_{E}$, and $\Delta p$ for $\alpha>$ $r_{N}>0$, that is, $\beta<0$, with the following conclusions:

(i) the price $p_{E}$ decreases towards +0 , because $\beta<0$;

(ii) the price $p_{S}$ increases towards $+\infty$ for $r_{E}>\alpha>r_{N}$ (i.e., $\beta^{\prime}>0>\beta$ ) and $p_{S 0}>p_{S 0}^{* *}=p_{S \max }^{*}$ or after a minimum for $p_{S 0}^{* *}>p_{S 0}>p_{S 0}^{*}$; (iii) the price $p_{S}$ tends to $\left(p_{S 0}-p_{S 0}^{*}\right)$ for $r_{E}=\alpha>r_{N}$;

(iv) the price $p_{S}$ decreases towards $-\infty$ for $r_{E}>\alpha>r_{N}$ and $p_{S 0}<p_{S 0}^{*}=p_{S \min }^{*}$;

(v) the price $p_{S}$ decreases towards 0 without or with a minimum, in the other two cases;

(vi) the price difference $\Delta p$ increases towards $+\infty$ for $r_{E}>$ $\alpha>r_{N}$ and $\Delta p_{0}>\Delta^{*} p_{\max }$, if $r_{E}>2 r_{N}$, if $r_{E}=2 r_{N}$, if $r_{E}<2 r_{N}$ and $\Delta p_{0}=\Delta^{*} p_{\max }$. If $r_{E}<2 r_{N}$ a minimum is present if $\Delta^{* *} p_{0}>\Delta p_{0}>\Delta^{*} p_{0}$; 
TABLE 5: Final conclusions of the price trends at $t \rightarrow \infty$ of selling resources, $p_{S}$, for $r_{N}=0, p_{S 0}^{*}=p_{S 0}^{* *}=0$.

\begin{tabular}{|c|c|c|c|c|}
\hline & $\begin{array}{l}\text { Relation } \\
\text { between } \\
\beta^{\prime} \text { and } \beta\end{array}$ & & $\beta$ & $p_{S 0}>p_{S 0}^{*}=p_{S 0}^{* *}=0$ \\
\hline \multirow{5}{*}{ A } & \multirow{5}{*}{$\beta^{\prime}>\beta$} & A.1 & $\beta^{\prime}>\beta>0$ & $+\infty$ \\
\hline & & A. 2 & $\beta^{\prime}>\beta=0$ & $+\infty$ \\
\hline & & A. 3 & $\beta^{\prime}>0>\beta$ & $+\infty$ \\
\hline & & A. 4 & $\beta^{\prime}=0>\beta$ & $p_{S 0}$ \\
\hline & & A. 5 & $0>\beta^{\prime}>\beta$ & +0 \\
\hline
\end{tabular}

(vii) the price difference $\Delta p$ tends to $\left(\Delta p_{0}-\Delta^{*} p_{0}\right)$ if $r_{E}=$ $\alpha>r_{N}$ for every $\Delta p_{0}$

(viii) the price difference $\Delta p$ decreases towards $-\infty$ for $r_{E}>$ $\alpha>r_{N}$ and $\Delta p_{0}<\Delta^{*} p_{\min }$, or $\Delta p_{0}=\Delta^{*} p_{\min }$ for $r_{E}>$ $2 r_{N}$ while $\Delta p$ passes through a maximum if $\Delta^{*} p_{0}>$ $\Delta p_{0}>\Delta^{* *} p_{0}$ and for $r_{E}>2 r_{N} ;$

(ix) the price difference $\Delta p$ remains constant at $\Delta^{*} p_{0}$ for $r_{E}>\alpha>r_{N}, r_{E}=2 r_{N}$ and $\Delta p_{0}=\Delta^{*} p_{0} ;$

(x) the price difference $\Delta p$ tends to 0 in the other three cases.

Table 5 resumes the trends of $p_{S}$ for $r_{N}=0$, that is, $\beta^{\prime}>\beta$, $p_{S 0}^{*}=p_{S 0}^{*}=0$.

The price $p_{S}$ increases towards $+\infty$ if $\beta^{\prime}>0$, remains constant at $p_{S 0}$ if $\beta^{\prime}=0$, and decreases to +0 if $\beta^{\prime}<0$.

Table 6 resumes the trends of $\Delta p$ for $r_{N}=0$, that is, $\beta^{\prime}>\beta$. The trends can be divided according to the initial conditions which are grouped into four categories.

The greater value between $\Delta^{*} p_{0}$ and $\Delta^{* *} p_{0}$ is indicated as $\Delta^{*} p_{\max }$ while the smaller one as $\Delta^{*} p_{\min }$. Consider the following:

(i) for $\Delta p_{0}>\Delta^{*} p_{\max }, \Delta p$ increases to $+\infty$ if $\beta^{\prime}>0, \Delta p$ tends to $p_{S 0}=\Delta p_{0}-\Delta^{*} p_{0}$ if $\beta^{\prime}=0$, and $\Delta p$ tends to +0 if $\beta^{\prime}<0$;

(ii) for $\Delta p_{0}=\Delta^{*} p_{\max }, \Delta p$ increases to $+\infty$ if $\beta^{\prime}>\beta>0$, $\Delta p$ remains constant at $\Delta p_{0}$ if $\beta^{\prime}>\beta=0, \Delta p$ tends to 0 if $\beta^{\prime}>0>\beta$, and $\beta^{\prime}<0, \Delta p$ tends to $p_{S 0}=$ $\Delta p_{0}-\Delta^{*} p_{0}$ if $\beta^{\prime}=0$

(iii) for $\Delta^{*} p_{0}=\Delta^{*} p_{\min }<\Delta p_{0}<\Delta^{*} p_{\max }=\Delta^{* *} p_{0}, \Delta p$ increases to $+\infty$ after a minimum if $\beta^{\prime}>0$, and $\Delta p$ tends to +0 after a maximum if $\beta^{\prime}<0$;

(iv) for $\Delta^{*} p_{0}=\Delta^{*} p_{\min }>\Delta p_{0}, \Delta p$ decreases to $-\infty$ if $\beta^{\prime}>\beta>0, \Delta p$ remains constant at $\Delta p_{0}$ if $\beta^{\prime}>\beta=0$, and $\Delta p$ tends to 0 if $\beta^{\prime}<0$.

Table 7 resumes the trends of $p_{S}$ for $r_{N}$ different from 0 . The trends can be divided into four classes, A-B-C-D, according to the relation between $\beta^{\prime}$ and $\beta$, and $\beta^{\prime}=0$. In each class the trends are depending on the value of $\beta$ or $\beta^{\prime}$, and the initial value $p_{S 0}$. The greater between $p_{S 0}^{*}$ and $p_{S 0}^{* *}$ is indicated as $p_{S \max }^{*}$ and the smaller one as $p_{S \text { min }}^{*}$.

In class $\mathrm{A}, \beta^{\prime}>\beta$, the trends of $p_{S}$ are to increase towards $+\infty$ for $\beta^{\prime}>\beta>0$ if $p_{S 0} \geq p_{S \max }^{*}=p_{S 0}^{*}$, for $\beta^{\prime}>\beta=0$ if $p_{S 0}>p_{S 0}^{*}=p_{S \max }^{*}$, and for $\beta^{\prime}>0>\beta$ if $p_{S 0} \geq p_{S \max }^{*}$ and if $p_{S 0}^{*}>p_{S 0}>p_{S 0}^{* *}$ after a minimum. A temporary increase, followed by a decrease towards $-\infty$, is present if $p_{S 0}^{*}=p_{S \text { max }}^{*}>p_{S 0}>p_{S \text { min }}^{*}=p_{S 0}^{* *}$ and $\beta>0$. In all the other cases $p_{S}$ tends towards asymptotes equal to $p_{S 0}, 0, p_{S 0}-p_{S 0}^{*}$, or decreases towards $-\infty$.

In class $\mathrm{B},\left(\beta^{\prime}=\beta\right)$, for $\beta>0$ a temporary increase, followed by a decrease towards $-\infty$, is present if $p_{S 0} \geq p_{S 0}^{* *}$. In all the other cases $p_{S}$ tends towards an asymptote, equal to +0 , or decreases towards $-\infty$.

In class $\mathrm{C},\left(\beta^{\prime}<\beta\right)$, for $\beta>0$ a temporary increase, followed by a decrease towards $-\infty$, is present if $p_{S 0} \geq$ $p_{S \max }^{*}=p_{S 0}^{* *}$. In all the other cases $p_{S}$ tends towards asymptotes equal to $p_{S 0}^{*}, 0$, or decreases towards $-\infty$.

In class $\mathrm{D},\left(\beta^{\prime}=0\right), p_{S}$ decreases towards $-\infty$.

Table 8 resumes the trends of $\Delta p$ for $r_{N}$ different from 0 . The trends can be divided into four classes, A-B-C-D, according to the relation between $\beta^{\prime}$ and $\beta$, and $\beta^{\prime}=0$. In each class the trends depend on the value of $\beta$ or $\beta^{\prime}$, and the initial value $\Delta p_{0}$. The greater between $\Delta^{*} p_{0}$ and $\Delta^{* *} p_{0}$ is indicated as $\Delta^{*} p_{\max }$ and the smaller one as $\Delta^{*} p_{\min }$

In class $\mathrm{A},\left(\beta^{\prime}>\beta\right)$, the trends of $\Delta p$ are to increase towards $+\infty$ in the following cases:

(i) for $\beta^{\prime}>0$ and $\Delta p_{0}>\Delta^{*} p_{\max }$;

(ii) for $\beta^{\prime}>\beta>0$ and $\Delta p_{0}=\Delta^{*} p_{\max } \neq 0$;

(iii) for $\beta^{\prime}>0>\beta$ and $\Delta p_{0}=\Delta^{*} p_{\max }>0$;

(iv) for $\beta^{\prime}>\beta>0, \beta^{\prime}>0>\beta$ and $\Delta^{* *} p_{0}>\Delta p_{0}>\Delta^{*} p_{0}$ after a minimum.

A temporary increase, followed by a decrease towards $-\infty$, is present for $\beta^{\prime}>\beta>0$ and $\beta^{\prime}>0>\beta$ if $\Delta^{*} p_{0}=$ $\Delta^{*} p_{\max }>\Delta p_{0}>\Delta^{*} p_{\text {min }}=\Delta^{* *} p_{0}$. In all the other cases $\Delta p$ decreases towards asymptotes equal to $\Delta^{*} p_{0}, 0$, or decreases towards $-\infty$.

In class $\mathrm{B},\left(\beta^{\prime}=\beta\right)$, for $\beta>0$ a temporary increase, followed by a decrease towards $-\infty$, is present if $\Delta p_{0}>p_{S 0}^{* *}$. In all the other cases $\Delta p$ decreases towards the asymptote, equal to 0 , or decreases towards $-\infty$.

In class $\mathrm{C},\left(\beta^{\prime}<\beta\right), \Delta p$ decreases towards asymptotes, equal to $\Delta^{*} p_{0},+0$, or decreases towards $-\infty$.

In class $\mathrm{D},\left(\beta^{\prime}=0\right), \Delta p$ decreases towards the asymptotes, equal to $\left(\Delta p_{0}-\Delta^{*} p_{0}\right)$, or decreases towards $-\infty$.

\section{Energy Supply Curve}

7.1. Supply Curve of Extracted Resources. The mass conservation equations of extracted and sold resources, under the hypothesis of no accumulation nor depletion of the resources, can be written in dimensionless form as

$$
G_{E}^{\prime}=\frac{G_{E}}{G_{E 0}}=G_{S}^{\prime}=\frac{G_{S}}{G_{S 0}}=\exp (\alpha t) .
$$

The price evolution with time of extracted resources is, in dimensionless form,

$$
p_{E}^{\prime}=\frac{p_{E}}{p_{E 0}}=\exp (\beta t)
$$




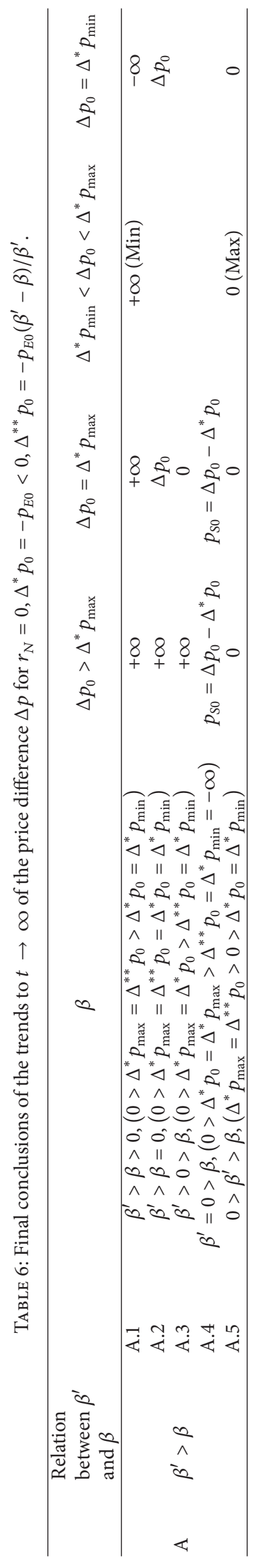




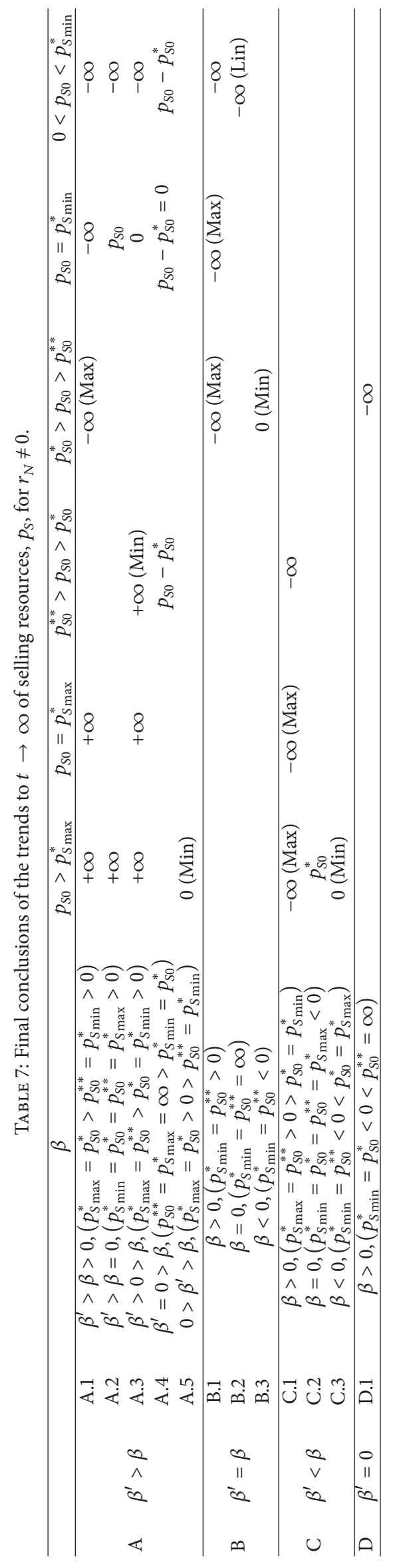




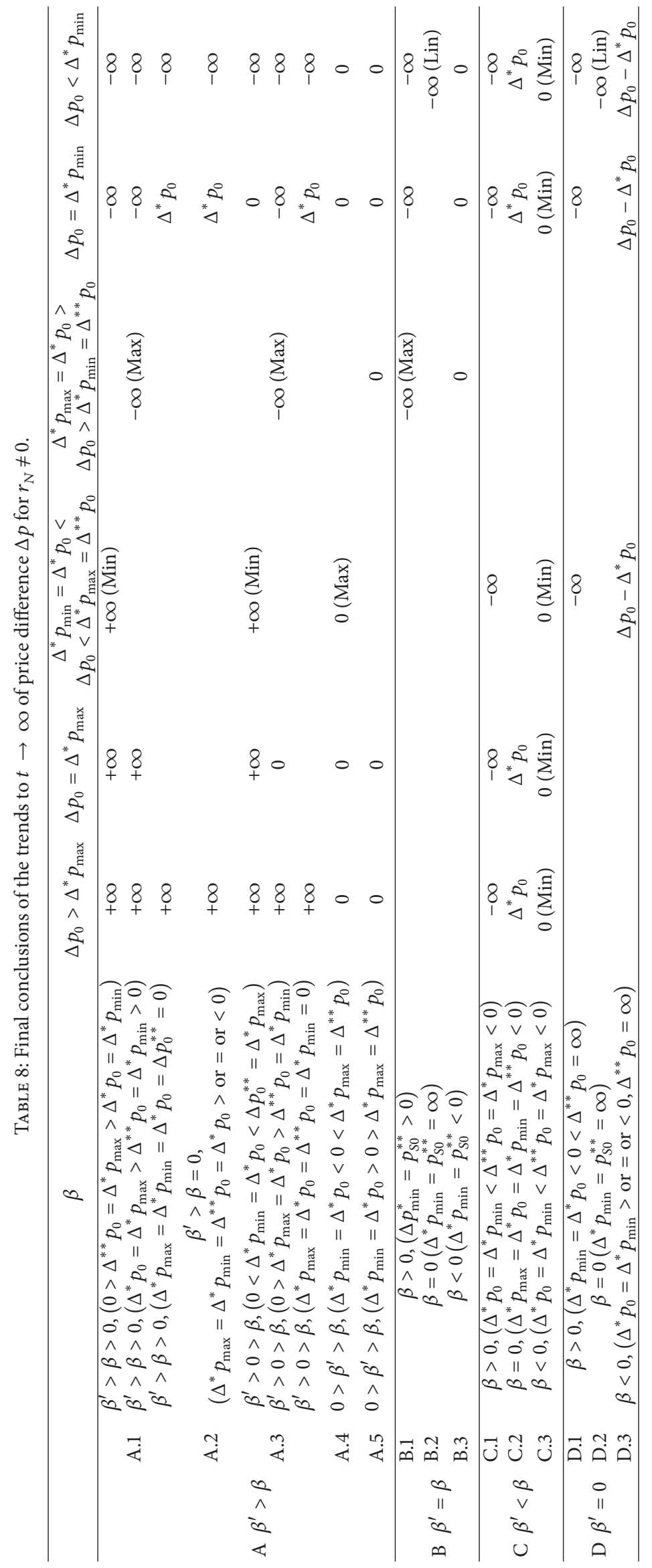


The extraction rate, $\alpha$, can be obtained from (65) on the base of the mass flow rates of extraction in two successive years,

$$
\alpha=\frac{\ln G_{S}^{\prime}}{t} .
$$

The elimination of the time variable, $t$, between (65) and (66), allows obtaining the relation, called supply curve of extracted resources, between the dimensionless price, $p_{E}^{\prime}$, and the dimensionless mass flow rate, $G_{E}^{\prime}$, of extracted resources,

$$
p_{E}^{\prime}=G_{E}^{\prime(\beta / \alpha)}=G_{E}^{\prime(y-1)},
$$

where the new variable, $y$,

$$
y=\frac{r_{N}}{\alpha}
$$

is called rate of interest of nonextracted resources on the extraction rate, RINE.

The variation of $p_{E}^{\prime}$ with $G_{E}^{\prime}$ is presented in Figure 17 where the only variable affecting the evolution is $y$. Consider the following:

(i) for $y=0$ (i.e., $r_{N}=0$ or $\alpha= \pm \infty$ ), (68) is an equilateral hyperbole: $p_{E}^{\prime}$ decreases with the increase of $G_{E}^{\prime}$ or increases with the decrease of $G_{E}^{\prime}$;

(ii) for $0<y<1, p_{E}^{\prime}$ decreases with the increase of $G_{E}^{\prime}$;

(iii) for $y=1$ (i.e., $\alpha=r_{N}$ ), $p_{E}^{\prime}$ is constant with the increase of $G_{E}^{\prime}$;

(iv) for $y>1, p_{E}^{\prime}$ increases with the increase of $G_{E}^{\prime}$;

(v) for $y= \pm \infty$ (or $\alpha=0$ ), (68) is a vertical line: $p_{E}^{\prime}$ increases at constant $G_{E}^{\prime}=1$;

(vi) for $y<0, p_{E}^{\prime}$ increases with the decrease of $G_{E}^{\prime}$.

7.2. Supply Curve of Sold Resources. The price evolution with time of sold resources becomes, in dimensionless form,

$$
p_{S}^{\prime}=\frac{p_{S}}{p_{S 0}}=\exp \left(\beta^{\prime} t\right)-p_{S 0}^{\prime *}\left[\exp \left(\beta^{\prime} t\right)-\exp (\beta t)\right],
$$

where

$$
p_{S 0}^{\prime *}=\frac{p_{S 0}^{*}}{p_{S 0}}=\frac{r_{N} p_{E 0}}{p_{S 0} \cdot\left(\beta^{\prime}-\beta\right)}=\frac{p_{E 0} \cdot y}{p_{S 0}(x-y)}
$$

is the dimensionless critical initial price of sold resources, DCIPS, and the new variable, $x$,

$$
x=\frac{r_{E}}{\alpha},
$$

is the rate of interest of sold resources on the extraction rate, RISE.

For $x \neq y$ (i.e., $\left.r_{N} \neq r_{E}\right)$, (70), combined with (65), becomes

$$
\begin{aligned}
p_{S}^{\prime} & =\frac{p_{S}}{p_{S 0}}=G_{S}^{\prime\left(\beta^{\prime} / \alpha\right)}-p_{S 0}^{\prime *}\left(G_{S}^{\prime\left(\beta^{\prime} / \alpha\right)}-G_{S}^{\prime(\beta / \alpha)}\right) \\
& =G_{S}^{\prime(x-1)}-p_{S 0}^{\prime *}\left(G_{S}^{\prime(x-1)}-G_{S}^{\prime(y-1)}\right) \\
& =G_{S}^{\prime(x-1)}\left(1-p_{S 0}^{\prime *}\right)+p_{S 0}^{\prime *} G_{S}^{\prime(y-1)} .
\end{aligned}
$$

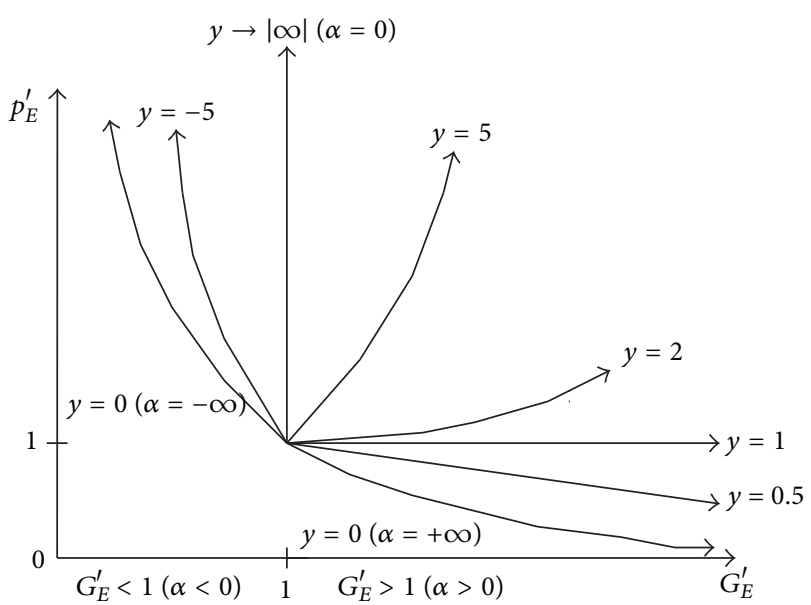

FIGURE 17: Dimensionless price of extracted resources, $p_{E}^{\prime}$, versus $G_{E}^{\prime}$.

An extreme value of $p_{S}^{\prime}$ is present for

$$
G_{S}^{\prime}=\left\{\frac{[y(1-y)]}{[(x-1)(x-2 y)]}\right\}^{1 /(x-y)},
$$

when $p_{E 0}=p_{S 0}$, and

$$
G_{S}^{\prime}=\left\{\frac{\left[p_{S 0}^{\prime *}(1-y)\right]}{\left[(x-1)\left(1-p_{S 0}^{\prime *}\right)\right]}\right\}^{1 /(x-y)},
$$

when $p_{E 0} \neq p_{S 0}$.

The maximum of $p_{S}^{\prime}$ is present at $G_{S}^{\prime}=1$ for $p_{S 0}^{\prime}$

$$
\begin{aligned}
p_{S 0}^{\prime} & =p_{S 0}^{\prime * *}=\frac{p_{S 0}^{* *}}{p_{S 0}}=p_{S 0}^{\prime *} \frac{\left(\beta^{\prime}-\beta\right)}{\beta^{\prime}} \\
& =\frac{r_{N} p_{E 0}}{p_{S 0} \cdot \beta^{\prime}}=\frac{p_{E 0} \cdot y}{p_{S 0}(x-1)},
\end{aligned}
$$

which is the dimensionless critical initial price extreme of sold resources, DCIPES.

7.2.1. Supply Curve of Sold Resources for $r_{N}=0$, That Is, $p_{S 0}^{\prime *}=$ 0 . For $r_{N}=0$, that is, $p_{S 0}^{\prime *}=0,(73)$ becomes

$$
p_{S}^{\prime}=\frac{p_{S}}{p_{S 0}}=\exp \left(\beta^{\prime} t\right)
$$

which, combined with (65), gives

$$
p_{S}^{\prime}=G_{S}^{\prime\left(\beta^{\prime} / \alpha\right)}=G_{S}^{\prime(x-1)} \text {. }
$$

The variation of $p_{S}^{\prime}$ with $G_{S}^{\prime}$ is presented in Figure 18 for $y=0$ (i.e., $r_{N}=0$ ).

The only variable affecting the evolution is $x$. Consider the following:

(i) for $x=0$ (i.e., $r_{E}=0$ or $\alpha= \pm \infty$ ), (78) is an equilateral hyperbole: $p_{S}^{\prime}$ decreases with the increase of $G_{S}^{\prime}$ or increases with the decrease of $G_{S}^{\prime}$;

(ii) for $0<x<1, p_{S}^{\prime}$ decreases with the increase of $G_{S}^{\prime}$; 


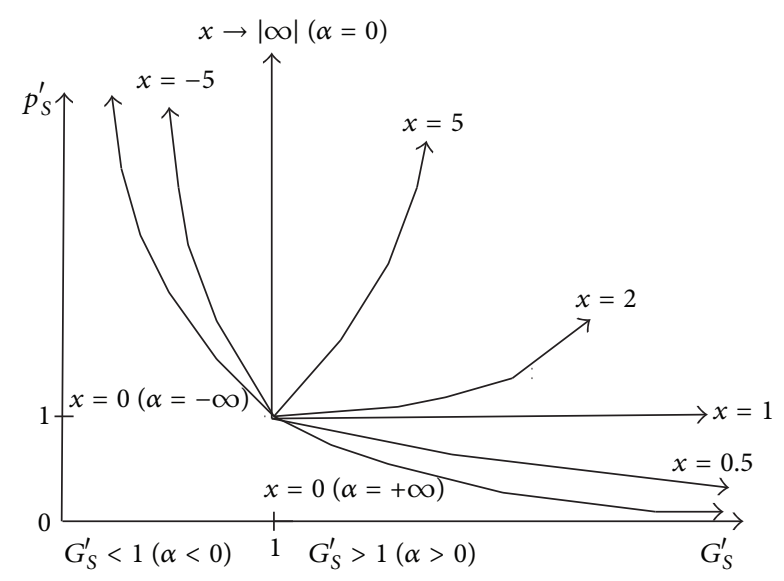

FIGURE 18: Dimensionless price of selling resources, $p_{S}^{\prime}$, versus $G_{S}^{\prime}$, for $r_{N}=0$.

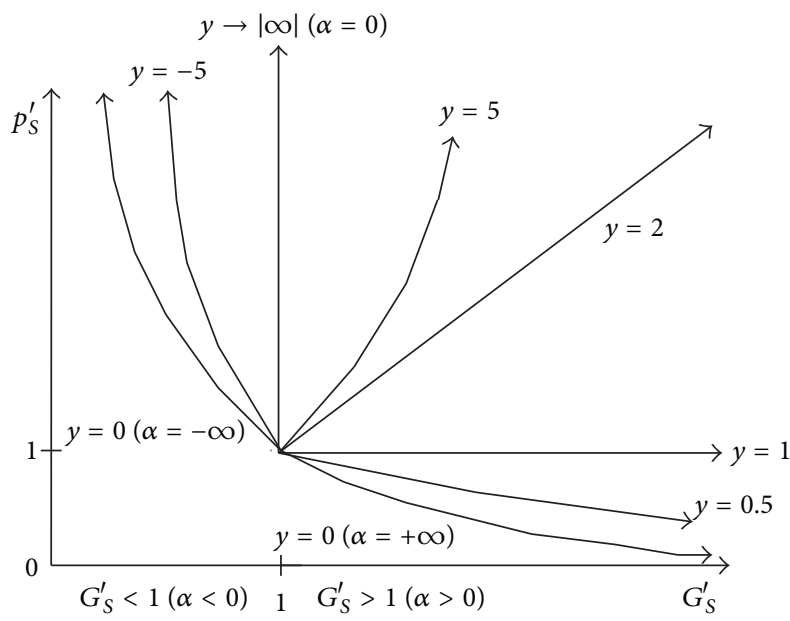

FIGURE 19: Dimensionless price of selling resources, $p_{S}^{\prime}$ versus $G_{S}^{\prime}$, for $p_{S 0}^{\prime *}=1$, (i.e., $x=2 y$ if $p_{S 0}=p_{E 0}=1$ ).

(iii) for $x=1$ (i.e., $\alpha=r_{E}$ ), $p_{S}^{\prime}$ is constant with the increase of $G_{S}^{\prime}$;

(iv) for $x>1, p_{S}^{\prime}$ increases with the increase of $G_{S}^{\prime}$;

(v) for $x= \pm \infty$ (or $\alpha=0$ ), (78) is a vertical line: $p_{S}^{\prime}$ increases at constant $G_{S}^{\prime}=1$;

(vi) for $x<0$, $p_{S}^{\prime}$ increases with the decrease of $G_{S}^{\prime}$.

7.2.2. Supply Curve of Selling Resources for $p_{S 0}^{\prime *}=1$. For $p_{S 0}^{\prime *}=$ $1,(73)$ reduces to

$$
p_{S}^{\prime}=\frac{p_{S}}{p_{S 0}}=G_{S}^{\prime(y-1)}
$$

and the variation of $p_{S}^{\prime}$ is only dependent on $y$, RINE.

The variation of $p_{S}^{\prime}$ with $G_{S}^{\prime}$ for $p_{S 0}^{\prime *}=1$ (i.e., $x=2 y$ if $\left.p_{E 0}=p_{S 0}=1\right)$ is presented in Figure 19. The only variable involved in the evolution is $y$. Consider the following:

(i) for $y=0$ (i.e., $r_{E}=0$ or $\alpha= \pm \infty$ ), (79) is an equilateral hyperbole: $p_{S}^{\prime}$ decreases with the increase of $G_{S}^{\prime}$ or increases with the decrease of $G_{S}^{\prime}$; (ii) for $0<y<1$, $p_{S}^{\prime}$ decreases with the increase of $G_{S}^{\prime}$;

(iii) for $y=1, p_{S}^{\prime}$ is constant with the increase of $G_{S}^{\prime}$;

(iv) for $y>1, p_{S}^{\prime}$ increases with the increase of $G_{S}^{\prime}$. A special case is $y=2$ when the variation of $p_{S}^{\prime}$ is a linear increase with the increase of $G_{S}^{\prime}$;

(v) for $y= \pm \infty$ (or $\alpha=0)$, (79) is a vertical line: $p_{S}^{\prime}$ increases at constant $G_{S}^{\prime}=1$;

(vi) for $y<0, p_{S}^{\prime}$ increases with the decrease of $G_{S}^{\prime}$.

7.2.3. Supply Curve of Sold Resources for $|x|>|y|>1$. The variation of $p_{S}^{\prime}$ with $G_{S}^{\prime}$ is presented in Figure 20 for $|x|>$ $|y|>1$ (i.e., $r_{E}>r_{N}>\alpha$ ).

The variables involved in the evolution are here two, that is, $p_{S 0}^{\prime *}$ and $p_{S 0}^{\prime * *}$. The main role is played by $p_{S 0}^{\prime *}$ when $p_{S 0}^{\prime *} \leq 1$, but, when $p_{S 0}^{\prime *}>1$, it is determinant the second variable $p_{S 0}^{\prime * *}$. Consider the following:

(i) for $p_{S 0}^{\prime *} \leq 1, p_{S}^{\prime}$ increases with the increase or the decrease of $G_{S}^{\prime}$;

(ii) for $p_{S 0}^{\prime *}>1>p_{S 0}^{\prime * *}, p_{S}^{\prime}$ increases up to a maximum and then decreases with the increase or the decrease of $G_{S}^{\prime}$;

(iii) for $p_{S 0}^{\prime * *}=1, p_{S}^{\prime}$ decreases with the increase or the decrease of $G_{S}^{\prime}$ and the maximum is at $G_{S}^{\prime}=1$;

(iv) for $p_{S 0}^{\prime *}>p_{S 0}^{\prime * *}>1, p_{S}^{\prime}$ decreases with the increase or the decrease of $G_{S}^{\prime}$.

7.2.4. Supply Curve of Sold Resources for $|y|>|x|>1$ or $y>$ $1>x$. The variation of $p_{S}^{\prime}$ with $G_{S}^{\prime}$ is presented in Figure 21 for $|y|>|x|>1$ (i.e., $r_{N}>r_{E}>\alpha$ and $p_{S 0}^{\prime *}<0<p_{S 0}^{\prime * *}$ ).

The only variable influencing the evolution is $p_{S 0}^{\prime * *}$ because $p_{S 0}^{\prime *}<0$. Consider the following:

(i) for $p_{S 0}^{\prime * *}<1, p_{S}^{\prime}$ increases up to a maximum and then decreases with the decrease or the increase of $G_{S}^{\prime}$;

(ii) for $p_{S 0}^{\prime * *}=1, p_{S}^{\prime}$ decreases with the decrease or the increase of $G_{S}^{\prime}$ and the maximum is at $G_{S}^{\prime}=1$;

(iii) for $p_{S 0}^{\prime * *}>1, p_{S}^{\prime}$ decreases with the increase or the decrease of $G_{S}^{\prime}$.

The variation of $p_{S}^{\prime}$ with $G_{S}^{\prime}$ is presented in Figure 21 also for $y>1>x$ (i.e., $r_{N}>\alpha>r_{E}$ and $0>p_{S 0}^{\prime *}>p_{S 0}^{\prime * *}$ ). The price $p_{S}^{\prime}$ decreases with the increase of $G_{S}^{\prime}$.

The conclusion of Figure 21 is that $p_{S}^{\prime}$ cannot increase indefinitely for $|y|>|x|>1$ or $y>1>x$.

7.2.5. Supply Curve of Sold Resources for $y=1$ or $x=1$. The variation of $p_{S}^{\prime}$ with $G_{S}^{\prime}$ is presented in Figure 22 for $y=1$ (i.e., $\alpha=r_{N}>0$ and $p_{S 0}^{\prime *}=p_{S 0}^{\prime * *}$ ). 


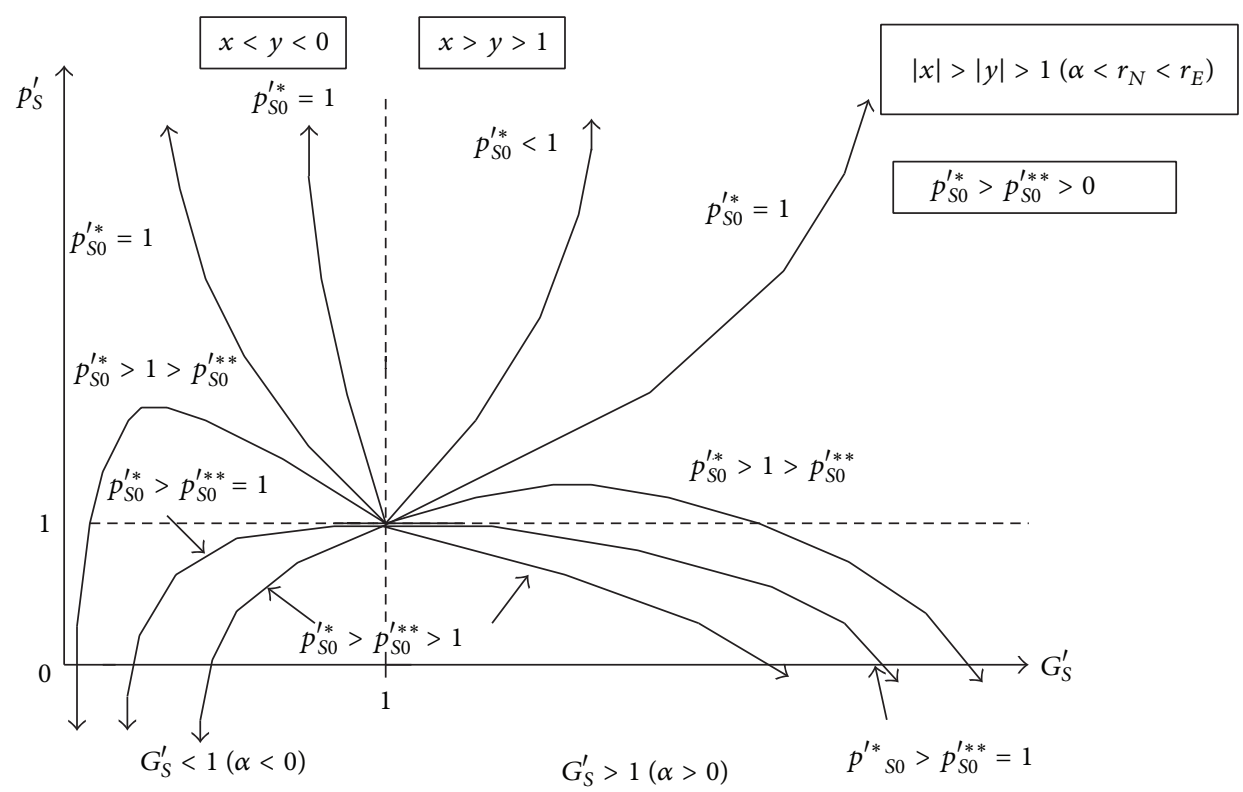

FIGURE 20: Dimensionless price of selling resources, $p_{S}^{\prime}$, versus $G_{S}^{\prime}$, for $|x|>|y|>1$.

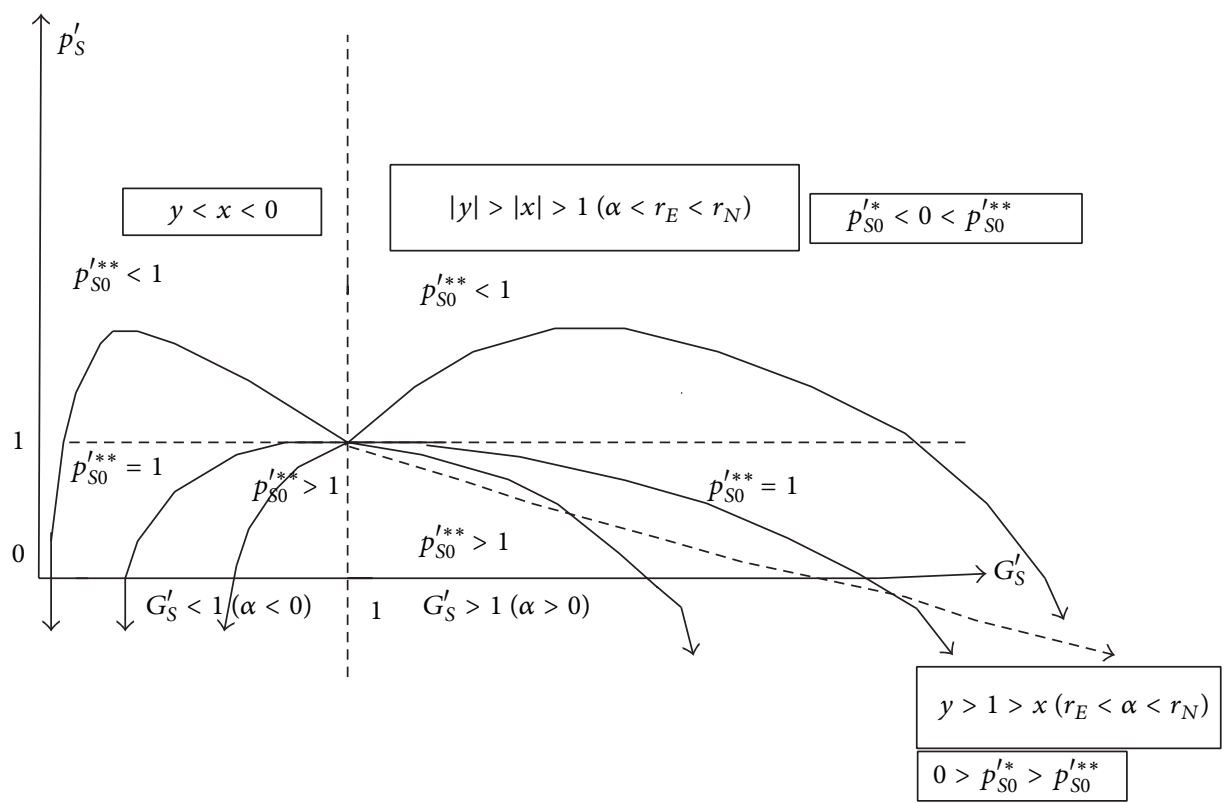

FIGURE 21: Dimensionless price of sold resources, $p_{S}^{\prime}, G_{S}^{\prime}$, for $|y|>|x|>1$ or $y>1>x$.

The main variable influencing the evolution is $p_{S 0}^{\prime * *}=p_{S 0}^{\prime *}$. Consider the following:

(i) for $x>y=1$ (i.e., $\alpha=r_{N}<r_{E}$ and $p_{S 0}^{\prime * *}=p_{S 0}^{\prime *}>$ $0), p_{S}^{\prime}$ increases with the increase of $G_{S}^{\prime}$ if $p_{S 0}^{\prime *}<1$; $p_{S}^{\prime}$ remains constant with $G_{S}^{\prime}$ if $p_{S 0}^{\prime *}=1 ; p_{S}^{\prime}$ decreases with $G_{S}^{\prime}$ if $p_{S 0}^{\prime *}>1$;

(ii) for $x<y=1$ (i.e., $\alpha=r_{N}>r_{E}$ and $p_{S 0}^{\prime * *}=p_{S 0}^{\prime *}<0$ ), $p_{S}^{\prime}$ decreases asymptotically to $p_{S 0}^{\prime *}$ with the increase of $G_{S}^{\prime}$.
The evolution of $p_{S}^{\prime}$ with $G_{S}^{\prime}$ is presented in Figure 22 also for $x=1<y$ (i.e., $r_{N}>r_{E}=\alpha$ and $p_{S 0}^{\prime *}<0, p_{S 0}^{\prime * *}=+\infty$ ). The price $p_{S}^{\prime}$ decreases with the increase of $G_{S}^{\prime}$.

7.2.6. Supply Curve of Sold Resources for $y<1$. The variation of $p_{S}^{\prime}$ with $G_{S}^{\prime}$ is presented in Figure 23 for $y<1$ (i.e., $\alpha>r_{N}$ ).

The main variables influencing the evolution are $p_{S 0}^{\prime *}$ and $p_{S 0}^{\prime * *}$. Consider the following:

(i) for $x>1>y$ (i.e., $r_{E}>\alpha>r_{N}$ and $p_{S 0}^{\prime * *}>p_{S 0}^{\prime *}>0$ ) five cases are possible: $p_{S}^{\prime}$ increases with $G_{S}^{\prime}$ if $p_{S 0}^{\prime * *} \leq 1$; 


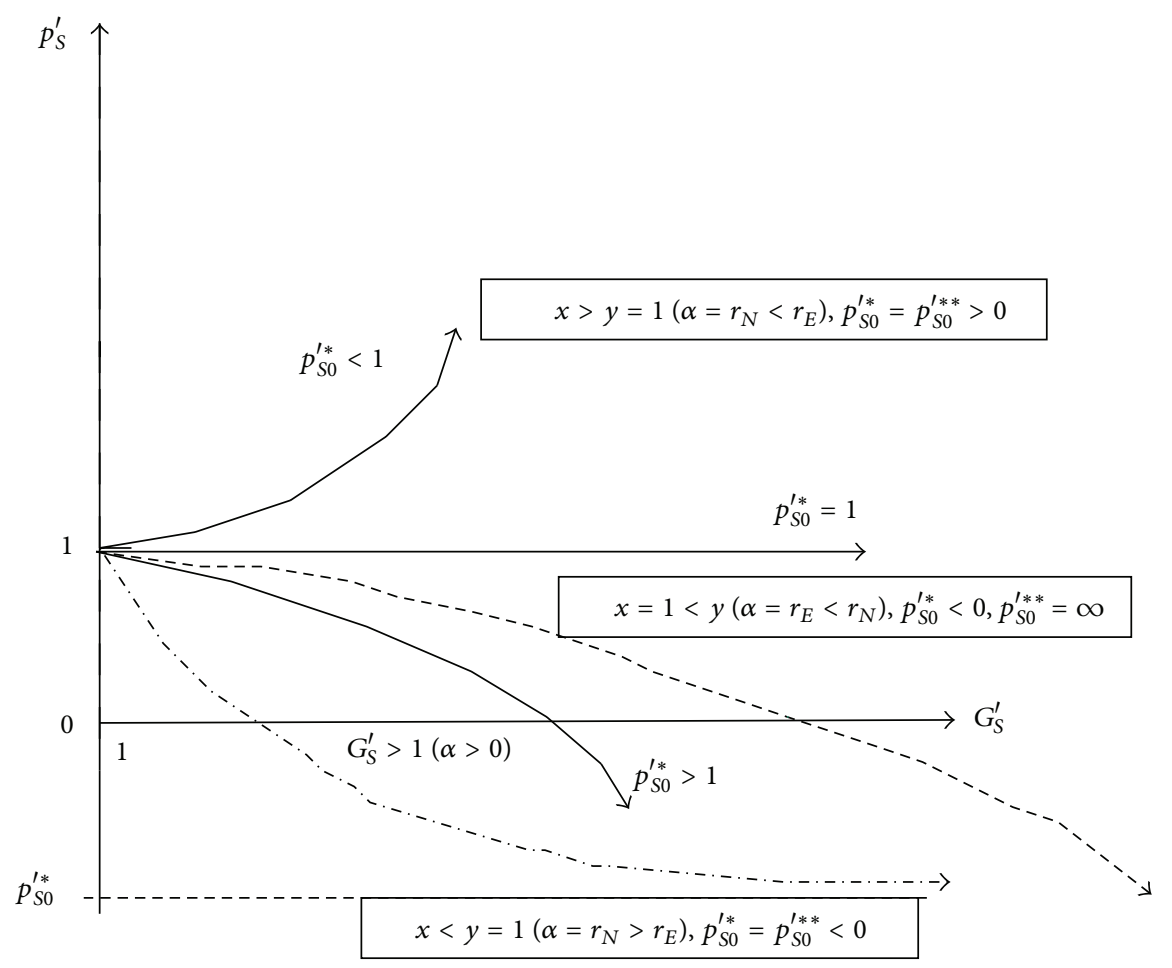

FIGURE 22: Dimensionless price of sold resources, $p_{S}^{\prime}$, versus $G_{S}^{\prime}$, for $y=1$ or $x=1$.

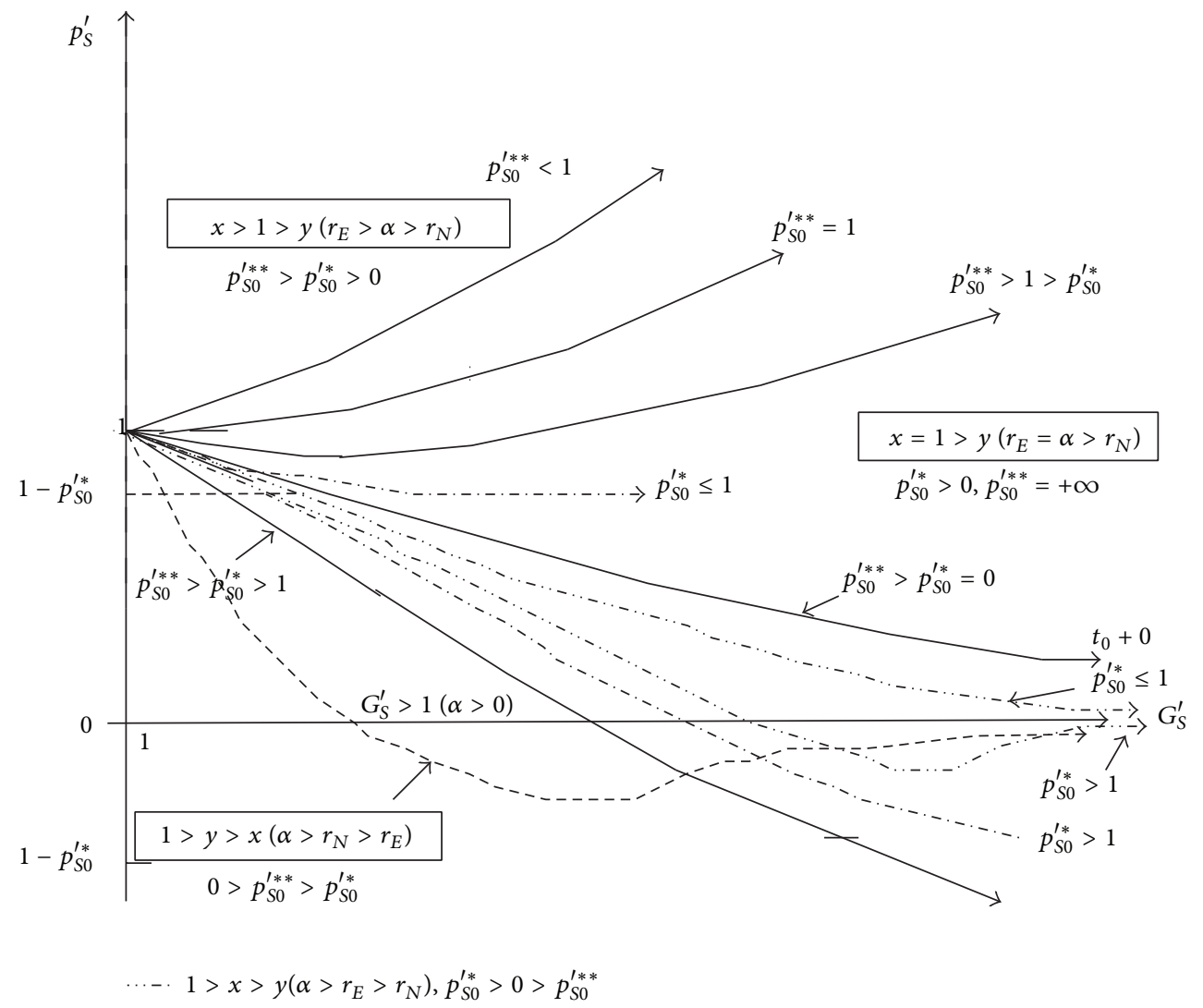

FIgURE 23: Dimensionless price of sold resources, $p_{S}^{\prime}$, versus $G_{S}^{\prime}$, for $y<1$. 


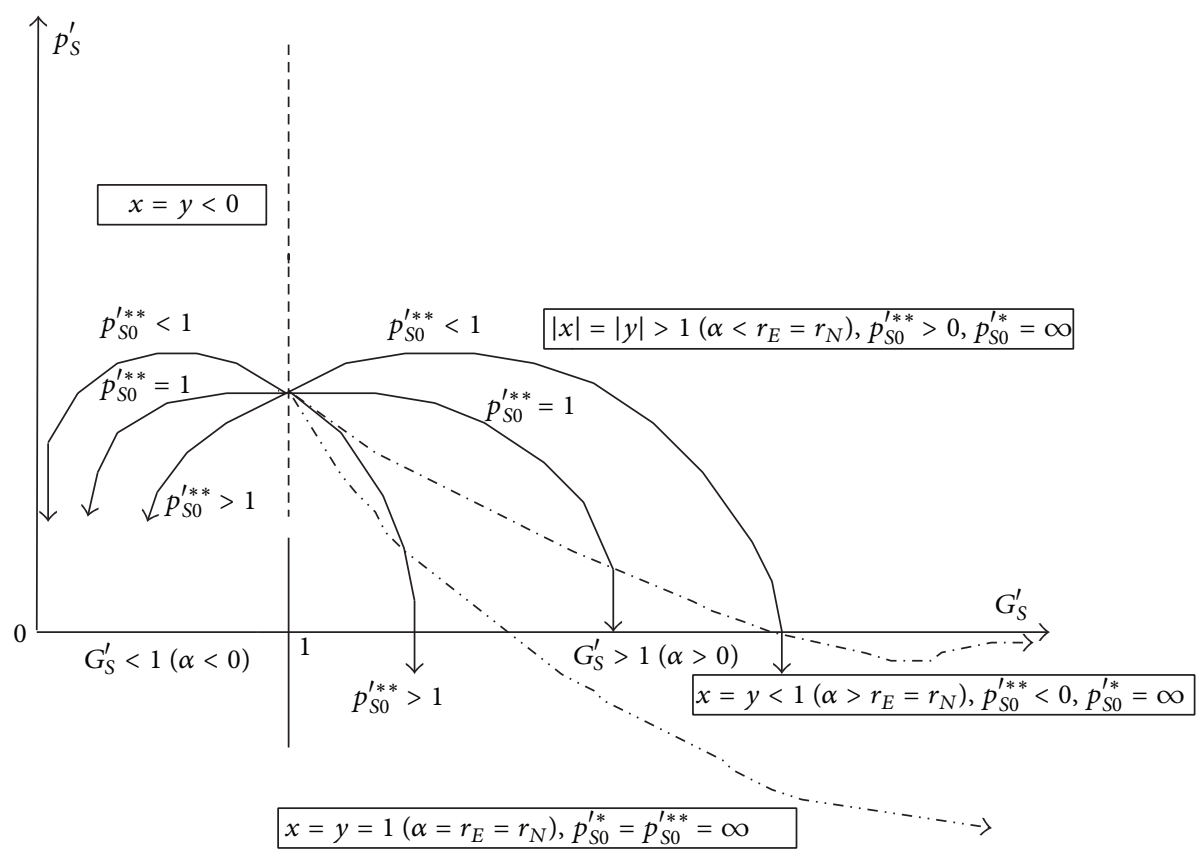

Figure 24: Dimensionless price of sold resources, $p_{S}^{\prime}$, versus $G_{S}^{\prime}$, for $x=y$.

$p_{S}^{\prime}$ increases with $G_{S}^{\prime}$, after a minimum, if $p_{S 0}^{\prime * *}>$ $1>p_{S 0}^{\prime *} ; p_{S}^{\prime}$ decreases asymptotically to +0 with $G_{S}^{\prime}$ if $p_{S 0}^{\prime * *}>p_{S 0}^{\prime *}=1 ; p_{S}^{\prime}$ decreases with $G_{S}^{\prime}$ if $p_{S 0}^{\prime * *}>p_{S 0}^{\prime *}>$ 1 ;

(ii) for $x=1>y$ (i.e., $r_{E}=\alpha>r_{N}$ and $p_{S 0}^{\prime * *}=+\infty$, $\left.p_{S 0}^{\prime *}>0\right) p_{S}^{\prime}$ decreases asymptotically to $\left(1-p_{S 0}^{\prime *}\right)$ with the increase of $G_{S}^{\prime}$;

(iii) for $1>x>y$ (i.e., $\alpha>r_{E}>r_{N}$ and $p_{S 0}^{\prime *}>0>p_{S 0}^{\prime * *}$ ) two cases are possible: $p_{S}^{\prime}$ decreases asymptotically to +0 with $G_{S}^{\prime}$ if $p_{S 0}^{\prime *} \leq 1 ; p_{S}^{\prime}$ decreases asymptotically to -0 with $G_{S}^{\prime}$, after a minimum, if $p_{S 0}^{\prime *}>1$;

(iv) for $1>y>x$ (i.e., $\alpha>r_{N}>r_{E}$ and $0>p_{S 0}^{\prime * *}>$ $\left.p_{S 0}^{\prime *}\right) p_{S}^{\prime}$ decreases asymptotically to -0 with $G_{S}^{\prime}$ after a minimum.

7.2.7. Supply Curve of Sold Resources for $x=y$ (i.e., $r_{N}=r_{E}$ ). The price evolution of sold resources, for $x=y$ (i.e., $r_{N}=r_{E}$ ), can be written in dimensionless form as

$$
p_{S}^{\prime}=\frac{p_{S}}{p_{S 0}}=\left(1-p_{S 0}^{\prime * *} \beta t\right) \exp (\beta t) .
$$

Using (65), (80) becomes finally

$$
\begin{aligned}
p_{S}^{\prime} & =\frac{p_{S}}{p_{S 0}}=G_{S}^{(\beta / \alpha)}\left[\frac{1-p_{S 0}^{\prime * *} \beta\left(\ln \left(G_{S}^{\prime}\right)\right)}{\alpha}\right] \\
& =G_{S}^{(y-1)}\left[1-p_{S 0}^{\prime * *}(y-1)\left(\ln \left(G_{S}^{\prime}\right)\right)\right] .
\end{aligned}
$$

The maximum value of $p_{S}^{\prime}$ corresponds to

$$
G_{S}^{\prime}=\exp \left[\frac{(x-y-1)}{y \cdot(y-1)}\right],
$$

for $p_{E 0}=p_{S 0}$, and to

$$
G_{S}^{\prime}=\exp \left[\frac{\left(1 / p_{S 0}^{\prime *}-1\right)}{(y-1)}\right],
$$

for $p_{E 0} \neq p_{S 0}$.

The maximum of $p_{S}^{\prime}$ is present at $G_{S}^{\prime}=1$ for

$$
\begin{aligned}
p_{S 0}^{\prime} & =p_{S 0}^{\prime * *}=\frac{p_{S 0}^{* *}}{p_{S 0}}=p_{S 0}^{\prime *} \frac{\left(\beta^{\prime}-\beta\right)}{\beta^{\prime}} \\
& =\frac{r_{N} p_{E 0}}{p_{S 0} \cdot \beta^{\prime}}=\frac{p_{E 0} \cdot y}{p_{S 0}(x-1)},
\end{aligned}
$$

which is the dimensionless critical initial price extreme of sold resources, DCIPES.

The price evolution of sold resources for $x=y=1$ (i.e., $r_{N}=r_{E}=\alpha$ ) becomes, in dimensionless form,

$$
p_{S}^{\prime}=\frac{p_{S}}{p_{S 0}}=\ln \left(G_{S}^{\prime}\right) \frac{1-p_{E 0}}{p_{S 0}} .
$$

The evolution of $p_{S}^{\prime}$ with $G_{S}^{\prime}$ is presented in Figure 24 for $x=y$ (i.e., $r_{N}=r_{E}$ ). Consider the following:

(i) for $|x|=|y|>1$ (i.e., $r_{E}=r_{N}>\alpha$ and $p_{S 0}^{\prime * *}>0$, $\left.p_{S 0}^{\prime *}=+\infty\right)$ the only variable affecting the evolution is $p_{S 0}^{\prime * *}>0$. The price $p_{S}^{\prime}$ decreases with the increase or the decrease of $G_{S}^{\prime}$ for $p_{S 0}^{\prime * *} \geq 1$. The price $p_{S}^{\prime}$ increases up to a maximum and then decreases with the decrease or the decrease of $G_{S}^{\prime}$ for $p_{S 0}^{\prime * *}<1$;

(ii) for $x=y<1$ (i.e., $r_{E}=r_{N}<\alpha$ and $p_{S 0}^{\prime * *}<0$, $\left.p_{S 0}^{\prime *}=+\infty\right)$ the price $p_{S}^{\prime}$ decreases asymptotically to -0 with the increase of $G_{S}^{\prime}$ after a negative minimum; 


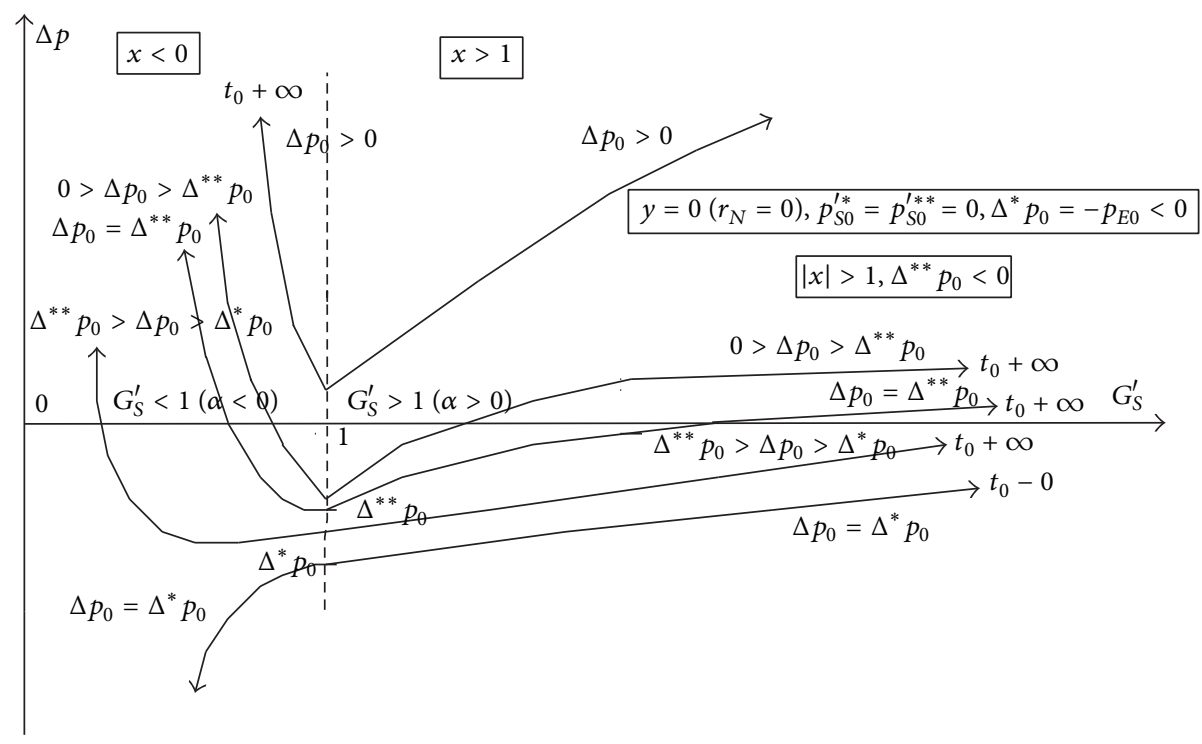

FIGURE 25: Price difference versus $G_{S}^{\prime}$, for $y=0$ and $|x|>1$.

(iii) for $x=y=1$ (i.e., $r_{E}=r_{N}=\alpha$ and $p_{S 0}^{\prime *}=p_{S 0}^{\prime * *}=+\infty$ ) the price $p_{S}^{\prime}$ decreases with the increase of $G_{S}^{\prime}$.

\section{Supply Curve of the Difference between Selling and Extracted Resources}

The difference $\Delta p$ between the price of selling and extracted resources is given by

$$
\Delta p=p_{S}-p_{E}=\left(\Delta p_{0}-\Delta^{*} p_{0}\right) G_{S}^{(x-1)}+\Delta^{*} p_{0} G_{S}^{(y-1)},
$$

where

$$
\Delta^{*} p_{0}=p_{S 0}^{*}-p_{E 0}=p_{E 0} \frac{\left(2 r_{N}-r_{E}\right)}{\left(r_{E}-r_{N}\right)}
$$

is the critical initial price difference, CIPD. The price difference $\Delta p$ has an extreme for

$$
G_{S}^{\prime}=\left\{\frac{\left[\Delta p_{S 0}^{\prime *}(1-y)\right]}{\left[(x-1)\left(1-\Delta p_{S 0}^{\prime *}\right)\right]}\right\}^{1 /(x-y)},
$$

which is equal to 1 for $\Delta p_{0}$ equal to

$$
\begin{aligned}
\Delta^{* *} p_{0} & =\Delta^{*} p_{0} \frac{(x-y)}{(x-1)} \\
& =\Delta^{*} p_{0} \frac{\left(\beta^{\prime}-\beta\right)}{\beta^{\prime}}=p_{E 0} \frac{\left(2 \cdot r_{N}-r_{E}\right)}{\beta^{\prime}},
\end{aligned}
$$

which is the critical extreme of the initial price difference, CEIPD. The relative evolutions of $\Delta p$ with $G_{S}^{\prime}$ are presented in Figures 25-28.

8.1. Supply Curve of $\Delta p$ for $y=0$ and $|x|>1$. Figure 25 presents the price difference $\Delta p$ for $y=0$ (i.e., $r_{N}=0$ ) and $|x|>1$ (i.e., $\alpha<r_{E}, \Delta^{*} p_{0}=-p_{E 0}<0$ and $\Delta^{*} p_{0}<\Delta^{* *} p_{0}<$ $0)$. Consider the following:

(i) for $\Delta p_{0}>0$ the price difference $\Delta p$ increases with the increase or the decrease of $G_{S}^{\prime}$, that is, for $G_{S}^{\prime}<1$ or $G_{S}^{\prime}>1$. For $G_{S}^{\prime}<1$ the difference $\Delta p$ increases exponentially while the difference $\Delta p$ increases at a lower rate for $G_{S}^{\prime}>1$;

(ii) for $\Delta p_{0}$ in the range from 0 to $\Delta^{* *} p_{0}$, that is, $\Delta^{* *} p_{0}<$ $\Delta p_{0}<0$, the price difference $\Delta p$ increases with the increase or the decrease of $G_{S}^{\prime}$. The increase is exponential for $G_{S}^{\prime}<1$ while having a lower rate of increase for $G_{S}^{\prime}>1$;

(iii) for $\Delta p_{0}=\Delta^{* *} p_{0}$, the price difference $\Delta p$ increases with the increase or the decrease of $G_{S}^{\prime}$. For $G_{S}^{\prime}<1$ the difference $\Delta p$ increases exponentially with the minimum at $G_{S}^{\prime}=1$ while the increase has a lower rate for $G_{S}^{\prime}>1$;

(iv) for $\Delta p_{0}$ in the range from $\Delta^{*} p_{0}$ to $\Delta^{* *} p_{0}$, that is, $\Delta^{*} p_{0}<\Delta p_{0}<\Delta^{* *} p_{0}$, the price difference $\Delta p$ increases exponentially, after a minimum, with the decrease of $G_{S}^{\prime}$. For $G_{S}^{\prime}>1$ the difference $\Delta p$ increases with a lower rate;

(v) for $\Delta p_{0}=\Delta^{*} p_{0}$, the price difference $\Delta p$ increases asymptotically towards -0 for $G_{S}^{\prime}>1$, while $\Delta p$ decreases exponentially for $G_{S}^{\prime}<1$.

8.2. Supply Curve of $\Delta p$ for $y=0$ and $0<x \leq 1$. The price difference $\Delta p$ for $y=0$ (i.e., $r_{N}=0, \Delta^{*} p_{0}=-p_{E 0}<0$ ) and $0<x \leq 1$ (i.e., $\alpha \geq r_{E}>0$ ) has the following trends:

(i) for $x=1$ (i.e., $\alpha=r_{E}$ and $\Delta^{* *} p_{0}=-\infty$ ), the price difference $\Delta p$ increases asymptotically towards $p_{S 0}$ for any value of $\Delta p_{0}$ (i.e., $\Delta p_{0}>0,0>\Delta p_{0}>\Delta^{*} p_{0}$ or $\left.\Delta p_{0}=\Delta^{*} p_{0}\right)$

(ii) for $x<1$ (i.e., $\alpha>r_{E}>0$ and $\Delta^{* *} p_{0}>0$ ) the price difference $\Delta p$ tends to 0 for any value of $\Delta p_{0}$. 


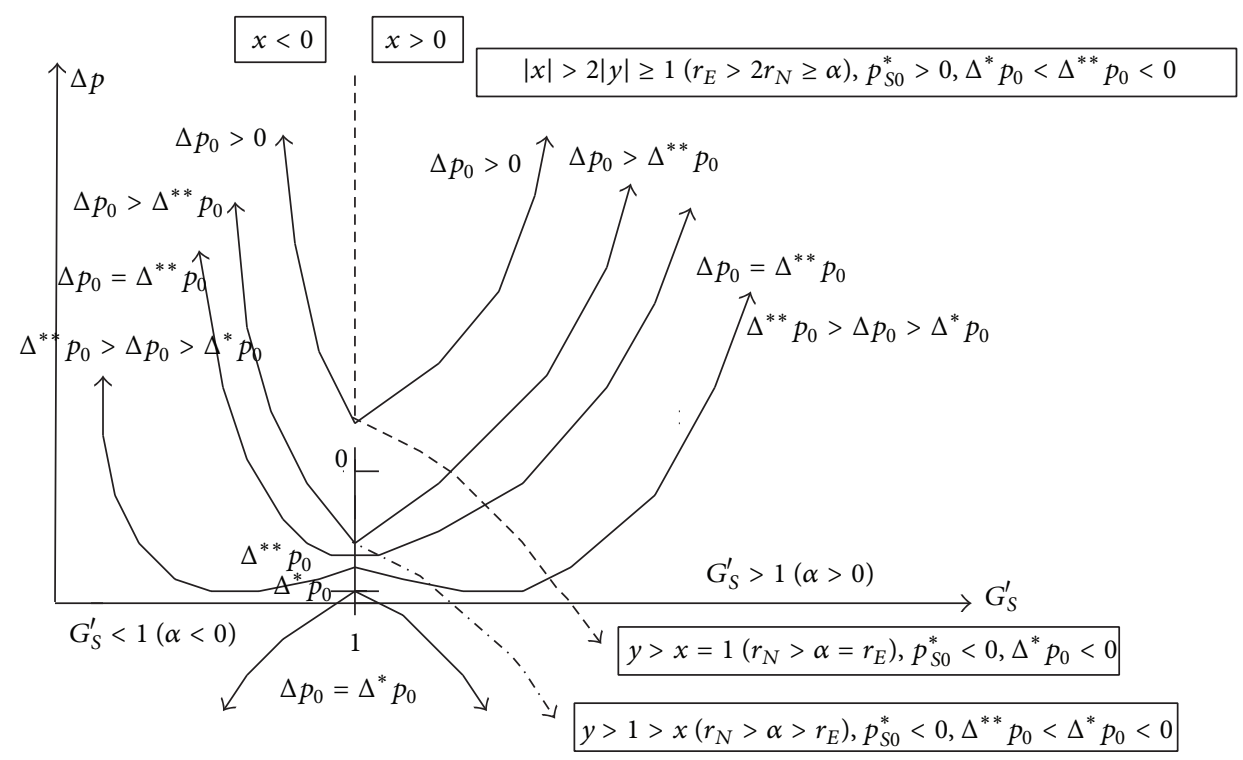

FIGURE 26: Price difference versus $G_{S}^{\prime}$, for $|x|>2|y| \geq 1$, or $y>x=1$, or $y>1>x$.

8.3. Supply Curve of $\Delta p$ for $|x|>2|y| \geq 1$, or $y>x=1$, or $y>1>x$. Figure 26 presents the price difference $\Delta p$ for: $|x|>2|y| \geq 1$ (i.e., $r_{E}>2 r_{N} \geq \alpha$ and $\Delta^{*} p_{0}<\Delta^{* *} p_{0}<0$ ); $y>x=1$ (i.e., $r_{N}>\alpha=r_{E}$ and $\Delta^{*} p_{0}<0$ ); $y>1>x$ (i.e., $r_{N}>\alpha>r_{E}$ and $\Delta^{* *} p_{0}<\Delta^{*} p_{0}<0$. Consider the following:

(i) for $|x|>2|y| \geq 1$ and $\Delta p_{0}>0$ or $\Delta p_{0}>\Delta^{* *} p_{0}$ the price difference $\Delta p$ increases exponentially with the increase or the decrease of $G_{S}^{\prime}$. For $\Delta p_{0}=\Delta^{* *} p_{0}$ the price difference $\Delta p$ increases exponentially with a minimum at $G_{S}^{\prime}=1$. For $\Delta^{* *} p_{0}>\Delta p_{0}>\Delta^{*} p_{0}$ the price difference $\Delta p$ increases exponentially, after a minimum, with the decrease or the increase of $G_{S}^{\prime}$. For $\Delta p_{0}=\Delta^{*} p_{0}$ the price difference $\Delta p$ decreases exponentially with the decrease or the increase of $G_{S}^{\prime}$.

Figure 26 presents also the price difference $\Delta p$ for $y>$ $x=1$ (i.e., $r_{N}>\alpha=r_{E}$ and $\Delta^{*} p_{0}<0$ ) and for $y>1>x$ (i.e., $r_{N}>\alpha>r_{E}$ and $\left.\Delta^{* *} p_{0}<\Delta^{*} p_{0}<0\right)$. The price difference $\Delta p$ decreases exponentially with $G_{S}^{\prime}$.

8.4. Supply Curve of $\Delta p$ for $|y|>1$ and $|x|=2 y$. The price difference $\Delta p$ for $|y|>1$ and $|x|=2|y|$ (i.e., $\alpha<r_{N}, r_{E}=$ $2 r_{N}$, and $\left.\Delta^{*} p_{0}=\Delta^{* *} p_{0}=0\right)$ has the following trends. For $\Delta p_{0}>0$ the price difference $\Delta p$ increases exponentially with the increase or the decrease of $G_{S}^{\prime}$. For $\Delta p_{0}<\Delta^{*} p_{0}$ the price difference $\Delta p$ decreases exponentially with the increase or the decrease of $G_{S}^{\prime}$.

8.5. Supply Curve of $\Delta p$ for $|y|>1$ and $|x|<2 y$. Figure 27 presents the price difference $\Delta p$ for $|y|>1$ and $|x|<2|y|$ (i.e., $\alpha<r_{N}, r_{E}<2 r_{N}$ and $\Delta^{*} p_{0}>\Delta^{* *} p_{0}>0$ ).

For $\Delta p_{0} \geq \Delta^{*} p_{0}$ the price difference $\Delta p$ increases exponentially with the increase or the decrease of $G_{S}^{\prime}$. For $\Delta^{*} p_{0}>\Delta p_{0}>\Delta^{* *} p_{0}$ the price difference $\Delta p$ increases up to a maximum and then decreases exponentially with the increase or the decrease of $G_{S}^{\prime}$. For $\Delta p_{0}=\Delta^{* *} p_{0}$ the price difference
$\Delta p$ decreases exponentially with the increase or the decrease of $G_{S}^{\prime}$ and the maximum is at $G_{S}^{\prime}=1$. For $\Delta p_{0}<\Delta^{* *} p_{0}$ the price difference $\Delta p$ decreases exponentially with the increase or the decrease of $G_{S}^{\prime}$.

8.6. Supply Curve of $\Delta p$ for $y=1$. The price difference $\Delta p$ for $y=1$ (i.e., $\alpha=r_{N}$ ) has the following trends:

(i) for $x>y=1$ (i.e., $0<\alpha=r_{N}<r_{E}$ and $\Delta^{*} p_{0}=$ $\left.\Delta^{* *} p_{0}\right)$, three cases are possible. For $\Delta p_{0}>\Delta^{*} p_{0}$ the price difference $\Delta p$ increases with the increase of $G_{S}^{\prime}$; for $\Delta p_{0}=\Delta^{*} p_{0}$ the price difference $\Delta p$ remains constant with the increase of $G_{S}^{\prime}$; for $\Delta p_{0}<\Delta^{*} p_{0}$ the price difference $\Delta p$ decreases with the increase of $G_{S}^{\prime}$.

(ii) for $x<y=1$ (i.e., $\alpha=r_{N}>r_{E}$ and $\Delta^{*} p_{0}=\Delta^{* *} p_{0}$ ), the price difference $\Delta p$ decreases with the increase of $G_{S}^{\prime}$.

8.7. Supply Curve of $\Delta p$ for $y<1$. The price difference $\Delta p$ for $y<1$ (i.e., $\alpha>r_{N}$ ) and $\Delta^{* *} p_{0}>\Delta^{*} p_{0}>0$ has the following trends. For $\Delta p_{0}>\Delta^{* *} p_{0}$ the price difference $\Delta p$ increases with the increase of $G_{S}^{\prime}$. For $\Delta p_{0}=\Delta^{* *} p_{0}$ the price difference $\Delta p$ increases with the increase of $G_{S}^{\prime}$ and the minimum is at $G_{S}^{\prime}=1$. For $\Delta^{* *} p_{0}>\Delta p_{0}>\Delta^{*} p_{0}$ the price difference $\Delta p$ increases with the increase of $G_{S}^{\prime}$ after a minimum. For $\Delta p_{0}=$ $\Delta^{*} p_{0}$ the price difference $\Delta p$ decreases asymptotically to +0 with the increase of $G_{S}^{\prime}$. For $\Delta p_{0}<\Delta^{*} p_{0}$ the price difference $\Delta p$ decreases with the increase of $G_{S}^{\prime}$.

The price difference $\Delta p$ for $y<1$ (i.e., $\alpha>r_{N}>0$ ) and $\Delta^{* *} p_{0}<\Delta^{*} p_{0}<0$ has the following trends. For $\Delta p_{0}>0>\Delta^{*} p_{0}$ the price difference $\Delta p$ increases with the increase of $G_{S}^{\prime}$. For $\Delta p_{0}=\Delta^{*} p_{0}$ the price difference $\Delta p$ increases asymptotically to -0 with the increase of $G_{S}^{\prime}$. For $\Delta^{*} p_{0}>\Delta p_{0}>\Delta^{* *} p_{0}$ the price difference $\Delta p$ increases up to a maximum and then decreases with the increase of $G_{S}^{\prime}$. 


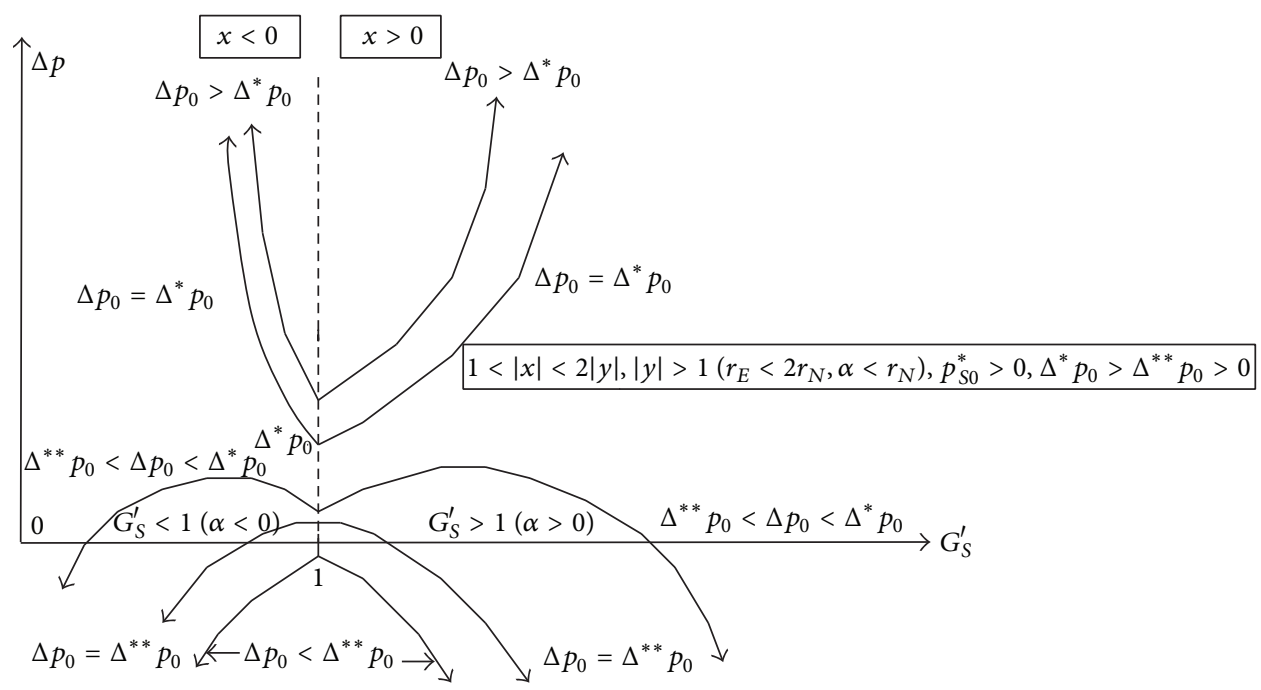

Figure 27: Price difference versus $G_{S}^{\prime}$, for $|y|>1$ and $|x|<2|y|$.

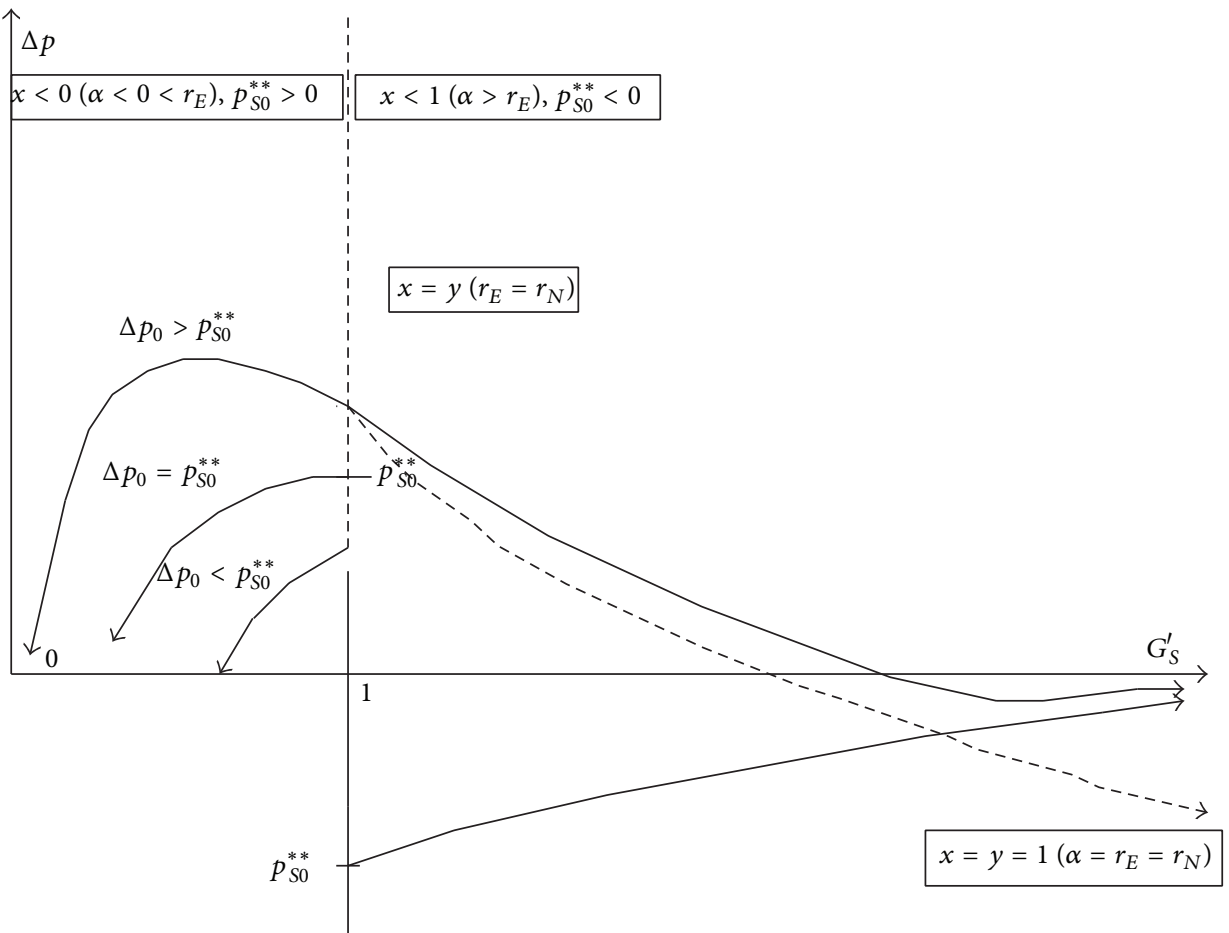

FIgURE 28: Price difference versus $G_{S}^{\prime}$, for $x=y$.

For $\Delta p_{0} \leq \Delta^{* *} p_{0}$ the price difference $\Delta p$ decreases with the increase of $G_{S}^{\prime}$.

The price difference $\Delta p$ for the other three cases which are possible according to the relation between $x$ and $y$ (i.e., $\alpha$ and $r_{E}$ ) has the following trends:

(i) for $1 \geq x>y$ (i.e., $\alpha \geq r_{E}>r_{N}$ ) the price difference $\Delta p$ decreases asymptotically to +0 with the increase of $G_{S}^{\prime}$;

(ii) for $1>y>x$ (i.e., $\alpha>r_{N}>r_{E}$ ) the price difference $\Delta p$ decreases asymptotically to -0 after a negative minimum with the increase of $G_{S}^{\prime}$.
8.8. Supply Curve of $\Delta p$ for $x=y$. The price difference, $\Delta p$, is, in dimensionless form,

$$
\Delta p=p_{S}-p_{E}=\left(\Delta p_{0}-p_{S 0}^{* *} \beta^{\prime} t\right) \exp \left(\beta^{\prime} t\right) .
$$

For $x=y$ the critical initial price difference $\Delta^{*} p_{0}$ and the critical initial extreme price difference $\Delta^{* *} p_{0}$ are not defined and the only critical price defined is the critical initial price extreme of the sold resources $p_{S 0}^{* *}$.

The price difference $\Delta p$, as a function of $G_{S}^{\prime}$, is then

$$
\Delta p=\left[\Delta p_{0}-p_{S 0}^{* *}(y-1) \ln \left(G_{S}^{\prime}\right)\right] G_{S}^{(y-1)} .
$$


The price difference $\Delta p$ has an extreme for

$$
G_{S}^{\prime}=\exp \left[\frac{\left(\Delta p_{0}-p_{S 0}^{* *}\right)}{p_{S 0}^{* *} \cdot(1-y)}\right],
$$

which is equal to 1 if $\Delta p_{0}$ is equal to

$$
\Delta p_{0}=p_{0}^{* *} .
$$

Figure 28 presents the price difference $\Delta p$ for $x=y$ (i.e., $\left.r_{N}=r_{E}\right)$. Consider the following:

(i) for $x<0$ (i.e., $\alpha<0<r_{E}$ and $p_{0}^{* *}>0$ ), three cases are possible with the decrease of $G_{S}^{\prime}$. For $\Delta p_{0}>p_{0}^{* *}$ the price difference $\Delta p$ decreases after a maximum; for $\Delta p_{0}=p_{0}^{* *}$ the price difference $\Delta p$ decreases with the maximum at $G_{S}^{\prime}=1$; for $\Delta p_{0}<p_{0}^{* *}$ the price difference $\Delta p$ decreases exponentially;

(ii) for $x<1$ (i.e., $\alpha>r_{E}$ and $p_{0}^{* *}<0$ ), three cases are possible with the increase of $G_{S}^{\prime}$. For $\Delta p_{0}>0>p_{0}^{* *}$ the price difference $\Delta p$ decreases asymptotically to -0 after a negative minimum; for $0>\Delta p_{0}>$ or $=$ or $<$ $p_{0}^{* *}$ the price difference $\Delta p$ increases asymptotically to -0 ;

(iii) for $x=y=1$ (i.e., $\alpha=r_{E}=r_{N}$ ) the price difference $\Delta p$, which has the following dependence on $G_{S}^{\prime}$,

$$
\Delta p=\Delta p_{0}-y p_{E 0} \ln \left(G_{S}^{\prime}\right)
$$

\begin{tabular}{|c|c|}
\hline$G_{k}=G p r:$ & Capital flow rate \\
\hline$G:$ & Mass flow rate \\
\hline$K=G p$ & Capital flow \\
\hline$M:$ & Mass \\
\hline$p:$ & Price \\
\hline$p_{S 0}^{*}:$ & $\begin{array}{l}\text { Critical initial price of selling } \\
\text { resources, CIPS }\end{array}$ \\
\hline$p_{S 0}^{* *}:$ & $\begin{array}{l}\text { Critical initial extreme price of } \\
\text { selling resources, CIPES }\end{array}$ \\
\hline$p_{S 0}^{\prime *}:$ & $\begin{array}{l}\text { Dimensionless critical initial price } \\
\text { of sold resources, DCIPS }\end{array}$ \\
\hline$p_{S 0}^{\prime * *}:$ & $\begin{array}{l}\text { Dimensionless critical initial price } \\
\text { extreme of sold resources, DCIPES }\end{array}$ \\
\hline$r:$ & Interest rate $\left(\right.$ annum $\left.^{-1}\right)$ \\
\hline . & Time \\
\hline$x=r_{E} / \alpha:$ & $\begin{array}{l}\text { Rate of interest of sold resources } \\
\text { on extracted rate, RISE }\end{array}$ \\
\hline$y=r_{N} / \alpha$ & $\begin{array}{l}\text { Rate of interest of nonextracted } \\
\text { resources on extracted rate, RINE }\end{array}$ \\
\hline
\end{tabular}

decreases with the increase of $G_{S}^{\prime}$.

\section{Nomenclature}

Greek

$\alpha=(1 / G)(d G / d t):$ Extraction rate

$\beta=r_{N}-\alpha: \quad$ Price-increase factor of extracted resources, PIFE
$\beta^{\prime}=r_{E}-\alpha: \quad$ Price-increase factor of selling resources, PIFS

$\Delta p=p_{S}-p_{E}:$ Difference between price of sold and extracted resources

$\Delta^{*} p_{0}: \quad$ Critical initial price difference,

$\Delta^{* *} p_{0}: \quad$ Critical extreme initial price difference, CEIPD.

Subscript

0: Initial

c: Critical

E: $\quad$ Extracted resources

$f$ : Final

$k$ : Capital

$m$ : Maximum or minimum

max: Maximum

min: Minimum

$N$ : Nonextracted resources

$S$ : $\quad$ Selling resources.

\section{Conflict of Interests}

The author declares that there is no conflict of interests regarding the publication of this paper.

\section{References}

[1] H. Hotelling, “The economics of exhaustible resources," Journal of Political Economy, vol. 39, no. 2, pp. 137-175, 1931.

[2] P. S. Dasgupta and G. M. Heal, Economic Theory and Exhaustible Resources, Cambridge University Press, 1979.

[3] P. P. McCall, "Energy models and forecasts: a user's point of view," in Proceedings of the Conference on Energy Model and Forecast, pp. 159-165, Berkeley, Calif, USA, June 1974.

[4] J. G. Tewksbury, "Long range forecasting of foreign oil price: technique and results," in Proceedings of the AIME Symposium on Petroleum Economics and Valuation, pp. 89-96, Society of Petroleum Engineers, Dallas, Tex, USA, February 1977.

[5] R. S. Pindyck, "Higher energy prices and the supply of natural gas," Energy Systems and Policy, vol. 2, no. 2, pp. 177-209, 1978.

[6] M. A. Adelman, "International oil," Natural Resources Journal, vol. 18, no. 4, pp. 725-730, 1978.

[7] H. DuMoulin and E. V. Newland, "Foretelling the energy future," in Proceedings of the National Meeting of the American Chemical Society, pp. 21-31, Honolulu, Hawaii, USA, April 1979.

[8] D. Pearce, "World energy demand and crude oil prices to the year 2000," Journal of Agricultural Economics, vol. 32, no. 3, pp. 341-354, 1981.

[9] M. W. French, "Energy forecast for 1983-1993," Energy Economics, Policy and Management, vol. 3, no. 3, pp. 4-9, 1983.

[10] M. L. Roberts, "Crude oil prices-the direction?" Journal of Petroleum Technology, vol. 36, no. 5, pp. 811-816, 1984.

[11] J. M. Campbell and R. A. Hubbard, "Price forecasting and project evaluation in the 1980's," Journal of Petroleum Technology, vol. 36, no. 5, pp. 817-825, 1984.

[12] S. H. Clark, "US natural gas price forecasting," in Proceedings of the American Institute of Chemical Engineers Summer National Meeting, p. 13, Philadelphia, Pa, USA, 1984. 
[13] A. David and G. P. Carson, "Price forecast for energy lending," in Proceedings of the Eastern Regional Meeting, pp. 51-55, Society of Petroleum Engineers of AIME, Charleston, WVa, USA, 1984.

[14] L. Lorentsen and K. Roland, "Modelling the crude oil market: oil prices in the long term," in Bridge between Control Science and Technology: Biomedical Applications, Water Resources, Environment, Energy Systems, Development, Social Effects: Proceedings of the 9th Triennial World Congress of IFAC, vol. 6 of IFAC Proceedings Series, pp. 3309-3312, SWIIS Education, Budapest, Hungary, 1985.

[15] T. R. Curlee, "Forecasting world oil prices: the evolution of modeling methodologies and summary of recent projections," Materials and Society, vol. 9, no. 4, pp. 413-442, 1985.

[16] A. Anon, "Declining oil prices have not resulted in increased demand, decreased supply," Energy, vol. 11, no. 5, pp. 4-6, 1986.

[17] J. P. Dielwart and F. C. Coles, "Canadian petroleum prices and demand-an overview," in Proceedings of the 37th Annual Technical Meeting of the Petroleum Society of CIM, vol. 2, pp. 231-242, Alberta, Canada, 1986.

[18] G. W. Yohe, "Evaluating the efficiency of long-term forecasts with limited information. Revisions in the IEW poll responses," Resources and Energy, vol. 8, no. 4, pp. 331-339, 1986.

[19] P. Sekera, "Oil prices 1921 to 2121 (past, present and future)," in Proceedings of the 37th Annual Technical Meeting of the Petroleum Society of CIM, vol. 2, pp. 247-291, Alberta, Canada, 1986.

[20] D. Gately, "Prospects for oil prices, revisited," Annual Review of Energy, vol. 11, pp. 513-538, 1986.

[21] K. Holden, D. Peel, and B. Sandhu, "The accuracy of OECD forecasts," Empirical Economics, vol. 12, no. 3, pp. 175-186, 1987.

[22] E. L. Dougherty, "Oil prices: can we predict where they are going?" in Proceedings of the SPE Annual Technical Conference and Exhibition, pp. 147-157, Society of Petroleum Engineers of AIME, Dallas, Tex, USA, 1987.

[23] A. Amano, "A small forecasting model of the world oil market," Journal of Policy Modeling, vol. 9, no. 4, pp. 615-635, 1987.

[24] J. S. Garces, "Effects of natural gas storage on gas price forecasts," in Proceedings of the ASCE Energy Division Specialty Conference on Energy, pp. 59-64, Pittsburgh, Pa, USA, March 1991.

[25] J.-P. Angelier, “The determinants of oil prices," Energy Studies Review, vol. 3, no. 3, pp. 217-226, 1991.

[26] A. E. Bopp and G. M. Lady, "A comparison of petroleum futures versus spot prices as predictors of prices in the future," Energy Economics, vol. 13, no. 4, pp. 274-282, 1991.

[27] B. Abramson and A. Finizza, "Using belief networks to forecast oil prices," International Journal of Forecasting, vol. 7, no. 3, pp. 299-315, 1991.

[28] L. R. Charleson and E. J. Weber, "Energy forecasts for Western Australia 1992-2010," Energy Economics, vol. 15, no. 2, pp. 111$122,1993$.

[29] F. Fesharaki, "Oil prices in a new light," Hydrocarbon Processing, vol. 73, article 5, 1994.

[30] H. G. Huntington, "Oil price forecasting in the 1980s: what went wrong?” Energy Journal, vol. 15, no. 2, pp. 1-22, 1994.

[31] I. A. Moosa and N. E. Al-Loughani, "Unbiasedness and time varying risk premia in the crude oil futures market," Energy Economics, vol. 16, no. 2, pp. 99-105, 1994.

[32] B. Abramson, "The design of belief network-based systems for price forecasting," Computers \& Electrical Engineering, vol. 20, no. 2, pp. 163-180, 1994.
[33] A. M. Skov, "Analysis of forecasts of energy supply, demand, and oil prices," in Proceedings of the SPE Hydrocarbon Economics and Evaluation Symposium, pp. 239-253, Dallas, Tex, USA, March 1995.

[34] B. Abramson and A. Finizza, "Probabilistic forecasts from probabilistic models: a case study in the oil market," International Journal of Forecasting, vol. 11, no. 1, pp. 63-72, 1995.

[35] D. J. Santini, "An assessment of oil supply and its implications for future prices," Natural Resources Research, vol. 7, no. 2, pp. 101-121, 1998.

[36] M. D. Williams, "The future of OPEC and crude oil prices," International Journal of Global Energy Issues, vol. 10, no. 1, pp. 22-37, 1998.

[37] K. Chaudhuri and B. C. Daniel, "Long-run equilibrium real exchange rates and oil prices," Economics Letters, vol. 58, no. 2, pp. 231-238, 1998.

[38] R. S. Pindyck, "Long-run evolution of energy prices," Energy Journal, vol. 20, no. 2, pp. 1-27, 1999.

[39] P. Silvapulle and I. A. Moosa, "The relationship between spot and futures prices: evidence from the crude oil market," Journal of Futures Markets, vol. 19, no. 2, pp. 175-193, 1999.

[40] P. P. Alba and J.-M. Bourdaire, “The oil price," Revue de l'Energie, no. 516, pp. 209-217, 2000.

[41] Centre for Global Energy Studies (CGES), "Annual oil market forecast and review," Middle East Economic Survey, vol. 43, no. 5, pp. A17-A18, 2000.

[42] "EIA revises average oil price forecast for 2000 upward to $\$ 24 / \mathrm{b}$," Petrostrategies, vol. 14, no. 667, pp. 8-9.

[43] A. Hare, "Gas to follow oil price rise through 2001, EIA forecasts," Natural Gas Week, vol. 16, no. 11, p. 20, 2000.

[44] "Shell forecasts mid-teens average price for next 10 years," Middle East Economic Survey, vol. 43, no. 22, p. A12, 2000.

[45] "US Energy Department predicts WTI crude price of $\$ 30 / \mathrm{B}-$ plus for remainder of year," Middle East Economic Survey, vol. 43, no. 38, pp. A11-A12, 2000.

[46] T. Walde and E. M. dos Santos, "Comment on the ups (and past and future downs) of the oil price," Revue de l'Energie, no. 520, pp. 453-459, 2000.

[47] A. K. Birky, J. D. Maples, J. S. Moore Jr., and P. D. Patterson, "Future world oil prices and the potential for new transportation fuels," Transportation Research Record, no. 1738, pp. 94-99, 2000.

[48] B. Yang, "Prediction of world crude oil price in 2000," Petroleum Processing and Petrochemicals, vol. 31, no. 3, pp. 63-65, 2000.

[49] P. W. MacAvoy and N. V. Moshkin, "The new trend in the longterm price of natural gas," Resource and Energy Economics, vol. 22 , no. 4, pp. 315-338, 2000.

[50] C. Morana, "A semiparametric approach to short-term oil price forecasting," Energy Economics, vol. 23, no. 3, pp. 325-338, 2001.

[51] L. Tang and S. Hammoudeh, "An empirical exploration of the world oil price under the target zone model," Energy Economics, vol. 24, no. 6, pp. 577-596, 2002.

[52] J. Alvarez-Ramirez, M. Cisneros, C. Ibarra-Valdez, and A. Soriano, "Multifractal Hurst analysis of crude oil prices," Physica A: Statistical Mechanics and Its Applications, vol. 313, no. 3-4, pp. 651-670, 2002.

[53] M. Ye, J. Zyren, and J. Shore, "Forecasting crude oil spot price using OECD petroleum inventory levels," International Advances in Economic Research, vol. 8, no. 4, pp. 324-333, 2002.

[54] P. Sadorsky, "Time-varying risk premiums in petroleum futures prices," Energy Economics, vol. 24, no. 6, pp. 539-556, 2002. 
[55] W. M. Fong and K. H. See, "A Markov switching model of the conditional volatility of crude oil futures prices," Energy Economics, vol. 24, no. 1, pp. 71-95, 2002.

[56] M. Taal, I. Bulatov, J. Klemeš, and P. Stehlík, "Cost estimation and energy price forecasts for economic evaluation of retrofit projects," Applied Thermal Engineering, vol. 23, no. 14, pp. 18191835, 2003.

[57] G. Cortazar and E. S. Schwartz, "Implementing a stochastic model for oil futures prices," Energy Economics, vol. 25, no. 3, pp. 215-238, 2003.

[58] J. D. Cabedo and I. Moya, "Estimating oil price "value at risk" using the historical simulation approach," Energy Economics, vol. 25, no. 3, pp. 239-253, 2003.

[59] G. Burg, S. Richmond, I. Haine, A. Maurer, and T. Wells, "Energy: prices to remain high in 2004," Australian Commodities, vol. 11, no. 2, pp. 275-283, 2004.

[60] G. Burg, S. Richmond, I. Haine, and A. Maurer, "Energy: prices remain high in 2004," Australian Commodities, vol. 11, no. 3, pp. 419-429, 2004.

[61] S. Mirmirani and H. C. Li, "A comparison of VAR and neural networks with genetic algorithm in forecasting price of oil," Advances in Econometrics, vol. 19, pp. 203-223, 2004.

[62] S. Abosedra and H. Baghestani, "On the predictive accuracy of crude oil futures prices," Energy Policy, vol. 32, no. 12, pp. 13891393, 2004.

[63] F. Gori and C. Takanen, "Forecast of energy consumption of industry and household \& services in Italy," International Journal of Heat and Technology, vol. 22, no. 2, pp. 115-121, 2004.

[64] C.-S. Feng, J.-C. Wu, and F. Jiang, "Forecasting the oil price by ARFIMA model," Journal of University of Shanghai for Science and Technology, vol. 27, no. 6, pp. 539-542, 2005.

[65] N. Movassagh and B. Modjtahedi, "Bias and backwardation in natural gas futures prices," Journal of Futures Markets, vol. 25, no. 3, pp. 281-308, 2005.

[66] M. Ye, J. Zyren, and J. Shore, "A monthly crude oil spot price forecasting model using relative inventories," International Journal of Forecasting, vol. 21, no. 3, pp. 491-501, 2005.

[67] S. Yousefi, I. Weinreich, and D. Reinarz, "Wavelet-based prediction of oil prices," Chaos, Solitons and Fractals, vol. 25, no. 2, pp. 265-275, 2005.

[68] D.-L. Sun and J. Lai, "Oil price forecasting using neural networks method," Journal of Petrochemical Universities, vol. 19, no. 2, pp. 89-92, 2006.

[69] P. Sadorsky, "Modeling and forecasting petroleum futures volatility," Energy Economics, vol. 28, no. 4, pp. 467-488, 2006.

[70] M. Ye, J. Zyren, and J. Shore, "Short-run crude oil price and surplus production capacity," International Advances in Economic Research, vol. 12, no. 3, pp. 390-394, 2006.

[71] S. Moshiri and F. Foroutan, "Forecasting nonlinear crude oil futures prices," Energy Journal, vol. 27, no. 4, pp. 81-95, 2006.

[72] N. Snow, "EIA: world energy forecast reflects higher oil prices," Oil \& Gas Journal, vol. 104, no. 25, pp. 34-35, 2006.

[73] S. S. Ghouri, "Assessment of the relationship between oil prices and US oil stocks," Energy Policy, vol. 34, no. 17, pp. 3327-3333, 2006.

[74] M. Ye, J. Zyren, and J. Shore, "Forecasting short-run crude oil price using high- and low-inventory variables," Energy Policy, vol. 34, no. 17, pp. 2736-2743, 2006.

[75] F. Gori, "Mass and energy-capital conservation equations to study the price evolution of non-renewable energy resourcespart I: generalization of the Hotelling rule," Applied Thermal Engineering, vol. 26, no. 14-15, pp. 1746-1750, 2006.
[76] F. Gori, "Mass and energy-capital conservation equations to study the price evolution of non-renewable energy resourcespart II: extension to resources sold to the market," Applied Thermal Engineering, vol. 26, no. 14-15, pp. 1751-1770, 2006.

[77] F. Gori, D. Ludovisi, and P. F. Cerritelli, "Forecast of oil price and consumption in the short term under three scenarios: parabolic, linear and chaotic behaviour," Energy, vol. 32, no. 7, pp. 12911296, 2007.

[78] P. K. Narayan and S. Narayan, "Modelling oil price volatility," Energy Policy, vol. 35, no. 12, pp. 6549-6553, 2007.

[79] T. A. Knetsch, "Forecasting the price of crude oil via convenience yield predictions," Journal of Forecasting, vol. 26, no. 7, pp. 527-549, 2007.

[80] P. Dittrick, "Deloitte: Sieminski forecasts $\$ 80 /$ bbl oil in 2008," Oil \& Gas Journal, vol. 105, no. 48, pp. 29-30, 2007.

[81] R. MacAskie and C. Jablonowski, "The value of oil and gas price forecasts in the presence of futures," Energy Exploration \& Exploitation, vol. 26, no. 3, pp. 157-174, 2008.

[82] H. Askari and N. Krichene, "Oil price dynamics (2002-2006)," Energy Economics, vol. 30, no. 5, pp. 2134-2153, 2008.

[83] S. Xu, X. Chen, and A. Han, "Interval forecasting of crude oil price," Advances in Soft Computing, vol. 46, pp. 353-363, 2008.

[84] L. Yu, S. Wang, and K. K. Lai, "Forecasting crude oil price with an EMD-based neural network ensemble learning paradigm," Energy Economics, vol. 30, no. 5, pp. 2623-2635, 2008.

[85] Y. Fan, Q. Liang, and Y.-M. Wei, "A generalized pattern matching approach for multi-step prediction of crude oil price," Energy Economics, vol. 30, no. 3, pp. 889-904, 2008.

[86] S. H. Kang, S.-M. Kang, and S.-M. Yoon, "Forecasting volatility of crude oil markets," Energy Economics, vol. 31, no. 1, pp. 119125, 2009.

[87] J. D. Hamilton, “Understanding crude oil prices," Energy Journal, vol. 30, no. 2, pp. 179-206, 2009.

[88] J. C. Cuaresma, A. Jumah, and S. Karbuz, "Modelling and forecasting oil prices: the role of asymmetric cycles," Energy Journal, vol. 30, no. 3, pp. 81-90, 2009.

[89] M. Ye, J. Zyren, C. J. Blumberg, and J. Shore, "A short-run crude oil price forecast model with ratchet effect," Atlantic Economic Journal, vol. 37, no. 1, pp. 37-50, 2009.

[90] C. W. Cheong, "Modeling and forecasting crude oil markets using ARCH-type models," Energy Policy, vol. 37, no. 6, pp. 2346-2355, 2009.

[91] A. Ghaffari and S. Zare, "A novel algorithm for prediction of crude oil price variation based on soft computing," Energy Economics, vol. 31, no. 4, pp. 531-536, 2009.

[92] F. Gori, "Mass and energy-capital conservation equations to study price evolution of non-renewable energy resources-part III: energy supply curve," Applied Thermal Engineering, vol. 29, no. 11-12, pp. 2172-2186, 2009.

[93] F. Gori, "Mass and energy-capital conservation equations for the time evolution of non-renewable energy resources," in Thermal Engineering Research Developments, J. Evgova and O. Kostadinov, Eds., chapter 5, pp. 245-282, Nova Science, New York, NY, USA, 2009.

[94] E. G. de Souza e Silva, L. F. L. Legey, and E. A. de Souza e Silva, "Forecasting oil price trends using wavelets and hidden Markov models," Energy Economics, vol. 32, no. 6, pp. 1507-1519, 2010.

[95] A. W. W. He, J. T. K. Kwok, and A. T. K. Wan, "An empirical model of daily highs and lows of West Texas Intermediate crude oil prices," Energy Economics, vol. 32, no. 6, pp. 1499-1506, 2010. 
[96] J. I. Miller and S. Ni, "Long-term oil price forecasts: a new perspective on oil and the macroeconomy," Macroeconomic Dynamics, vol. 15, supplement 3, pp. 396-415, 2011.

[97] S. R. Yaziz, M. H. Ahmad, L. C. Nian, and N. Muhammad, "A comparative study on Box-Jenkins and Garch models in forecasting crude oil prices," Journal of Applied Sciences, vol. 11, no. 7, pp. 1129-1135, 2011.

[98] G. Prat and R. Uctum, "Modelling oil price expectations: evidence from survey data," Quarterly Review of Economics and Finance, vol. 51, no. 3, pp. 236-247, 2011.

[99] R. Jammazi and C. Aloui, "Crude oil price forecasting: experimental evidence from wavelet decomposition and neural network modeling," Energy Economics, vol. 34, no. 3, pp. 828841, 2012.

[100] T. Mingming and Z. Jinliang, "A multiple adaptive wavelet recurrent neural network model to analyze crude oil prices," Journal of Economics and Business, vol. 64, no. 4, pp. 275-286, 2012.

[101] C. Baumeister and L. Kilian, "Real-time forecasts of the real price of oil," Journal of Business \& Economic Statistics, vol. 30, no. 2, pp. 326-336, 2012.

[102] A. Azadeh, M. Moghaddam, M. Khakzad, and V. Ebrahimipour, "A flexible neural network-fuzzy mathematical programming algorithm for improvement of oil price estimation and forecasting," Computers \& Industrial Engineering, vol. 62, no. 2, pp. 421430, 2012.

[103] J. Wang, H. Pan, and F. Liu, "Forecasting crude oil price and stock price by jump stochastic time effective neural network model," Journal of Applied Mathematics, vol. 2012, Article ID 646475, 15 pages, 2012.

[104] J. J.-W. Hu, Y.-C. Hu, and R. R.-W. Lin, "Applying neural networks to prices prediction of crude oil futures," Mathematical Problems in Engineering, vol. 2012, Article ID 959040, 12 pages, 2012.

[105] J. C. Ruelke, C. Pierdzioch, and G. Stadtmann, “On the internal consistency of short-term, medium-term and long-term oil price forecasts," Applied Economics, vol. 44, no. 21, pp. 27572765, 2012.

[106] F. Gori, "Forecasting the time evolution of oil price with negative inflation rate," in Proceedings of the ASME International Mechanical Engineering Conference and Exhibition (IMECE '12), vol. 6, pp. 1491-1496, Houston, Tex, USA, November 2012.

[107] C. Pierdzioch, J.-C. Rülkeb, and G. Stadtmann, "Oil price forecasting under asymmetric loss," Applied Economics, vol. 45, no. 17, pp. 2371-2379, 2013.

[108] H. Shin, T. Hou, K. Park, C.-K. Park, and S. Choi, "Prediction of movement direction in crude oil prices based on semisupervised learning," Decision Support Systems, vol. 55, no. 1, pp. 348-358, 2013.

[109] R. Alquist, L. Kilian, and R. J. Vigfusson, "Forecasting the price of oil," in Handbook of Economic Forecasting, vol. 2, pp. 427-507, 2013.

[110] T. Xiong, Y. Bao, and Z. Hu, "Beyond one-step-ahead forecasting: evaluation of alternative multi-step-ahead forecasting models for crude oil prices," Energy Economics, vol. 40, pp. 405415, 2013.

[111] C. C. Chang and T. C. Lai, "The oil energy price cycle in economic activities: a stochastic model," Energy Sources B: Economics, Planning and Policy, vol. 8, no. 4, pp. 369-381, 2013.

[112] N. Salehnia, M. A. Falahi, A. Seifi, and M. H. M. Adeli, "Forecasting natural gas spot prices with nonlinear modeling using gamma test analysis," Journal of Natural Gas Science and Engineering, vol. 14, pp. 238-249, 2013.

[113] H. Shin, T. Hou, K. Park, C.-K. Park, and S. Choi, "Prediction of movement direction in crude oil prices based on semisupervised learning," Decision Support Systems, vol. 55, no. 1, pp. 348-358, 2013.

[114] X. L. Yang, Q. He, and F. Yang, "An error modified grey theory for forecasting international oil price," Applied Mechanics and Materials, vol. 380-384, pp. 1525-1528, 2013.

[115] F. Gori, "Forecasting the time evolution of the oil price during months of negative inflation rate," Journal of Energy Resources Technology, vol. 135, no. 1, Article ID 011602, 8 pages, 2013.

[116] F. Gori, "Mass and energy-capital conservation equations to forecast monthly oil price," Applied Thermal Engineering, vol. 61, no. 2, pp. 623-632, 2013.

[117] F. Gori, "Remarks on the paper 'Mass and energy-capital conservation equations to forecast monthly oil price"' Applied Thermal Engineering, vol. 68, no. 1-2, pp. 59-61, 2014. 

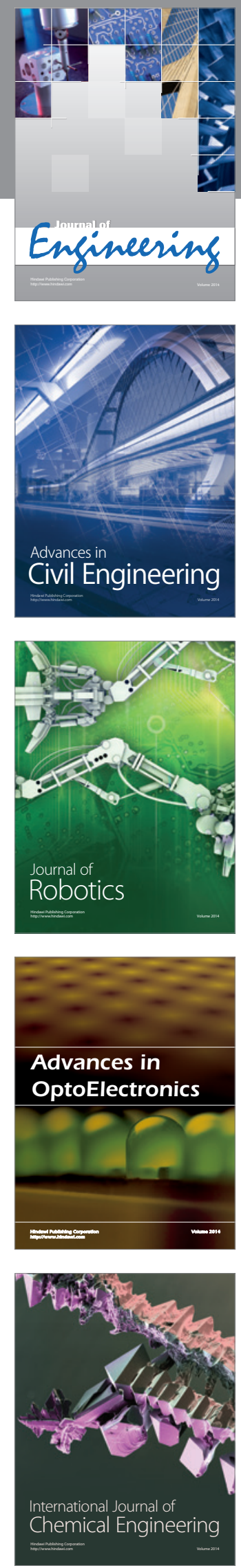

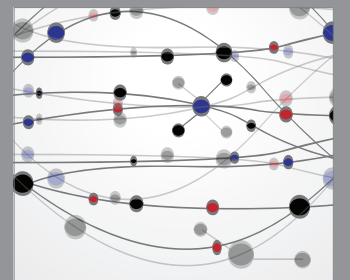

The Scientific World Journal
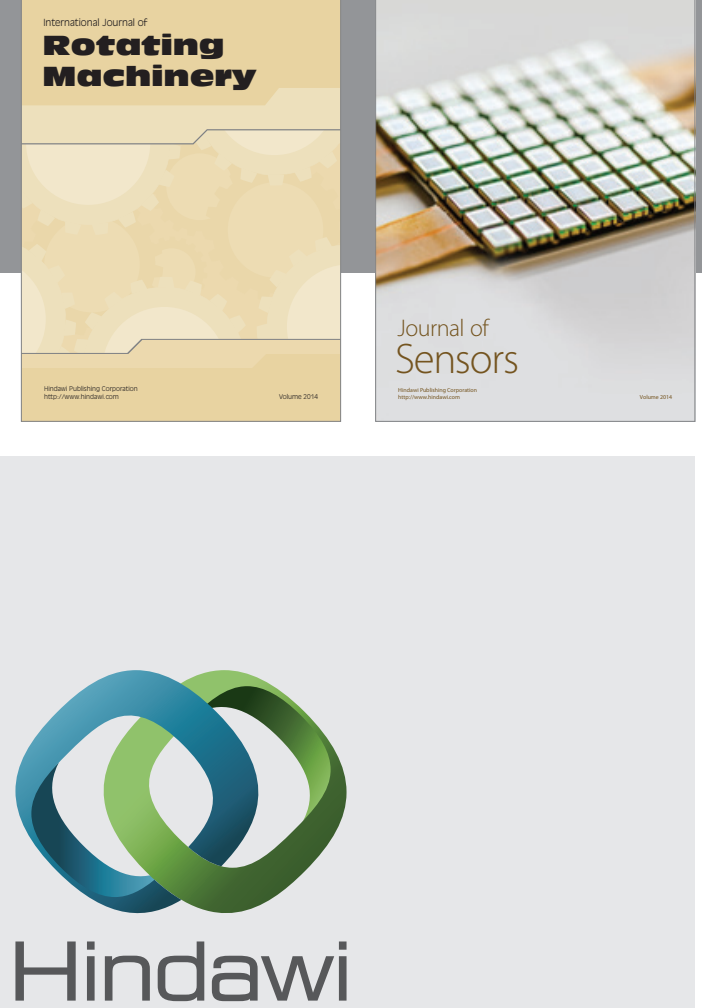

Submit your manuscripts at http://www.hindawi.com
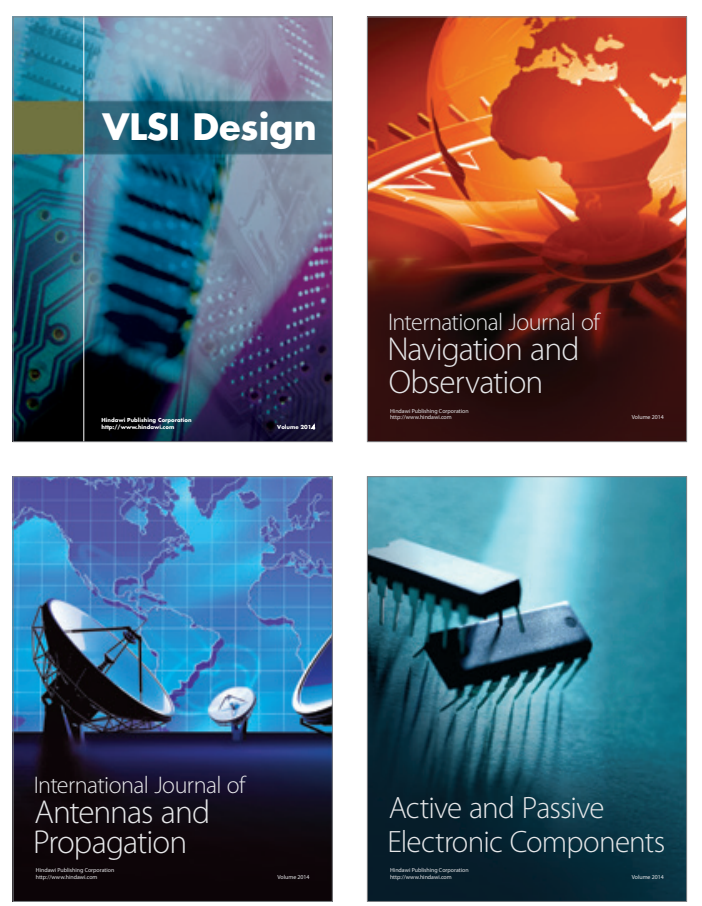
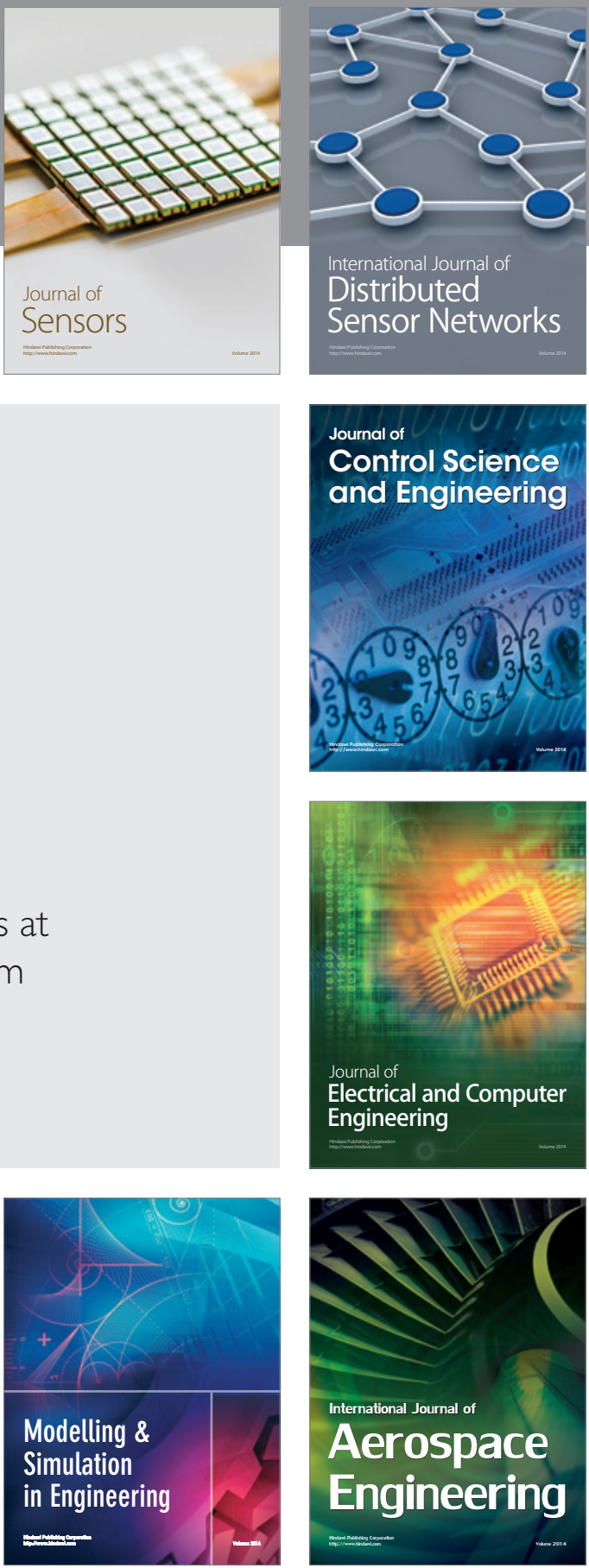

Journal of

Control Science

and Engineering
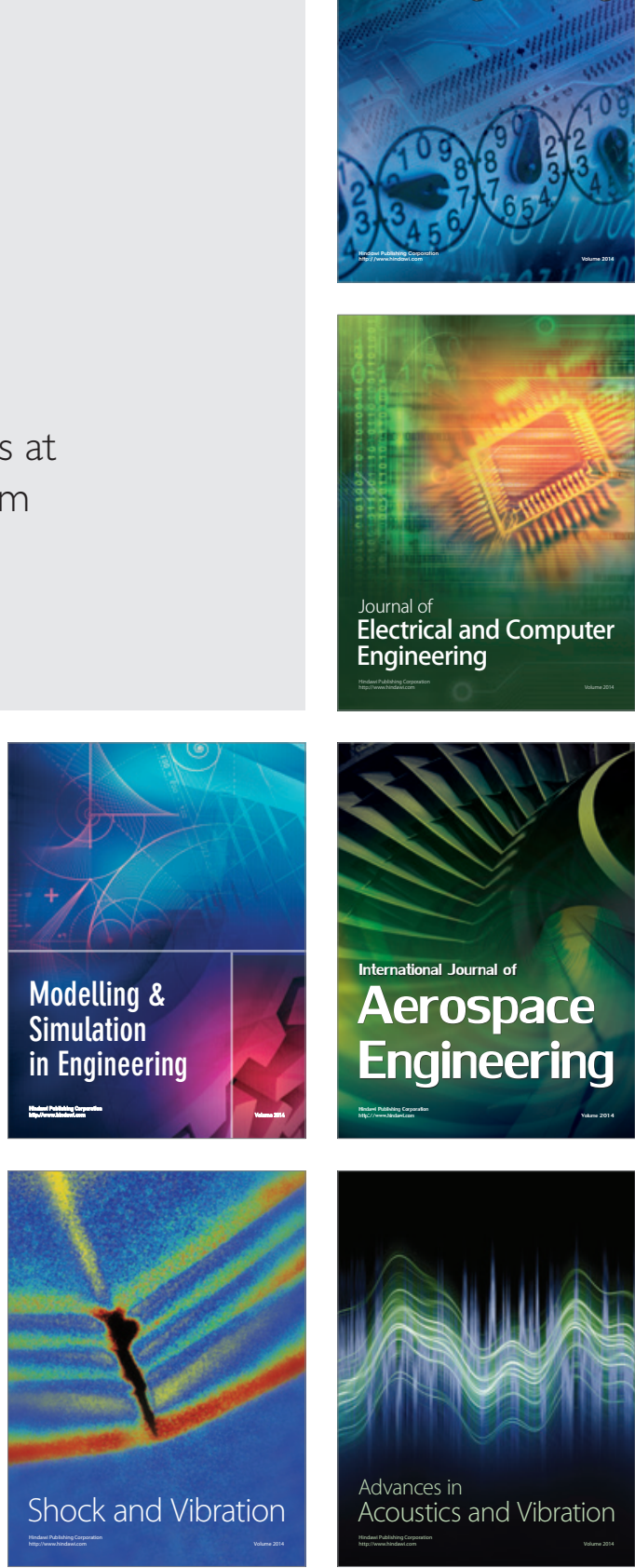